\title{
Modélisation de l'écosystème du Lac de Pareloup avec les modèles ASTER et MELODIA
}

\section{Modeling of the Lac de Pareloup Ecosystem with the ASTER and MELODIA Models}

\author{
Marie-José Salençon ${ }^{\star}$ et Jean-Marc Thébault** \\ - Electricité de France, Direction des Etudes et Recherches, Département Environnement, \\ 6 Quai Watier, F-78401 Chatou Cedex, France. \\ "* Laboratoire d'Hydrobiologie, Université Paul Sabatier, 118 Route de Narbonne, \\ F-31062 Toulouse Cedex, France.
}

\begin{abstract}
Résumé. - L'effort de recherche mené durant quatre ans sur le lac de Pareloup, réservoir hydroélectrique d'Electricité de France, a permis une meilleure compréhension du fonctionnement de cet écosystème, tant sur le plan biologique que sur le plan hydrodynamique. Les modèles de simulation, développés lors de cette étude, ont permis de proposer un outil d'aide à la gestion de l'eau.

La première étape a été l'élaboration du modèle ASTER. C'est un modèle biologique (deux groupes de phytoplancton, trois groupes de zooplancton, matière détritique, $\mathrm{PO}_{4}$ et $\mathrm{SiO}_{2}$ ), basé sur une structure physique simple (modèle bicouche). L'importante base de données disponible a permis de caler ce modèle et de s'assurer qu'il simule correctement l'évolution saisonnière de chacune des variables pendant cinq ans (19831987). Ce modèle a permis de mettre en évidence les mécanismes prépondérants dans l'évolution des variables biologiques.

La grande sensibilité de l'écosystème à l'hydrodynamique nous a conduits à la seconde étape, l'élaboration du modèle MELODIA. C'est un modèle de simulation d'un écosystème de résenoir résultant du couplage du modèle biologique bicouche (ASTER) au modèle vertical hydrodynamique et thermique (EOLE) qui simule l'évolution de la stratification thermique en prenant en compte les échanges d'énergie à l'interface air-eau ainsi que les entrées et sorties d'eau.

Ce modèle a permis de simuler, à l'échelle journalière, la dynamique verticale de l'écosystème pendant les cinq années de mesures de la base de données. La comparaison des profils calculés et mesurés pour chacune des variables montre une assez bonne représentation de cet écosysteme, à la fois pour la dynamique verticale et pour l'évolution saisonnière. De plus, les fluctuations interannuelles de l'écosystème sont bien représentées et les simulations ont montré à quel point la réponse de l'écosystème est sensible à la structure hydrodynamique.
\end{abstract}


Le modèle a été ensuite utilisé pour simuler différents scénarios de gestion de la retenue. Appliqué à une plus longue période, 1976-1987, il a permis de mettre en évidence les fluctuations interannuelles dues aux conditions hydrométéorologiques en signalant les périodes où le risque de perturbation est grand.

Cette étude a permis de mieux comprendre le rôle joué par la diatomée $A$. formosa, dominante au printemps. Cette diatomée, non consommée par le zooplancton, disparaît par sédimentation, immobilisant ainsi une quantité importante de nutriments, jusqu'à la période d'isothermie hivernale. Elle se comporte comme une épuratrice en phosphore du lac. Si un phénomène vient perturber son développement, la quantité de $\mathrm{PO}_{4}$ disponible l'été est plus importante, favorisant une forte croissance algale estivale. Si les perturbations printanières sont liées aux conditions météorologiques, elles dépendent également de la gestion hydraulique. C'est ce qu'a mis en évidence l'étude des scénarios de gestion.

Enfin, cette étude a permis de montrer la puissance d'un travail pluridisciplinaire ainsi que la nécessité d'une approche globale pour bien représenter un écosystème. Si tous les efforts ont convergé vers l'outil de modélisation, dépositaire de cette connaissance commune, cet outil n'existe que grâce à l'investissement à long terme de chacun, dans des domaines de compétence très variés. C'est, à n'en pas douter, le plus bel enseignement de ce travail.

Mots-clés. - Réservoir, modèle biologique, bicouche, unidimensionnel vertical, simulation de l'écosystème.

\footnotetext{
Abstract. - A four-year research project conducted at Pareloup lake, an Electricité de France hydroelectric reservoir, improved understanding of the dynamics of the ecosystem in both biological and hydrodynamic terms. The simulation models developed during the project enabled the proposal of a tool to aid in water resource management.

The first phase was development of the ASTER model. This is a biological model (two phytoplankton groups, three zooplankton groups, detritus, $\mathrm{PO}_{4}$ and $\mathrm{SiO}_{2}$ ) with a simple physical structure (two-layer model). The sizeable data base available enabled calibration of the model and ensuring that it correctly simulated seasonal evolution of each of the variables over a five-year period (1983-1987). Thanks to this model, the preponderant mechanisms in the evolution of biological variables were highlighted.

The great sensitivity of the ecosystem to hydrodynamic factors prompted us to undertake the second phase, which was development of the MELODIA model. This is a reservoir ecosystem management model obtained by coupling the two-layer biological model (ASTER) with a vertical hydrodynamic and thermal model (EOLE) which simulates the evolution in thermal stratification and takes into account energy exchanges across the air-water interface, as well as inflow and outflow.

This model enabled simulation on a one-day scale of the vertical dynamics of the ecosystem for the five years of measurements in the data base. Comparison of the calculated and measured profiles for each of the variables indicates quite good representation of the ecosystem, both in terms of vertical dynamics and in terms of seasonal evolution. Furthermore, year-to-year fluctuations in the ecosystem are well represented, and simulations showed the extent to which the ecosystem is sensitive to the hydrodynamic structure.

The model was then used to study different reservoir management modes. Applied to a longer period of time, 1976-1987, it pointed up the year-to-year fluctuations due to hydrometeorological conditions and identified periods in which the risk of eutrophication is great.
} 
This study provided deeper understanding of the role played by the diatom $A$. formosa, which is dominant in spring. This diatom is not consumed by zooplankton, but disappears by sinking, trapping a large proportion of nutrients until winter mixing. It acts as a "purifier" of phosphorus in the lake. If some phenomenon disturbs its development, the amount of $\mathrm{PO}_{4}$ available in the summer is greater, thereby fostering strong summer algal growth. While such disturbances in the spring are related to meteorological conditions, they are also dependent on the hydraulic management mode. This was highlighted in a study of management scenarios.

Lastly, this project underscored the benefits of multidisciplinary research, as well as the need for a global approach if the ecosystem is to be represented well. While our efforts converged in the development of a modeling tool, which is now the repository of our common knowledge, this tool must actually be seen as the fruit of the long-term personal investment on the part of each in the team, in widely varying fields of competence. There is no doubt that this is the most important lesson to be learned from our project.

Key-words. - Reservoir, biological model, two-layer, one-dimensional vertical, ecosystem simulation.

\section{INTRODUCTION}

La ressource en eau que constitue un lac naturel ou artificiel doit satisfaire de multiples usages, parfois contradictoires : production d'électricité, soutien d'étiage, écrêtement de crues, alimentation en eau potable, activités touristiques, pêche...

Gérer cette ressource nécessite de préserver l'équilibre de l'écosystème, ce qui demande une bonne connaissance de son fonctionnement. Pour cela des études pluridisciplinaires, associant expérimentation et modélisation, sont nécessaires.

Ces études pluridisciplinaires réunissent trois axes de recherche : campagnes de mesures in situ, travaux de laboratoire et modélisation. L'objectif final est de proposer un outil permettant d'envisager la gestion non seulement du point de vue des usages de l'eau mais également de la qualité de l'eau.
Le modèle de simulation d'un écosystème est un outil qui permet de décrire mais aussi de prévoir l'évolution de la qualité physico-chimique et biologique des eaux en fonction de la gestion hydraulique, de conditions météorologiques différentes, d'une modification des apports du bassin versant, etc...

La construction du modèle de l'écosystème de Pareloup a nécessité de nombreuses étapes de réflexion, en particulier une interaction permanente entre les travaux de modélisation et les travaux expérimentaux. Finalement, deux modèles ont été réalisés simultanément:

- un modèle simulant la dynamique des principales variables biologiques et chimiques: ASTER; il comporte une structure physique simple (modèle bicouche simulant la stratification thermique saisonnière) et a pour objectif une meilleure compréhension des processus dominants im- 
pliqués dans le fonctionnement de l'écosystème (Thébault et Salençon, 1993),

- un modèle hydrodynamique et thermique (modèle unidimensionnel vertical) : EOLE; ce modèle prend en compte la bathymétrie de la retenue, les échanges d'énergie à l'interface air-eau ainsi que les entrées et sorties d'eau (rivières, pompages, turbinages, débits réservés etc...) (Salençon, 1994a, 1994b). Il permet de représenter plus finement la dynamique verticale et de tester les différents modes de gestion de la retenue. Ce modèle est ensuite couplé au modèle biologique afin d'être utilisé comme outil de simulation de scénarios.

Nous présentons ici, le modèle biologique bicouche ASTER, qui a permis de mettre en évidence les mécanismes prépondérants dans l'évolution des variables biologiques, et le modèle complet de simulation de l'écosystème de la retenue, MELODIA, qui résulte du couplage du modèle hydrodynamique et thermique EOLE avec le modèle biologique ASTER (Salençon et Thébault, 1995).

L'importante base de données collectées sur le site de 1983 à 1987 a permis de caler ces modèles et de s'assurer qu'ils simulent correctement l'évolution saisonnière de chacune des variables d'état.

La fiabilité des résultats obtenus avec MELODIA nous a conduits à l'utiliser ensuite comme outil de simulation de scénarios. Appliqué à une plus longue période, 1976-1987, il a permis de mettre en évidence les fluc- tuations interannuelles liées aux conditions climatiques et à la gestion hydraulique, en signalant les périodes où le risque de perturbation de l'écosystème est grand.

La démarche suivie initialement pour l'étude de l'écosystème de $\mathrm{Pa}$ reloup a été, depuis, appliquée pour l'étude d'autres sites qui ont ainsi pu bénéficier de l'expérience acquise, en tenant compte toutefois de la particularité de chaque écosystème.

\section{DESCRIPTION DE LA RETENUE DE PARELOUP ET DONNEES DISPONIBLES}

\section{II.1 Description de la retenue}

La retenue de Pareloup est située dans l'Aveyron, près de Rodez, sur le plateau du Lévezou dont l'altitude varie de 700 à $900 \mathrm{~m}$. Ce plateau, situé sur les premiers reliefs à l'Est du Bas$\sin$ Aquitain, est soumis à un régime climatique globalement océanique, caractérisant surtout le printemps et l'automne, avec une influence continentale en hiver et méditerranéenne en été. Les hivers longs et rigoureux (100 à 120 jours de gel par an) se prolongent au début du printemps. Les étés sont courts et frais, avec une température moyenne dépassant rarement $20^{\circ} \mathrm{C}$. Les précipitations sont assez régulièrement réparties dans l'année, avec des orages l'été et un enneigement important l'hiver en raison de l'altitude. Le plateau du Lévezou est venté une grande partie de 
l'année. On peut distinguer les vents violents froids et secs qui soufflent l'hiver du secteur Nord-Nord-Est, les vents humides océaniques d'OuestNord-Ouest dominants au printemps et à l'automne et les vents chauds et humides de Sud-Sud-Est, responsables des orages d'été. On peut dire que, dans son ensemble, le Lévezou a un climat rude.

L'aménagement du Pouget, qui utilise le dénivelé existant entre le plateau du Lévezou et le sillon creusé par le Tarn, $500 \mathrm{~m}$ plus bas, est organisé autour du lac de Pareloup, ré- servoir culminant qui occupe une dépression favorable sur le cours du Vioulou (fig. 1). La très grande capacité de cette retenue $\left(169 \mathrm{hm}^{3}\right)$, lui permet d'emmaganiser l'eau pendant les saisons de moindre besoin en électricité, pour l'utiliser pendant les saisons de forte demande (principalement l'hiver). La cote du plan d'eau reste haute et stable en été, pendant la période touristique.

Outre les apports naturels du Vioulou, de la Gourde, du Ceor, la retenue reçoit l'eau des bassins versants du Viaur et du Bage, par l'intermédiaire

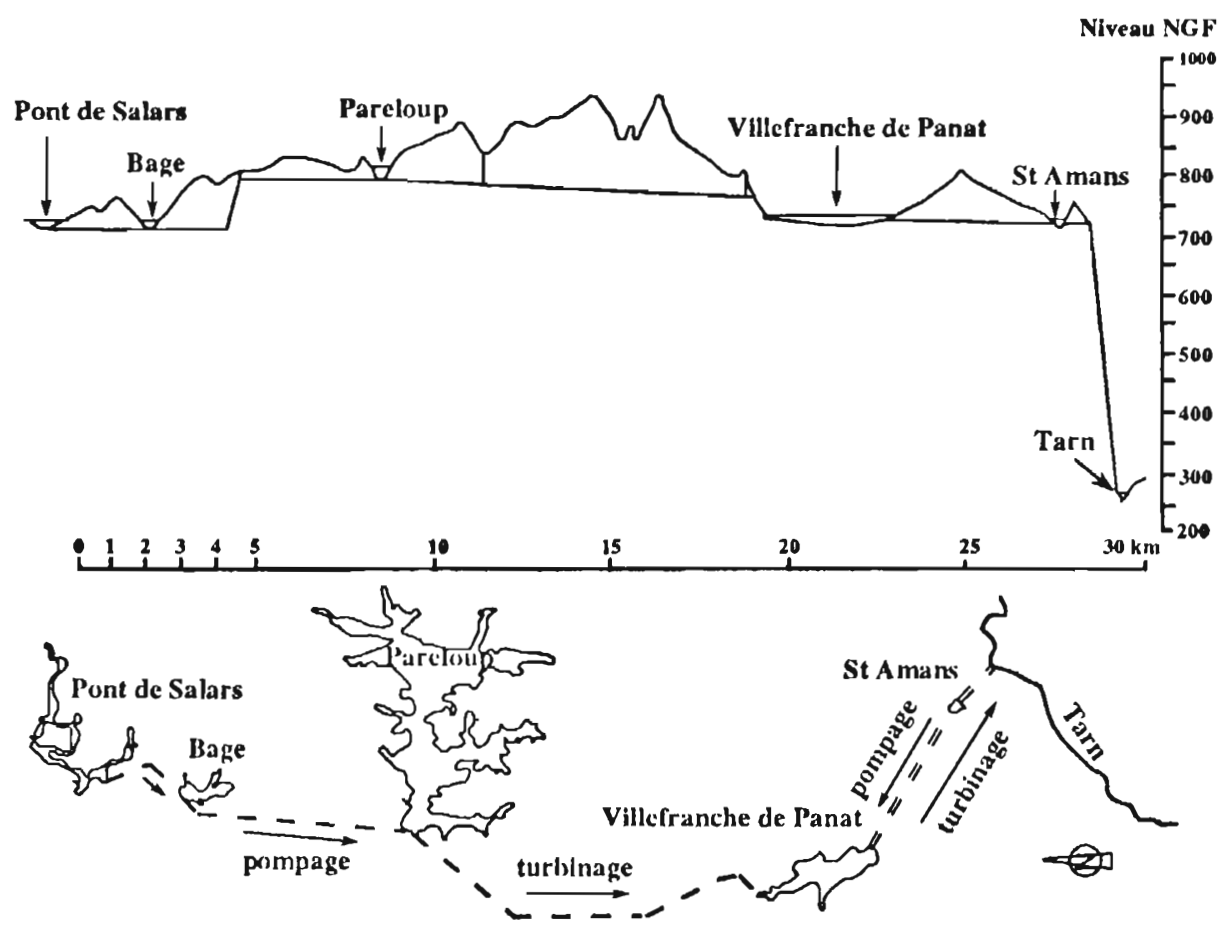

Fig. 1. - Profil en long général du complexe hydro-électrique de Pareloup (d'après EDF-GRPH Languedoc).

Fig. 1. - Schematic presentation of the Pareloup hydroelectric system. (from EDF-GRPH Languedoc). 


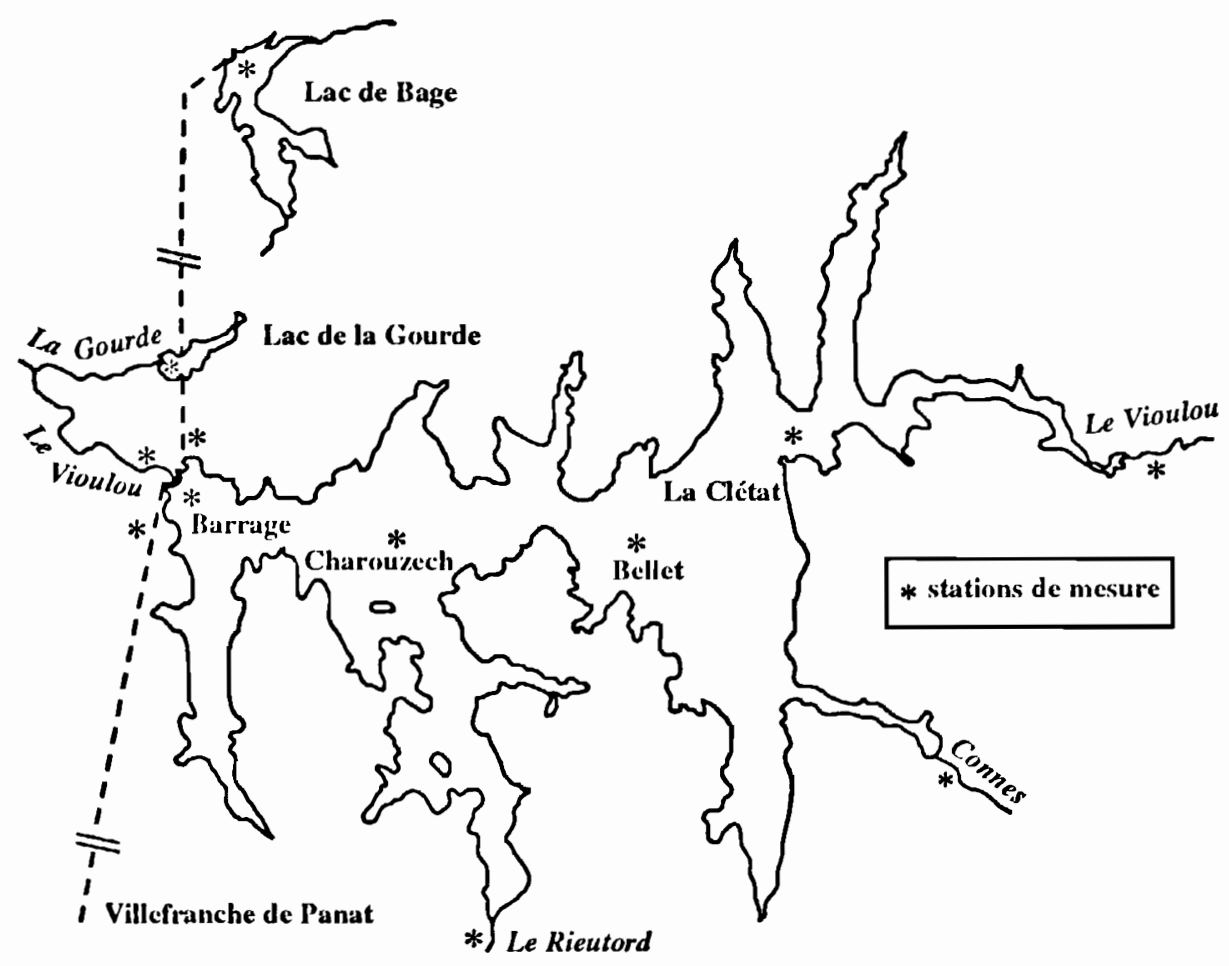

Fig. 2. - Plan des lacs de Pareloup, La Gourde et Bage.

Fig. 2. - Map of Pareloup, La Gourde and Bage lakes.

des retenues de Pont de Salars (20 $\mathrm{hm}^{3}$ ) et de Bage $\left(4 \mathrm{hm}^{3}\right)$, qui fonctionnent en vases communicants. La station de pompage de Bage $\left(14 \mathrm{~m}^{3} \cdot \mathrm{s}^{-1}\right)$, remonte ces apports sur les $98 \mathrm{~m}$ de dénivellation séparant Bage de Pareloup. La conduite de Bage débouche dans le lac à la cote 768 NGF".

Dans la partie aval de l'aménagement, l'eau stockée dans Pareloup est turbinée à l'usine d'Alrance (chute de $80 \mathrm{~m}$ ) puis, après avoir transité par le réservoir de Villefranche de Panat,

- NGF : Niveau Général de la France est restituée au Tarn à l'usine du Pouget qui exploite une chute de $461 \mathrm{~m}$. Une station de pompage au Pouget $\left(6,6 \mathrm{~m}^{3} . \mathrm{s}^{-1}\right)$ permet de remonter les eaux du Tarn dans le réservoir de Villefranche de Panat.

Le lac est composé d'un corps principal orienté Est-Ouest correspondant à la vallée du Vioulou sur lequel est construit le barrage et de bras latéraux dont les 3 principaux sont situés au Sud et orientés Nord-Sud (fig. 2).

A la cote maximale (805 NGF), sa capacité totale est de $169 \mathrm{hm}^{3}$ et la superficie de $12,6 \mathrm{~km}^{2}$. La profondeur 
maximale de la retenue à proximité du barrage est de 40 mètres. Elle diminue rapidement à 25 mètres au droit de l'ancien lit du Vioulou. L'essentiel du volume de la retenue est situé en surface, la capacité utile entre les cotes 775 et 805 NGF représentant $167,7 \mathrm{hm}^{3}$, la profondeur moyenne étant de $12,5 \mathrm{~m}$ et le centre de volume du lac étant situé à $9,75 \mathrm{~m}$.

Les sorties d'eau de Pareloup sont de deux sortes: le débit réservé du Vioulou, restitué par une vanne en pied de barrage, et le débit turbiné. Le débit réservé, prélevé à la cote 764 NGF, est faible $\left(103 \mathrm{I} . \mathrm{s}^{-1}\right)$, alors que le débit turbiné prélevé dans le lac par une tour dont l'ouverture est comprise entre les cotes 775 NGF et 784 NGF, peut atteindre $25 \mathrm{~m}^{3} \cdot \mathrm{s}^{-1}$.

Son temps de séjour est assez élevé (300 jours), ce qui entraîne une stratification thermique marquée de la colonne d'eau de mi-juin à début octobre ainsi qu'en hiver avec formation, certaines années, d'une couverture de glace. Les mesures de concentration de chlorophylle a relevées depuis le début de l'étude la classent dans la catégorie des lacs mésotrophes.

On observe dès la fin du mois de février un développement de phytoplancton, essentiellement des diatomées: Asterionella formosa Hassal (plus de $80 \%$ de la biomasse) et $A u$ lacoseira ambigua (Grun.) Simonsen (Syn. Melosira ambigua); leur déclin, fin mai, coïncide avec l'apparition du gradient thermique. Cette phase d'eaux claires est associée à la chute des teneurs en $\mathrm{SiO}_{2}$ dans la zone euphotique, à la réduction de la turbu- lence qui favorise la sédimentation et au développement du zooplancton filtreur. Le peuplement d'été est moins dense mais plus diversifié (Dictyosphaerium, Crucigenia, Sphaerocystis, Gomphosphaeria, Anabaena, Merismopedia...). Lors de l'enfoncement de la thermocline en automne, on observe un nouveau développement de diatomées associées à quelques espèces de très petite taille.

\section{II.2 Les données}

Les mesures et les prélèvement d'eau pour analyse ont été effectués sur une verticale (de 5 à 12 profondeurs) avec une fréquence hebdomadaire ou bimensuelle de juin 1983 à décembre 1987: mesures physico-chimiques (transparence de l'eau - disque de Secchi et/ou coefficient d'extinction-, $\mathrm{pH}, \mathrm{O}_{2}, \mathrm{~N}, \mathrm{P}, \mathrm{Si}$ ) et biologiques (concentration de chlorophylle $a$, comptage et détermination des espèces de phyto et de zooplancton, poids secs, dosage $C, N, P$ et pigments du seston, densité de bactéries). Ces mesures étaient interrompues à la mi-novembre pour redémarrer au printemps suivant. On verra, par la suite, les conséquences d'une telle interruption, en particulier pour les mesures de la transparence de l'eau.

Nous disposons également de mesures hebdomadaires, des débits des principaux ruisseaux et de leurs concentrations en $\mathrm{P}_{\text {total }}$ et silicates. En 1986 et 1987 des analyses complètes ont été réalisées pendant les crues du 
Vioulou avec une fréquence de $30 \mathrm{mi}-$ nutes.

Pour le calage du modèle thermique, les profils thermiques ont été mesurés en plusieurs points du lac, toutes les trois heures, à l'aide de thermographes enregistreurs (11 capteurs thermiques répartis sur une verticale). Ces mesures ont été complétées par des profils hebdomadaires manuels au droit du barrage. Le suivi thermique de la retenue de Pareloup a démarré en 1976, mais, seule la période 1983-1987 ne comporte pas d'interruptions.

Une station météorologique implantée sur le site a permis de disposer, toutes les trois heures, de la pression atmosphérique, la vitesse et la direction du vent, la température de l'air, l'humidité, la pluviométrie et du rayonnement solaire.

\section{DESCRIPTION DU MODELE BIOLOGIQUE BICOUCHE : ASTER}

Le modèle ASTER est avant tout un outil de base destiné à déterminer quels sont les mécanismes les plus fortement impliqués dans le fonctionnement de l'écosystème. II a été élaboré et calé sur les données de la période 1983-1985 puis validé sur la période 1983-1987 (Thébault et Salençon, 1993).

Comme dans toute modélisation, seuls les processus indispensables à une représentation satisfaisante du système ont été modélisés.

\section{III.1 Structure du modèle}

La structure du système physique est très simple: la masse d'eau est divisée en deux couches homogènes spatialement, qui représentent la stratification thermique saisonnière. La couche du fond est en contact avec une couche de sédiment. La couche de surface, l'épilimnion, est turbulente. Elle est séparée de la couche de fond non turbulente, l'hypolimnion, par une thermocline.

Chaque couche est caractérisée par sa température, son volume, sa profondeur et lintensité du rayonnement solaire à sa limite supérieure.

La dynamique des deux masses d'eau est représentée par une vitesse d'entraînement qui n'est pas simulée par le modèle mais introduite sous forme de forçage à partir des mesures thermiques ou des résultats du modèle thermique EOLE.

La sédimentation est prise en compte dans le modèle par une vitesse spécifique de chaque variable. La matière sédimentée atteint la couche immédiatement inférieure.

On ne tient pas compte des apports du bassin versant, ni des sorties au barrage, le temps de séjour important dans cette retenue, de l'ordre de l'année, permettant d'accepter, dans une première phase, cette hypothèse très réductrice. 


\section{III.2 Les variables du modèle et les processus}

Notre démarche a été la suivante : débuter la simulation avec un modèle de base le plus simple possible, puis le sophistiquer au fur et à mesure afin d'améliorer la concordance entre résultats calculés et observés. Ainsi sont identifiés les mécanismes prépondérants dans cet écosystème particulier, qui sont ensuite introduits dans le modèle. Pour cette raison, des processus apparaissant importants dans d'autres systèmes, ne seront pas représentés dans ce modèle, car ils participent peu à sa dynamique ou sont masqués par des mécanismes jouant un plus grand rôle.
Le diagramme de la figure 3 synthétise l'ensemble des flux entre les variables du modèle.

\section{III.2.1 Le phytoplancton}

Le phytoplancton a été divisé en deux groupes dont les besoins nutritionnels sont différents :

- d'une part les diatomées de grande taille abondantes au printemps (A. formosa), qui ont besoin de silice pour croitre et ne sont pas consommées par le zooplancton,

- d'autre part, un groupe contenant de nombreuses espèces de petite taille dont la caractéristique commune est d'être consommées par le zooplancton filtreur.

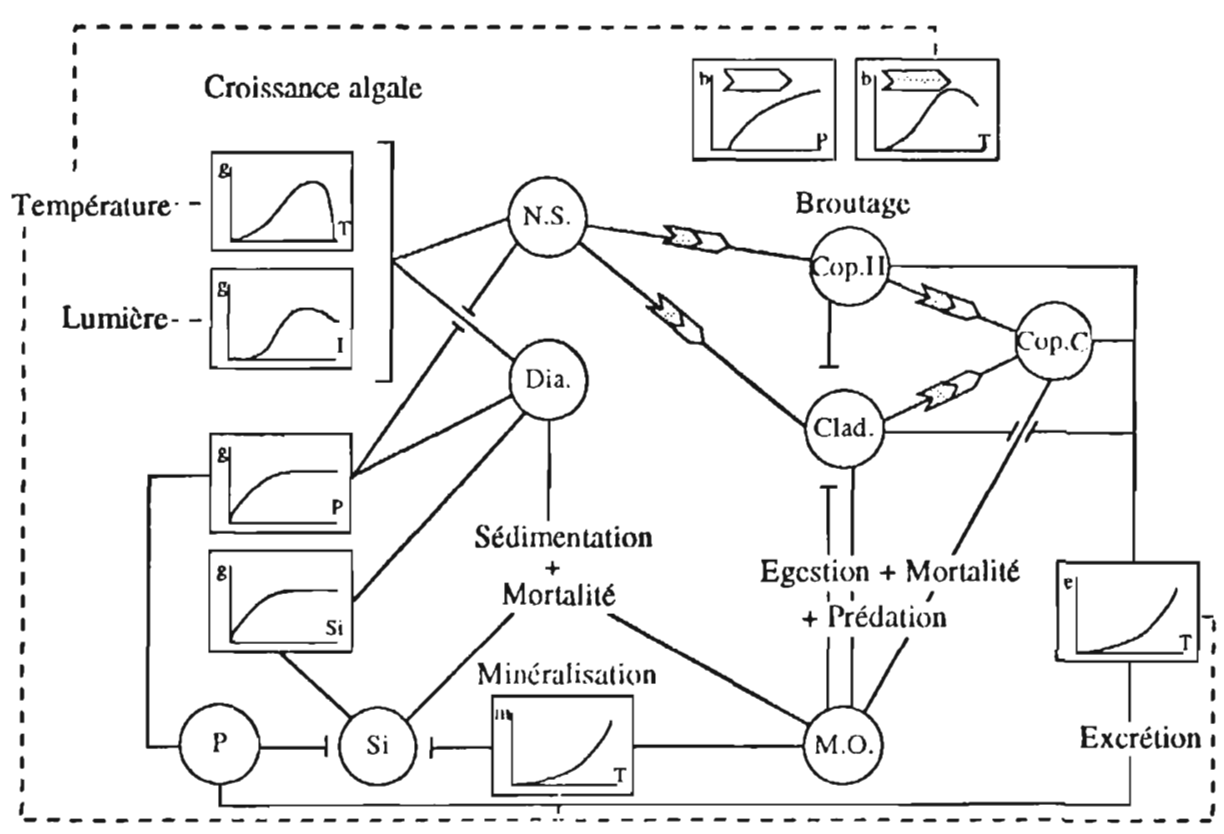

Fig. 3. - Diagramme de fonctionnement du modèle biologique.

Fig. 3. - Dynamics of the biological model. 
Les cyanophycées n'ont pas été prises en compte dans ce modèle, car très peu abondantes durant l'étude (Le Cohu et al., 1994).

L'évolution de ces variables sont le résultat d'un bilan de production et de disparition de biomasse.

\section{III.2.1.1 Production}

La production de biomasse est due à la croissance phytoplanctonique.

La lumière, la température et la concentration en nutriments (phosphore et silice) sont les facteurs qui peuvent réduire le taux de croissance du phytoplancton, surtout dans des gammes de valeurs éloignées des valeurs optimales.

Pour les nutriments, c'est l'élément le moins abondant qui limite la croissance, l'assimilation étant de type Michaelis-Menten (Droop, 1974; 1975; Rhee, 1978).

Les effets de la lumière, de la température et des nutriments sont, dans de nombreux modèles, supposés indépendants (Lehman et al., 1975; Canale et al., 1976; Jorgensen et al., 1978; Kremer et Nixon, 1978; Keller, 1989). Cette hypothèse ne nous a pas permis de représenter correctement la dynamique des diatomées printanières. Aussi avons-nous construit, à partir de données obtenues en laboratoire sur plusieurs espèces d'algues, un sous-modèle couplant les effets de la lumière et de la température (Talbot et al., 1991), ce qui nous a permis de bien simuler le pic algal de printemps.

\subsubsection{Disparition}

Les quatre facteurs de disparition représentés sont la respiration, la sédimentation, la prédation et la mortalité.

La sédimentation des diatomées nous est apparue comme l'un des mécanismes fondamentaux dans l'évolution de ce système puisque ces algues de grande taille ne sont pas consommées. Une vitesse de sédimentation constante ne permettant pas de représenter la disparition des diatomées à la fin du printemps, nous avons relié la vitesse de sédimentation des diatomées à l'état physiologique des cellules (Smayda et Boleyn, 1965 ; 1966 ; Harrison et Turpin, 1982) par l'intermédiaire d'une fonction dépendant des concentrations dans le milieu.

\section{III.2.2 Le zooplancton}

Le zooplancton a été divisé en trois groupes : cladocères, copépodes herbivores et carnivores (Cyclopides adultes), définis à partir de l'étude du peuplement zooplanctonique (Francisco et Rey, 1994).

Les herbivores consomment exclusivement les algues non-siliceuses, les carnivores capturent indifféremment les copépodes et les cladocères.

Le taux d'ingestion du zooplancton dépend principalement à court terme de la température du milieu et de la concentration de nourriture. Nous avons utilisé le modèle proposé par Thébault (1985) qui permet de simuler leurs effets combinés. Nous avons cependant simplifié la formulation en remplaçant la fonction reliant l'inges- 
tion à la quantité de proies (trois paramètres dépendant de la température) par une fonction de type Michaelis-Menten (Mullin et al., 1975). Nous avons ajouté à cette fonction un seuil en deçà duquel la ration est nulle, l'énergie dépensée par les animaux pour la recherche de nourriture étant supérieure à l'apport d'énergie alimentaire (Lam et Frost, 1976; Lehman, 1976). Dans ce cas, seul le coefficient ration maximale est une fonction de la température. Dans ce type de modèle, cette simplification n'affecte pas les résultats et permet l'économie d'un grand nombre de coefficients.

La mortalité du zooplancton est essentiellement due à la prédation par les poissons. La complexité de la dynamique des populations de poissons ainsi que la grande variété d'espèces présentes à Pareloup ne permettent pas d'envisager une modélisation de ce niveau trophique. A partir des observations qualitatives réalisées in situ (Le Jolivet, 1988), une fonction de forçage a été établie.

\section{III.2.3 La matière détritique et les nutriments}

La variable matière détritique prend en compte la matière non-assimilée par le zooplancton, du zooplancton mort (mortalité naturelle et prédation par les poissons) et du phytoplancton mort dans le sédiment. La minéralisation de la matière détritique et la dissolution des frustules de silice sont des fonctions de la température (Kremer et Nixon, 1978). La matière détritique sédimente à vitesse constante.
Les éléments nutritifs pris en compte sont $\mathrm{PO}_{4}$ et $\mathrm{SiO}_{2}$ car ils sont susceptibles de limiter la croissance phytoplanctonique. L'azote n'a pas été représenté dans la modélisation car, d'après les mesures, il n'est jamais limitant (Labroue et al., 1994).

\section{III.2.4 La dynamique du sédiment}

Le sédiment prend en compte les algues et la matière détritique sédimentées. Les algues y meurent lentement et sont transformées en matière détritique, minéralisée ensuite en phosphore et silice. En l'absence de mesures de flux de relargage du phosphore et de la silice à l'interface sédiment-eau, celui-ci est pris constant.

\section{III.3 Résultats du modèle bicouche ASTER}

Pendant la phase d'élaboration du modèle, les campagnes de mesures ont été poursuivies, en 1986 et 1987, selon un protocole enrichi de l'expérience déjà acquise (Salençon et Thébault, 1994).

Le modèle ASTER ayant été calé sur les années 1983-1985, la confrontation des résultats des simulations aux observations durant la période 1983-1987 (figures 4, 5, 6, 7 et 10) constitue, sinon une véritable validation, du moins une confirmation de la bonne adéquation du modèle aux mesures. Les figures 8 à 10 permettent de visualiser les taux de croissance, de sédimentation, les limitations de croissance spécifiques à chaque 

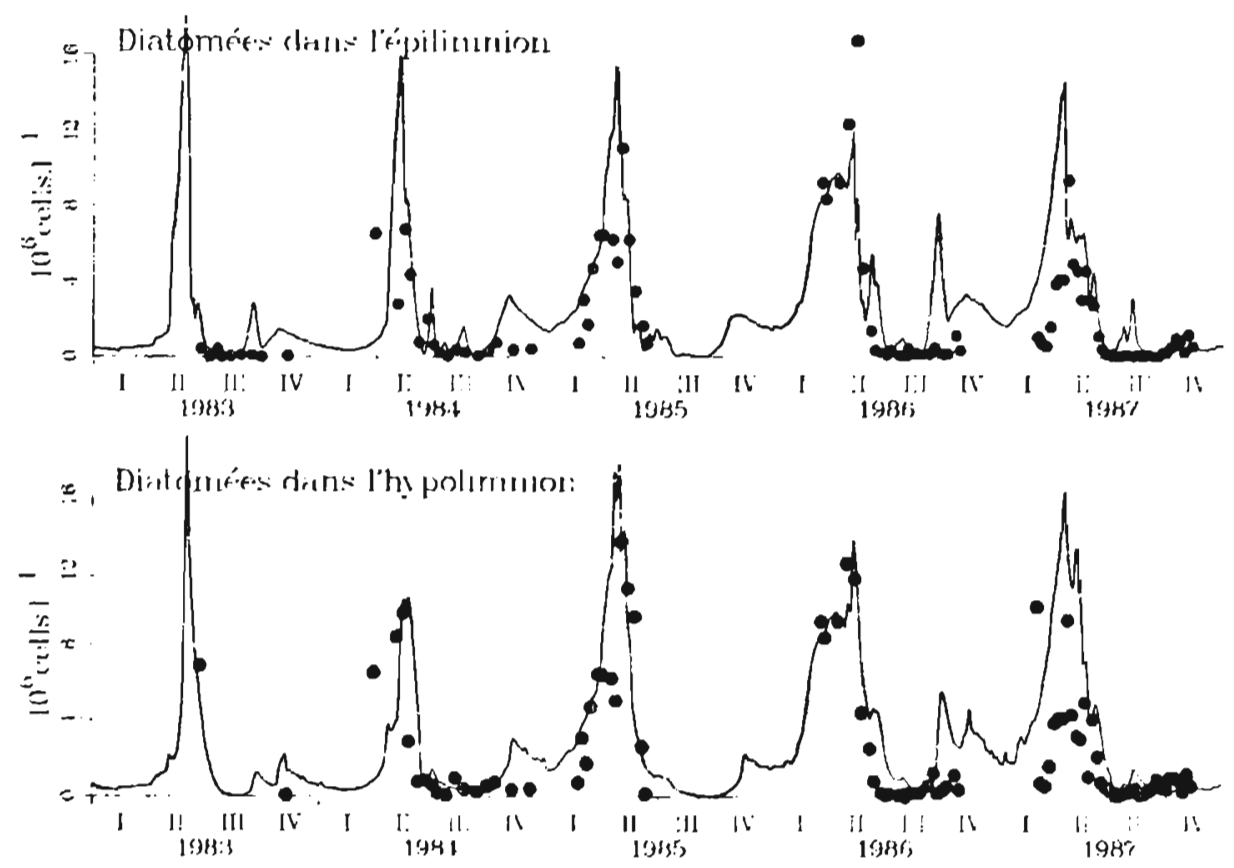

Fig. 4. - Evolution des diatomées dans l'épilimnion et l'hypolimnion durant la période 1983-1987. Modèle ASTER.

Fig. 4. - Evolution of diatoms in the epilimnion and hypolimnion, 1983-1987 - ASTER.

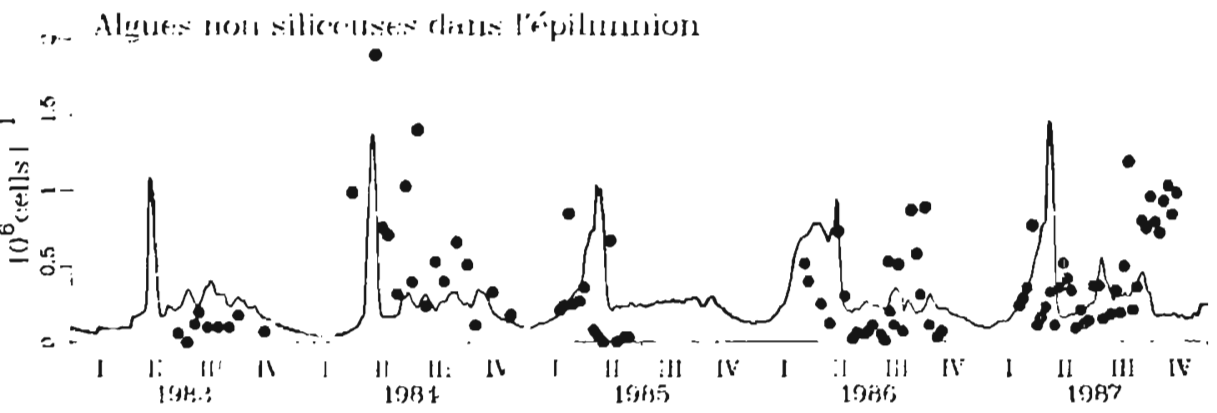

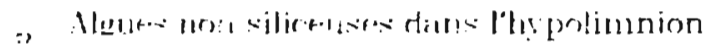

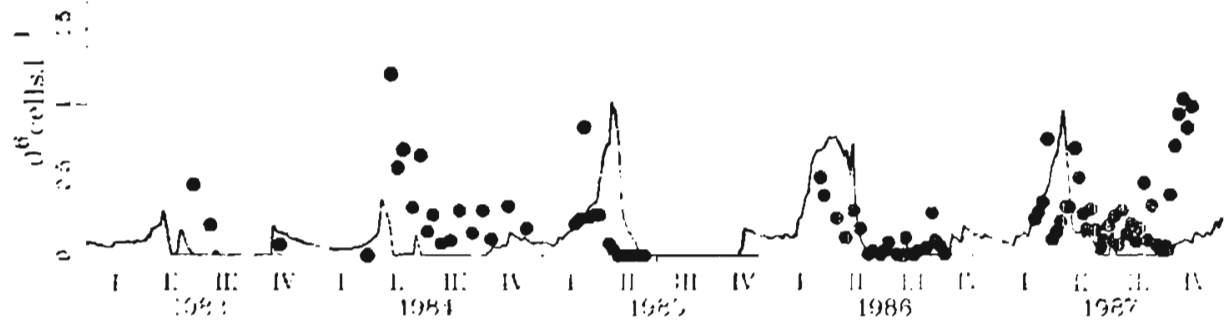

Fig. 5. - Evolution des algues non-siliceuses dans l'épilimnion et l'hypolimnion durant la période 1983-1987. Modele ASTER.

Fig. 5. - Evolution of non-siliceous algae in the epilimnion and hypolimnion, 1983-1987 - ASTER. 

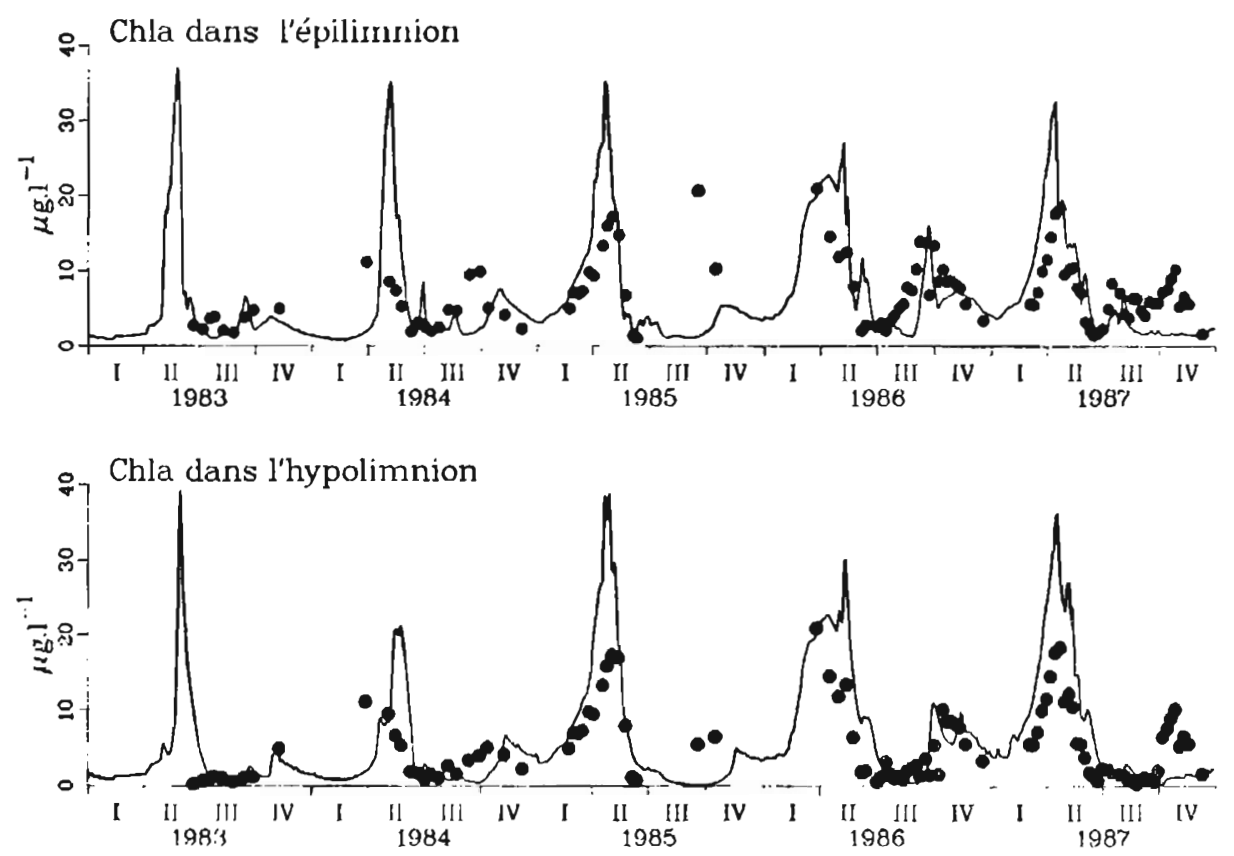

Fig. 6. - Evolution de la chlorophylle a dans l'épilimnion ef l'hypolimnion durant la période 19831987. Modèle ASTER.

Fig. 6. - Evolution of chlorophyll a in the epilimnion and hypolimnion, 1983-1987 - ASTER.

$\approx-\mathrm{SiO}_{2}$ dans l'épilimnion

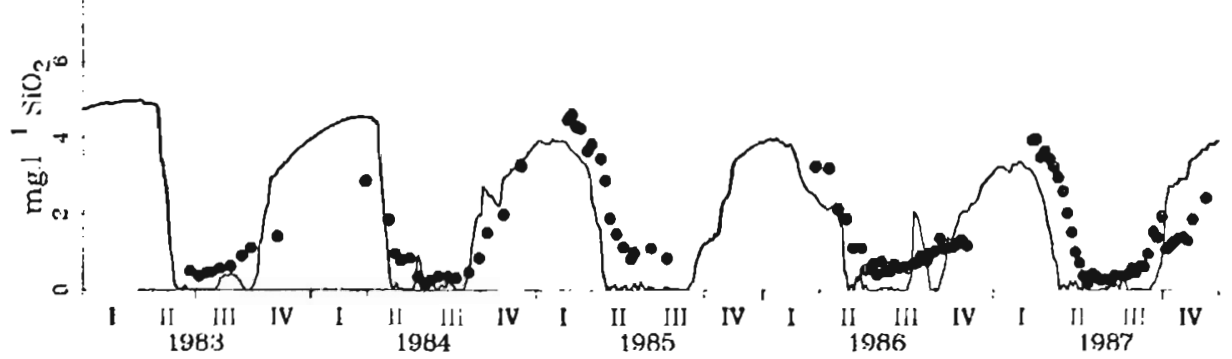

@- $\mathrm{PO}_{4}$ dans l'épilimnion

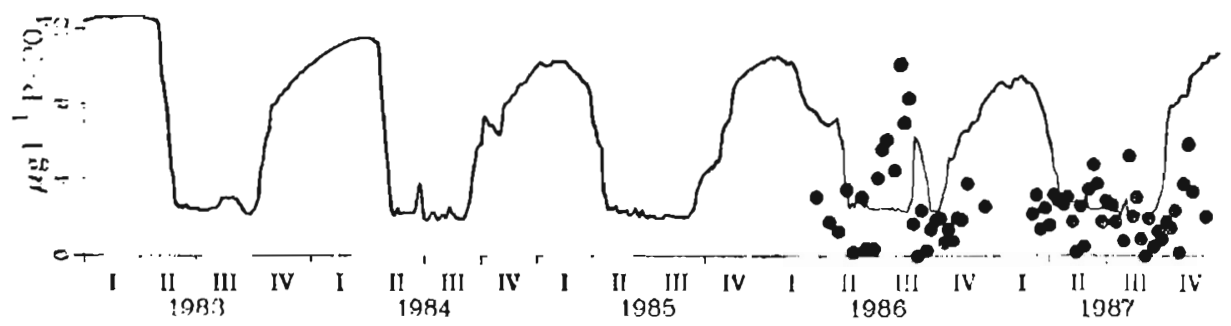

Fig. 7. - Evolution des silicates et des orthophosphates dans l'épilimnion durant la période 19831987. Modèle ASTER.

Fig. 7. - Evolution of silicates and orthophosphates in the epilimnion, 1983-1987 - ASTER. 
groupe de phytoplancton ainsi que l'intensité de broutage du zooplancton. La visualisation de ces variables calculées par le modèle aide considérablement à la compréhension de la dynamique du systeme.

\section{III.3.1 Phytoplancton et nutriments}

Les pics printaniers des deux catégories d'algues (figures 4 et 5) sont correctement représentés, aussi bien dans leur amplitude que pour leur démarrage et leur chute qui sont en phase avec les observations. Les fluctuations interannuelles sont bien marquées, mettant en évidence le rôle des conditions hydrométéorologiques. La disparition rapide des diatomées à la fin du printemps et la bonne représentation de leur évolution dans l'hypolimnion, montre que la fonction de sédimentation est bien représentée dans ce modèle: la figure 8 permet de visualiser qu'à la fin du printemps, la croissance des diatomées est fortement ralentie par la carence en silice et que, parallèlement, la vitesse de sédimentation augmente.

$\mathrm{Ce}$ modèle ne prend pas en compte les apports du bassin versant ni les sorties au barrage. Dans ce fonctionnement en circuit fermé, c'est le sédiment qui régule le stock de nutriments disponibles par l'intermédiaire des diatomées. En effet, lorsque les teneurs en silice deviennent limitantes à la fin du printemps, les diatomées, dont le seul facteur de disparition est la sédimentation, entraînent dans l'hypolimnion puis dans le sédiment la totalité de la silice et une part importante du phosphore.
Ces nutriments, après décomposition de la matière organique et des frustules siliceuses, sont lentement remis à disposition par relargage dans l'hypolimnion et n'atteindront la couche euphotique qu'à partir du mélange automnal. Ce processus se traduit dans le modèle par des cycles annuels d'évolution des deux nutriments.

Pour la silice, cette évolution cyclique est très marquée sur les observations et la concordance des valeurs calculées et mesurées est très satisfaisante (fig. 7a).

Par contre, pour le phosphore (fig. 7b), les concentrations de $\mathrm{PO}_{4}$ mesurées sont faibles et pratiquement constantes toute l'année. La plus grande partie du phosphore se trouve sous d'autres formes que $\mathrm{PO}_{4}$ (phosphore particulaire, phosphore organique dissous) (Harris, 1986). L'assimilation du $\mathrm{PO}_{4}$ par les organismes est alors compensée par l'équilibre entre les différentes fractions du phosphore (Peters, 1979). Le modèle ne simulant que l'évolution du $\mathrm{PO}_{4}$ ne peut pas représenter ces mécanismes complexes.

Avant la disparition de la silice, il y a compétition entre les deux groupes d'algues pour le phosphore. Cette phase est particulièrement importante pour l'écosystème. En effet, les diatomées, lors de leur disparition, jouent un rôle régulateur vis-à-vis du phosphore qui restera disponible en été dans l'épilimnion. Ce phénomène est évidemment très influencé par la dynamique propre des diatomées, donc, en particulier, par la quantité de silice disponible et par la structure 


\section{DIATOMEES'}

:- Taux de croissance (simulé)
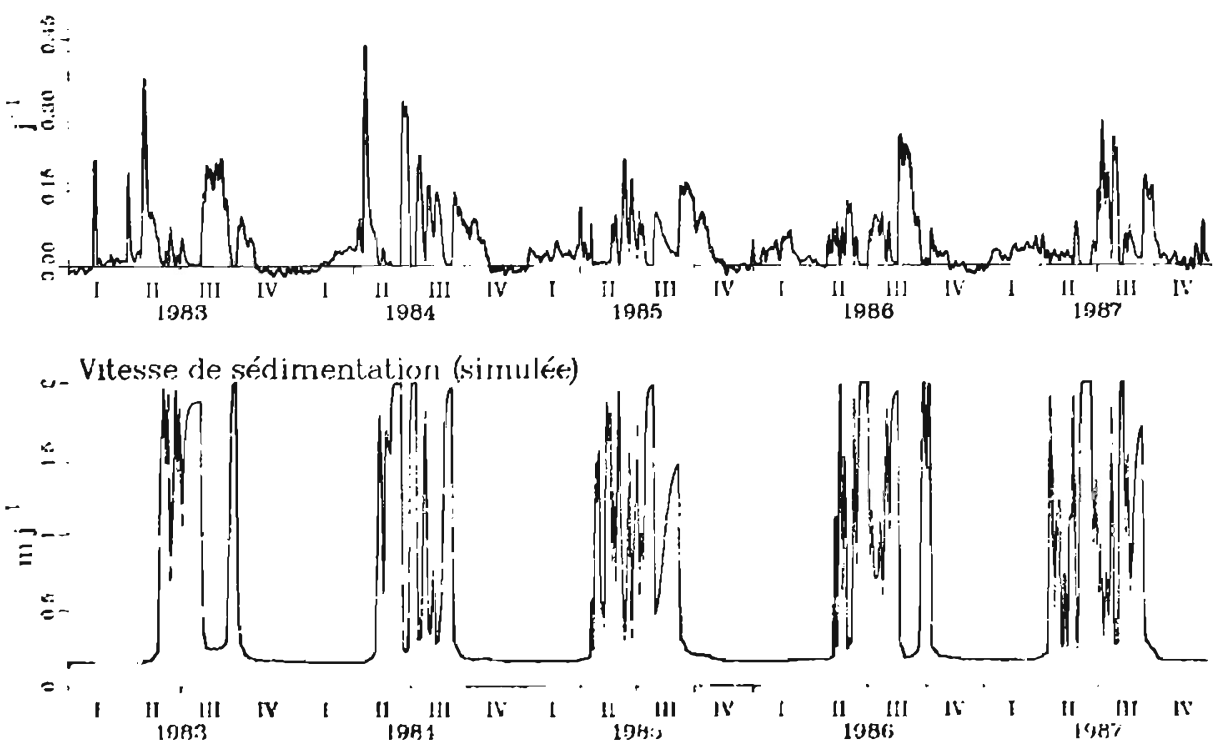

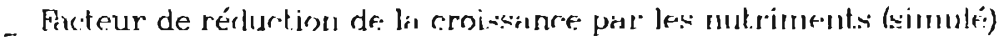

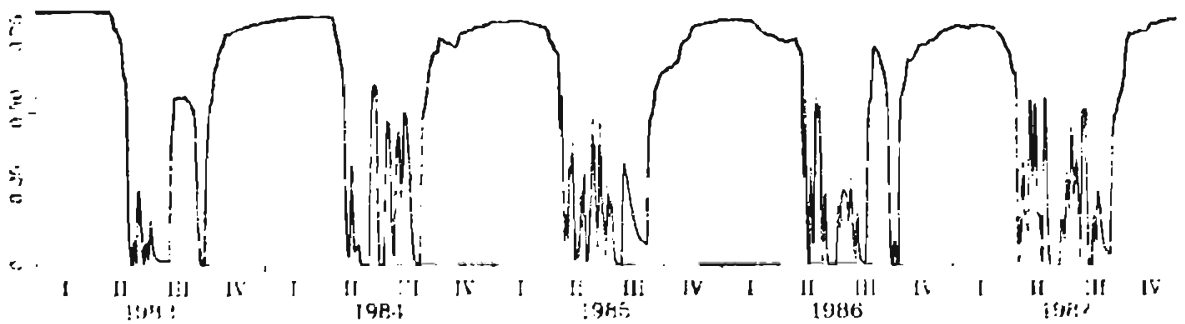

Fig. 8. - Evolution du taux de croissance, de la vitesse de sédimentation et de la limitation par les nutriments calculés par le modèle pour les diatomées. Modèle ASTER.

Fig. 8. - Evolution in growth rate, sinking speed and nutrient limitation rate for diatoms as calculated by ASTER.

thermique qui peuvent, lors de situations particulières, provoquer une perturbation de l'écosystème pendant toute l'année.

Ce rôle capital sera davantage mis en évidence lorsque seront pris en compte les apports du bassin versant, notamment dans le modèle vertical complet, où les fluctuations interannuelles seront non seulement liées aux conditions hydrométéorologiques, mais aussi aux apports exogènes. 


\section{ALGUES NON SILICEUSES}
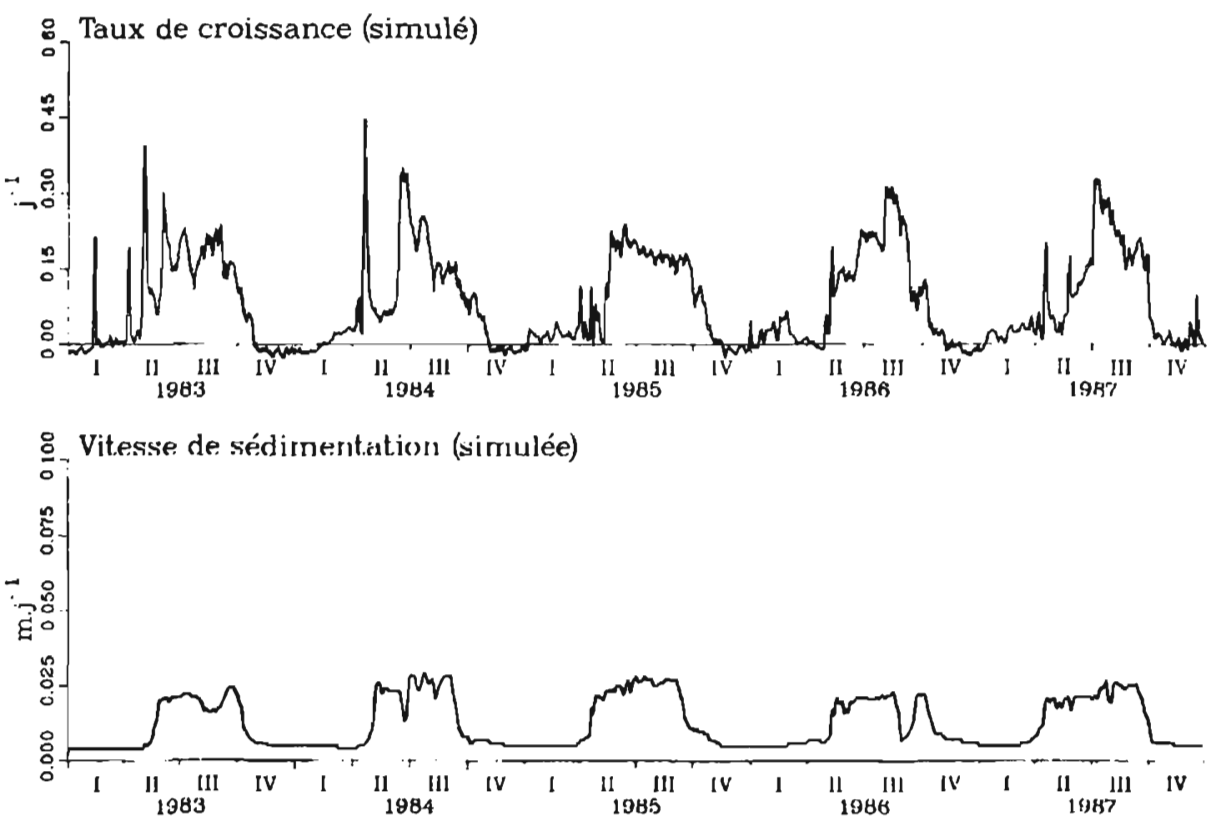

_. Fucteur de réduction de la croissinnce pur les nutriments (simulé)

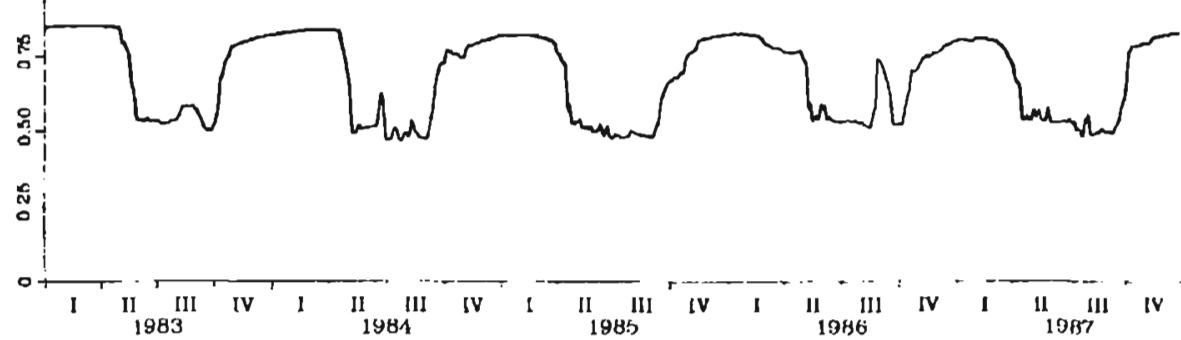

Fig. 9. - Evolution du taux de croissance, de la vitesse de sédimentation et de la limitation par les phosphates calculés par le modèle pour les algues non-siliceuses. Modèle ASTER.

Fig. 9. - Evolution in growth rate, sinking speed and phosphate limitation rate for non-siliceous algae as calculated by ASTER.

En été, les diatomées ne se développent plus, faute de silice (fig. $8 \mathrm{c}$ ). Bien que les densités des algues nonsiliceuses soient faibles, ce qui est conforme aux valeurs mesurées, la production est forte, comme le mon- trent le taux de croissance élevé ainsi que l'intensité du broutage (figures $9 a$ et 10a). D'autre part, la croissance des algues non-siliceuses est peu limitée par le phosphore (fig. 9c), malgré les faibles concentrations dans 


\section{ZOOPLA:NCTON}

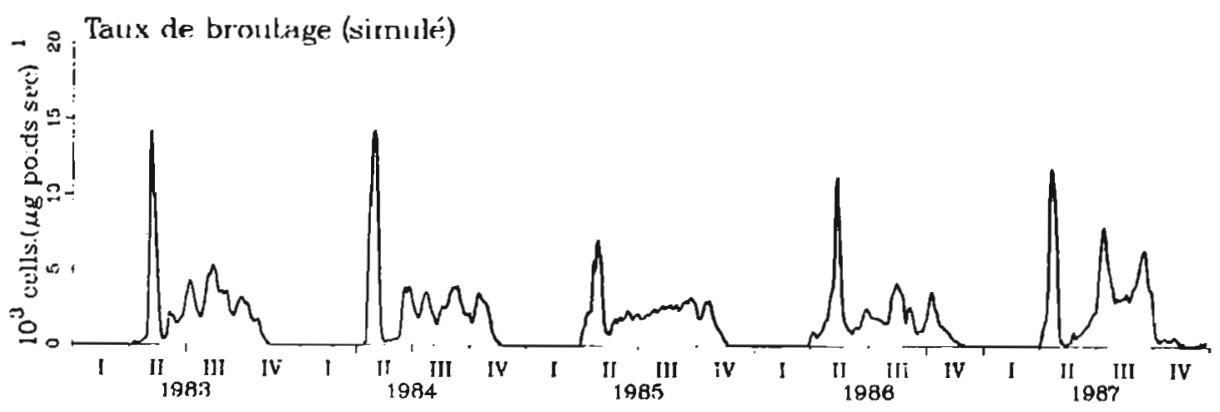

도. Zooplancton herbivore

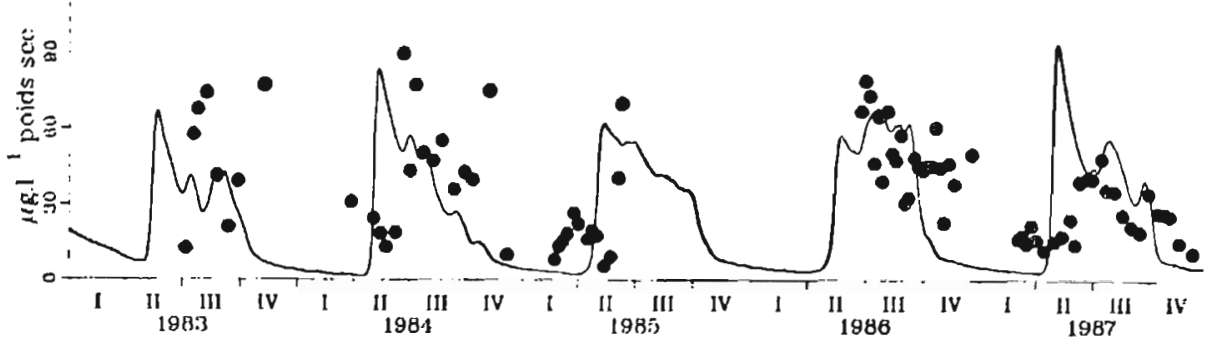

¿. Zooplancton carnivore

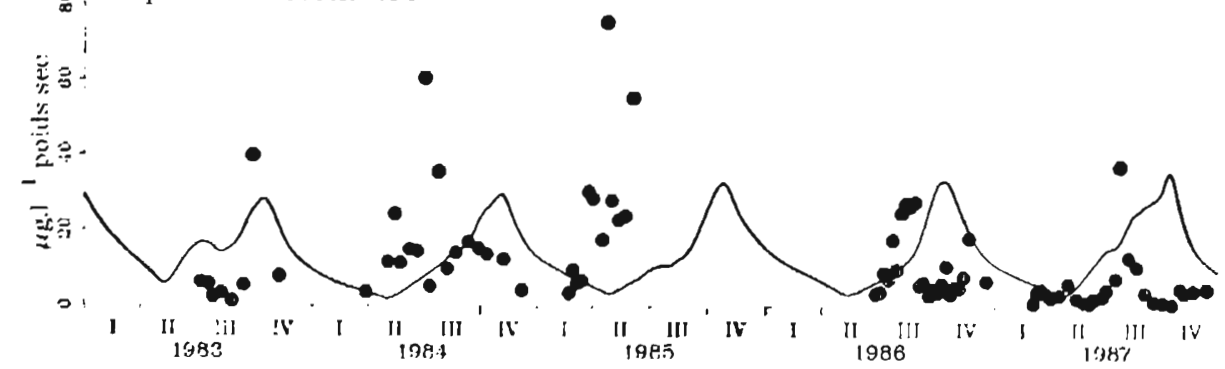

Fig. 10. - Evolution du zooplancton herbivore et carnivore dans l'ensemble de la masse d'eau durant la periode 1983-1987. Evolution de la quantité de cellules ingérées par le zooplancton herbivore. Modele ASTER.

Fig. 10. - Evolution of herbivorous and carnivorous zooplankton throughout the water mass, 19831987. Evolution in the number of cells ingested by herbivorous zooplankton - ASTER.

l'eau: la régénération rapide de la matière détritique dans la colonne d'eau permet au phosphore d'être rapidement rendu disponible pour les algues. Cette dynamique algale simulée par le modèle est conforme aux travaux de Harris (1986) qui observe qu'il peut $y$ avoir une forte croissance associée à une biomasse de phytoplancton faible et stable, si l'assimila- 
tion est compensée par une prédation intense et une régénération rapide de matière détritique.

Les résultats du modèle montrent qu'au printemps, la plupart de la production primaire est perdue par sédimentation, alors qu'en été, c'est le broutage zooplanctonique qui domine, ainsi que les processus de régénération dans la colonne d'eau. Ces résultats correspondent parfaitement aux mesures effectuées à Pareloup (Capblancq et al., 1994) et aux résultats des travaux de Tilzer (1984) et de Stabel (1985).

Les valeurs simulées de chlorophylle a ont été obtenues en sommant les deux variables phytoplanctoniques après transformation par un rapport constant chla: nombre de cellules spécifique à chacun des deux groupes. La comparaison avec les valeurs mesurées (fig. 6) confirme la bonne représentation de la dynamique phytoplanctonique.

\section{III.3.2 Zooplancton}

Le zooplancton, dans ce type de modèle, intervient à travers l'impact du broutage sur les algues. L'objectif est donc de simuler un transfert de matière et non la dynamique du zooplancton, ce qui nécessiterait de représenter l'évolution de la cohorte de chaque groupe ainsi que les différents modes de reproduction chez ces animaux (Thébault, 1984; Sciandra, 1986). Un tel modele serait beaucoup trop complexe pour qu'il soit envisagé de le coupler à un modèle hydrodynamique.
Etant donné cette schématisation, les ordres de grandeur de la biomasse zooplanctonique herbivore et carnivore obtenus avec le modèle sont relativement satisfaisants (fig. 10b et $10 c$ ).

\section{III.4 Discussion}

Les séries chronologiques des principales variables de l'écosystème de Pareloup, acquises pendant une durée de cinq ans, constituent une base de référence de choix qui a permis de tester le comportement du modele sur une longue période. La simulation débute le $1^{\text {er }}$ janvier 1983 où chaque variable est initialisée et elle se poursuit pendant cinq ans sans intervention ni réinitialisation.

Le modèle bicouche nous a permis, conformément à son objectif, d'identifier les processus essentiels qu'il était nécessaire de simuler pour bien représenter le fonctionnement de cet écosystème :

- la réponse des algues aux conditions de lumière et de température, et tout particulièrement aux basses températures, pour bien simuler la croissance printanière précoce des diatomées,

- la sédimentation des diatomées reliée à la carence nutritive de ces algues,

- la régulation du stock de nutriments par les échanges eau-sédiment dans les zones peu profondes,

- la fermeture du système par une fonction de forçage simulant la 
dynamique annuelle des poissons planctophages.

Cependant nous avons constaté, lors du calage du modèle, qu'il faut se garder de ne remettre en question que la conception du modèle ou le choix des valeurs des coefficients. En effet, les imprécisions inévitables des conditions de forçage sont à l'origine de perturbations importantes dans les résultats.

Les principales difficultés que nous avons rencontrées dans le forçage concernent l'estimation de la structure bicouche à partir des fluctuations de niveau de la thermocline et celle de Pabsorption de la lumière.

Lors de l'estimation de la structure bicouche du modèle, il est apparu important de représenter finement les quatre phases principales de la stratification (Pourcher et Salençon, 1990): mélange hivernal, thermoclines transitoires au printemps, thermocline saisonnière stable en été et déstratification progressive à l'automne.

Pour déterminer cette structure bicouche, nous disposons des profils thermiques mesurés quotidiennement et des profils trihoraires calculés par le modèle thermique vertical EOLE. Dans un premier temps, nous avons exploité les mesures thermiques, avec l'inconvénient des interruptions d'acquisition qui nous ont contraints à procéder à des interpolations. Nous avons également été confrontés à la difficulté d'estimer un positionnement moyen de la stratification en filtrant les ondes internes et les upwellings (Sa- lençon et Calmels, 1994), afin de ne pas induire artificiellement un transfert vertical de matière qui serait dû aux fluctuations du niveau de la thermocline.

Nous avons ensuite utilisé les résultats du modèle thermique vertical qui présentent l'avantage de la régularité d'une représentation spatiale moyenne et l'inconvénient d'une simulation moins fidèle à la réalité que des mesures.

Cependant, il est apparu très rapidement qu'une bonne représentation de la dynamique du phytoplancton sur tout le cycle annuel nécessitait une bonne simulation du démarrage printanier. Pour cela, il a été fondamental de reproduire les thermoclines transitoires établies lors de journées chaudes et détruites ultérieurement par un coup de vent: ces thermoclines jouent un rôle capital sur la croissance des algues par le biais de la disponibilité des nutriments et de la lumière.

Seul le modèle thermique a fourni simplement une telle dynamique.

Par contre, à l'automne, nous avons constaté un retard systématique de la poussée planctonique d'une à deux semaines par rapport aux mesures. Ce décalage est induit par la structure du modèle thermique qui ne prend pas en compte explicitement le cisaillement à la thermocline, ce qui retarde la déstratification (Salençon, 1994b).

Nous avons finalement choisi l'exploitation des résultats du modèle thermique qui ont apporté une amé- 

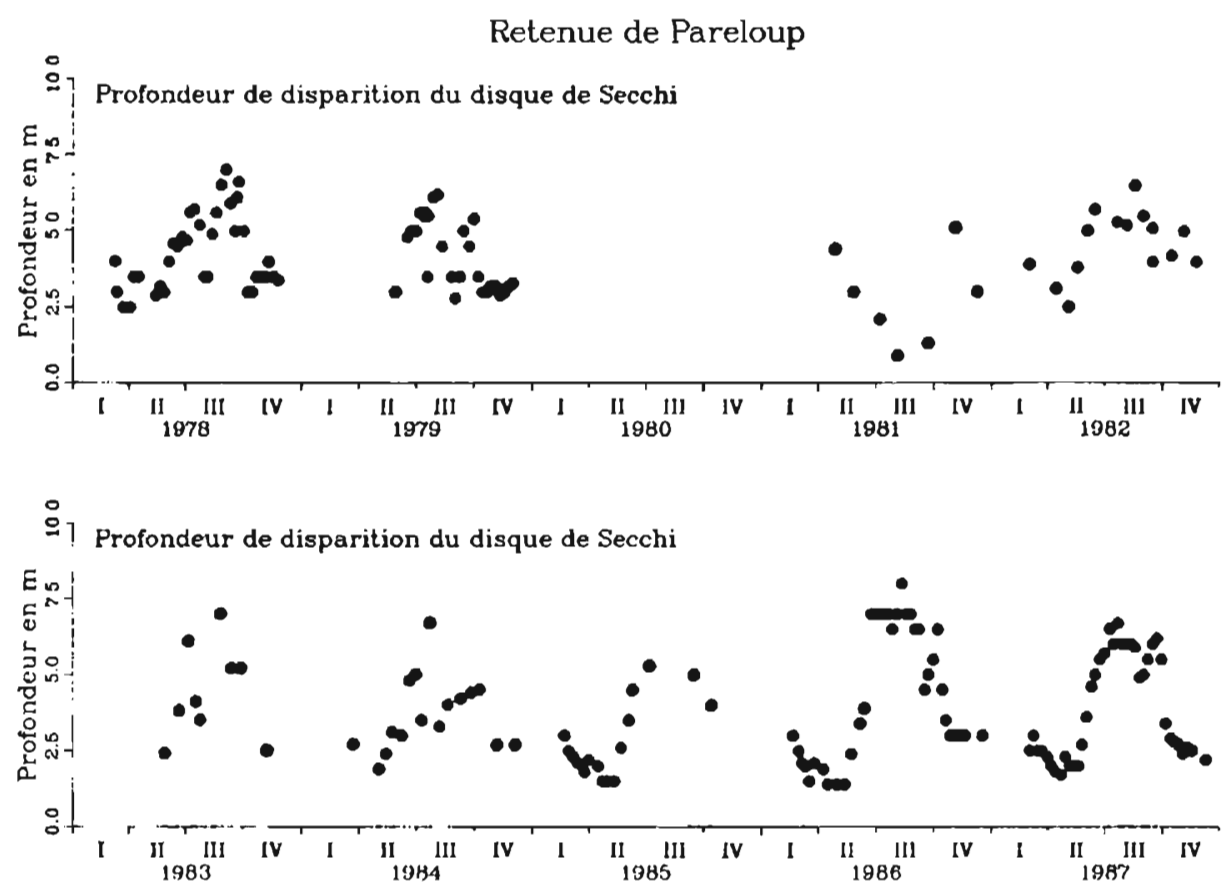

Fig. 11. - Profondeur de disparition du disque de Secchi dans la retenue de Pareloup de 1978 à 1987 .

Fig. 11. - Depth of disappearance of the Secchi disk in Pareloup reservoir, 1978-1987.

lioration sensible à la représentation globale du phytoplancton, ce qui constitue un premier pas vers le couplage des deux modèles.

Pour des raisons pratiques, les mesures hebdomadaires du coefficient d'extinction ont dû être interrompues en hiver, de novembre à mars, période peu spectaculaire mais néanmoins fondamentale pour certains mécanismes (fig. 11). A cette époque, la mise en suspension des sédiments et les apports terrigènes du bassin versant par les crues augmentent la turbidité du lac. Or, la lumière inci- dente est généralement faible et la masse d'eau étant homogène, les algues reçoivent moins de lumière que lorsque le lac est stratifié. La conjonction de ces deux phénomènes crée des conditions de lumière critiques pour la croissance (ou le déclin) des algues, quand la respiration est inférieure (ou supérieure) à la production brute.

II est donc très pénalisant, pour le modèle, de ne pas disposer des mesures du coefficient d'extinction en hiver. Une simple interpolation linéaire entre novembre et mars, ayant induit 
des résultats surprenants (forte croissance des diatomées dès novembre), nous avons dû légèrement augmenter ces valeurs du coefficient d'extinction pour tenir compte de l'accroissement de turbidité à cette époque.

En période de forte croissance algale, l'absorption de la lumière est augmentée par l'effet d'auto-ombrage. Dans le modèle, nous avons utilisé les valeurs mesurées du coefficient d'extinction qui tiennent compte implicitement de cet effet d'auto-ombrage. La difficulté réside alors dans le fait que, dans le cas où le modèle n'est pas exactement en phase avec les observations, il est soumis, malgré tout, à des conditions d'extinction de la lumière qui ne correspondent pas à sa dynamique propre. C'est ce que l'on constate à l'automne: le développement du phytoplancton, calculé par le modèle, a lieu avec un léger retard par rapport aux obsenvations (dû au retard dans la déstratification). On impose alors un coefficient d'extinction de la lumière, déduit des mesures, correspondant à une forte densité de phytoplancton mesurée, alors que, dans le modèle, la concentration de phytoplancton calculée est encore très faible. Cette limitation excessive de la croissance par la lumière accen- tue le retard de la poussée algale d'automne calculée, au point que, certaines années, malgré l'apport d'élément minéraux hypolimniques, cette poussée phytoplanctonique peut être inexistante car les conditions héliothermiques sont devenues trop défavorables.

Nous verrons qu'avec le modèle vertical, il est possible de calculer l'absorption de la lumière par la biomasse phytoplanctonique, ce qui permet d'éviter un tel biais.

II est intéressant de constater à quel point le comportement du modèle biologique est influencé par les conditions de forçage.

\section{COUPLAGE DU MODĖLE HYDRODYNAMIQUE VERTICAL EOLE ET DU MODĖLE BIOLOGIQUE : LE MODĖLE MELODIA}

\section{IV.1 Réalisation du couplage}

L'équation globale d'évolution d'une variable d'état $X$ peut être écrite schématiquement :

$$
\frac{1}{A} \cdot \frac{\partial A X}{\partial z}=W \frac{\partial X}{\partial z}+B\left(U_{\theta} X_{\theta}-U_{S} X\right)+\frac{\partial A \overline{W^{\prime} X^{\prime}}}{\partial z}+S-D
$$

\begin{tabular}{|c|c|c|c|}
\hline $\begin{array}{l}\text { transport } \\
\text { moyen } \\
\text { vertical }\end{array}$ & $\begin{array}{l}\text { transport } \\
\text { moyen } \\
\text { horizontal }\end{array}$ & $\begin{array}{l}\text { transpont } \\
\text { turbulent }\end{array}$ & source \\
\hline
\end{tabular}


où la variation en temps de la variable $X$ est la résultante:

- d'un terme de transport $\left(W \frac{\partial X}{\partial z}\right)$ par le courant moyen vertical $W$,

- d'un terme de transport $B\left(U_{e} X_{e}-U_{s} X\right)$ par le courant moyen horizontal ramené aux conditions aux limites d'entrée $U_{\theta}$ et de sortie $U_{s}$,

- d'un terme de transport turbulent $\left(\begin{array}{c}\partial A \overline{W^{\prime} X^{\prime}} \\ \partial z\end{array}\right)$ qui est ici traité par la méthode d'intégration sur la couche de mélange,

— du bilan d'évolution propre à cette variable que l'on exprime comme la résultante d'un terme source $S$ et d'un terme de disparition $D$.

Si des variables influencent la densité de l'eau (salinité, matières en suspension...), il faut les introduire dans l'équation d'état et prendre soin de modifier cette fonction dans le modèle thermique. Les variables d'état qui n'ont pas d'influence sur la densité de l'eau (variables de qualité d'eau, variables biologiques autres que température, salinité et MES) n'ont pas de couplage actif avec la stratification thermique, et suivent passivement les mouvements d'eau.

Cette propriété va grandement faciliter le traitement numérique de leurs équations d'évolution, par l'application de la méthode des pas fractionnaires (Yanenko, 1968) que nous avons déjà utilisée pour le modèle thermique. L'intérêt de ce procédé, qui consiste à séparer les opérateurs, est de décomposer les opérateurs complexes qui apparaissent dans les équations en opérateurs élémentaires qui seront résolus successivement avec des méthodes numériques mieux adaptées à chacun d'eux et donc moins coûteuses.

La résolution de l'équation précédente est alors fractionnée en 3 pas par rapport au temps. Les deux premiers pas sont étroitement liés à ceux du modèle thermique (mélange turbulent des couches supérieures et advection des masses d'eau). Dans le pas fractionnaire correspondant à la résolution des équations biologiques, nous avons utilisé une méthode de Runge-Kutta d'ordre 4, comme dans le modèle bicouche.

Le modèle couplé a donc conservé la structure globale du modèle hydrodynamique, en particulier une discrétisation spatiale à volumes finis en couches horizontales de $0,25 \mathrm{~m}$ d'épaisseur $(\Delta z)$ et une résolution avec un pas de temps $(\Delta t)$ de 3 heures (Salençon, 1994a).

Le temps de calcul relativement faible sur un ordinateur CRAY-YMP (120 secondes pour 5 ans de simulation) a permis un grand nombre de simulations.

Le bilan de masse (phosphore total du système) fait apparaître une perte de phosphore inférieure à $0,1 \%$ du phosphore total initial, après cinq ans de simulation, ce qui montre la bonne performance des méthodes numériques utilisées. 


\section{IV.2 Transformations apportées au modèle biologique lors du couplage}

Lors du couplage des modèles ASTER et EOLE, seuls ont été modifiés les coefficients et les fonctions liés spécifiquement à la structure bicouche du modèle précédent.

Les trois points particulièrement modifiés lors du couplage sont la sédimentation, la représentation du sédiment et le calcul du coefficient d'extinction (Salençon et Thébault, 1995).

\section{IV.2.1 La sédimentation}

Si, dans le modèle bicouche, la sédimentation représente le passage de matière de l'épilimnion vers l'hypolimnion, il n'en est pas de même dans le modèle vertical qui représente l'ensemble des phénomènes à une échelle plus fine, faisant apparaître de plus fortes variations de nutriments dans l'espace et dans le temps. Dans ce cas, l'état physiologique des cellules ne peut plus être directement relié aux conditions extérieures du milieu car les cellules réagissent en réalité avec une certaine inertie aux fluctuations extérieures.

Nous avons représenté cet effet intégrateur des cellules avec une moyenne des états de carence nutritive successifs dans chaque couche pendant une période donnée.

Pour les algues non-siliceuses, l'étude des flux simulés montre que le rôle de la sédimentation dans leur disparition est très faible vis-à-vis du broutage par le zooplancton.
Pour les diatomées, la vitesse de sédimentation ainsi calculée ne permet pas de simuler la disparition complète de la poussée d'A. formosa à la fin du printemps. Lund (1949; 1950a; 1950b) a montré que, à la suite de conditions de carence de longue durée en silice, la population de diatomées passe par une phase critique à partir de laquelle aucune division cellulaire n'est possible. Si la carence nutritive persiste, les cellules meurent (Sommer et Stabel, 1983; Sommer, 1989).

Nous avons représenté ces mécanismes complexes en rajoutant, dans le calcul de la vitesse de sédimentation, une fonction seuil: la sénescence de la population est atteinte lorsqu'un état de carence persiste audelà d'une certaine durée. Alors, la vitesse de sédimentation étant maximale, les diatomées sont entraînées dans le sédiment où elles meurent lentement. Les survivantes ensemenceront la retenue à la faveur d'une remise en suspension des couches superficielles du sédiment (Rhodes et Le Cohu, 1987).

\section{IV.2.2 Le sédiment}

La cuvette du lac de Pareloup a une forme particulière très évasée en surface et très encaissée dans le fond, au droit des lits des anciens ruisseaux. Aussi chaque couche d'eau du lac est en contact avec une couche de sédiment de fond de superficie très variable selon la profondeur. Pour tenir compte de cette particularité topographique dans les échanges eau-sédiment, nous avons introduit 
une discrétisation verticale du sédiment déposé : à chaque couche d'eau de la retenue est associée une couche de sédiment adjacente. Pour chaque niveau, la couche de sédiment recueille les dépôts particulaires qui ne passent pas dans la couche d'eau immédiatement inférieure à cause du rétrécissement topographique. De plus, après minéralisation de la matière organique qui y a sédimenté, les éléments minéraux sont relargués dans l'eau sous forme dissoute. La surface d'échange entre ces deux couches adjacentes est calculée à partir de la bathymétrie.

\section{IV.2.3 Le calcul du coefficient d'extinction}

La pénétration de la lumière dans l'eau est représentée par la loi de Beer-Lambert, où l'absorption de la lumière dans l'eau est due à l'ensemble des matières en suspension. Elle est généralement attribuée à la somme de deux facteurs: l'absorption due à la chlorophylle a et celle de l'eau ellemême et du matériel non chlorophyllien en suspension (Platt et al., 1977).

La valeur que nous avons retenue pour le premier terme a été obtenue à partir des mesures effectuées sur le site de Pareloup de 1983 à 1987 (Capblancq et al., 1988; 1994). Elle se situe dans la gamme des valeurs citées dans la littérature (Humphries et Lyne, 1988).

$\mathrm{Si}$ on peut admettre que le deuxième terme est à peu près constant dans certains milieux (océan, lac d'altitude) (Riley, 1956; Bannister, 1974; Kremer et Nixon, 1978), il ne nous a pas paru raisonnable de garder cette approximation pour la retenue de Pareloup, relativement turbide en hiver. A partir des mesures disponibles du disque de Secchi, nous avons estimé une évolution annuelle de ce terme.

\section{IV.3 Les apports de nutriments par les entrées d'eau}

Dans un réservoir, la stratification thermique est influencée par les phénomènes advectifs. Les entrées d'eau s'insèrent à une cote correspondant à leur couche de densité, entraînant avec elles des masses d'eau avoisinantes. Ce mélange peut être important, en particulier lorsque le niveau d'insertion des entrées est imposé, comme dans le cas d'un pompage. Les mouvements horizontaux ont pour effet d'engendrer des mouvements verticaux qui ont tendance à lisser les profils verticaux.

Dans le cas d'un réservoir, il est donc particulièrement important de bien connaître tous les apports et leurs caractéristiques physico-chimiques qui sont déterminantes dans le rôle qu'ils joueront pour l'écosystème.

Dans le modèle, les différentes entrées d'eau ont été regroupées en trois entrées de caractéristiques différentes: le pompage de Bage, le ruisseau du Vioulou, le ruisseau du Rieutord.

Les nutriments pris en compte dans le modèle sont $\mathrm{SiO}_{2}$ et $\mathrm{PO}_{4}$ biodisponible. Les mesures hebdomadaires ont permis d'ajuster des 
fonctions reconstituant, pour chaque entrée, les moyennes journalières.

Les concentrations hebdomadaires de $\mathrm{SiO}_{2}$ ont été interpolées linéairement pour obtenir des concentrations journalières.

Pour le phosphore, nous avons besoin de connaître la concentration des entrées en $\mathrm{PO}_{4}$. Or, seuls le phosphore total $\left(P_{\text {total }}\right)$ et les matières en suspension (MES) sont mesurés pendant le suivi hebdomadaire de routine 1983-1987, les concentrations en $\mathrm{PO}_{4}$ (complétant celles de $P_{\text {total }}$ et MES) n'ayant été mesurées que lors des épisodes de crues du Vioulou des années 1986 et 1987.

Le transport du phosphore dans les eaux superficielles étant étroitement associé à celui des MES, afin de pouvoir reconstituer les chronologies de $\mathrm{PO}_{4}$ sur toute la période, nous avons établi une fonction exprimant la relation entre $\mathrm{PO}_{4}, \mathrm{P}_{\text {total }}$ et MES, mesurés simultanément pendant les crues. Ces mesures, acquises toutes les $30 \mathrm{mn}$, présentent une grande dispersion. En effet, les sédiments transportés par les affluents sont le siège d'échanges très rapides et permanents entre le phosphore dissous $\left(\mathrm{PO}_{4}\right)$ et le phosphore lié aux MES. Les concentrations en $\mathrm{PO}_{4}$ dépendent donc directement du contenu des MES en phosphore échangeable, lui-même fluctuant considérablement selon la nature et l'origine des MES. Ces mesures caractérisent essentiellement les épisodes particuliers de crues (forts débits, fortes valeurs de MES). Afin de ne pas donner trop de poids à ces situations extrêmes, pour la re- constitution des apports quotidiens, nous avons choisi le meilleur ajustement obtenu en favorisant les faibles valeurs de MES. En accord avec les résultats fournis par des cinétiques de dilution isotopique (Capblancq et al., 1986), nous avons retenu une relation hyperbolique du type (fig. 12) :

$$
\mathrm{PO}_{4}=3,6 \frac{\mathrm{P}_{\text {total }}}{\mathrm{MES}}
$$

Cette relation indique que le sédiment en suspension joue le rôle de tampon, atténuant les fluctuations des teneurs en $\mathrm{PO}_{4}$ dissous. Lors d'une crue, le lessivage des sols entraîne une augmentation des MES et du $P_{\text {total. }}$. Alors, la proportion de $P_{\text {total }}$ présente sous forme de $\mathrm{PO}_{4}$ dissous décroît vers une valeur limite. Inversement, plus la charge en MES (et donc la concentration en $\mathrm{P}_{\text {total }}$ ) est faible, plus la proportion de $\mathrm{PO}_{4}$ dissous est élevée.

\section{IV.4 Résultats}

Le modèle MELODIA a été construit et calé avec les données de la période 1983-1985 et testé sur la période 1983-1987 (Salençon et al., 1988b; 1989).

Nous avons utilisé trois façons différentes de visualiser l'évolution chronologique des variables du modèle unidimensionnel vertical :

- la représentation bicouche, avec les valeurs moyennes dans l'épilimnion et l'hypolimnion, permet d'apprécier les fluctuations annuelles des cycles saisonniers. La difficulté de cette représentation est la détermination de chaque couche à partir du pro- 

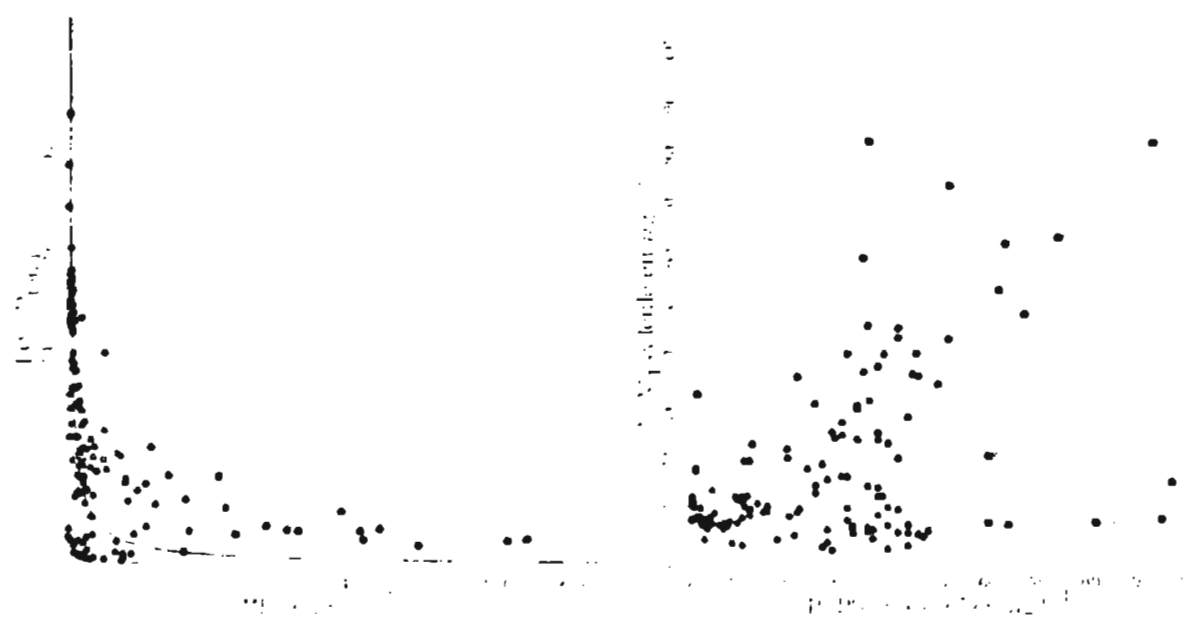

Fig. 12. - Relation entre le rapport $\mathrm{PO}_{4} / \mathrm{P}_{\text {th:al }}$ et MES. Les mesures sont effectuées toutes les demi-heures pendant les crues. Modele MELODIA.

Fig. 12. - Relationship between the $\mathrm{PO}_{4} / P_{\text {tulial }}$ ratio and suspended solids (MES). Measurements were taken every half-hour during high-water periods - MELODIA.

fil thermique, qui selon la hauteur estimée de la thermocline, peut entraîner des erreurs dans le calcul des valeurs moyennes.

- la représentation sous forme de profils permet de bien appréhender la dynamique verticale des variables. Cependant il suffit d'un décalage minime (quelques jours), entre les mesures et le calcul, pour qu'il n'y ait plus concordance entre les profils mesurés et simulés, alors que par ailleurs le calage semble correct dans la représentation précédente.

Ceci explique la complémentarité de ces deux représentations.

- les courbes isométriques des variables synthétisent linformation. Elles sont par contre plus difficiles à interpréter que les précédentes et ne permeitent pas la comparaison directe avec les mesures, qui, par ailleurs, ne sont pas suffisamment denses pour supporter ce genre de représentation.

\section{IV.4.1 Les diatomées et la silice}

Les cycles printaniers des diatomées sont particulièrement bien représentés par le modèle (fig. 13). Grâce à la modification apportée au calcul du coefficient d'extinction en hiver, la croissance des diatomées débute en février, conformément aux observations, et n'a jamais lieu en automne ni en hiver, comme cétait le cas avec le modèle bicouche. Cependant, on peut regretter l'absence de comptages d'algues en hiver pendant notre période d'étude. En effet, des observations récentes durant les hivers 1991 et 1992 montrent des poussées importantes d'Aulacoseira subarctica 
(O. Müll.) Haworth (syn. Melosira italica) en décembre et janvier, alors qu'A. formosa, diatomée simulée dans le modèle, n'est pas rencontrée à cette époque (Le Cohu et al., 1994).

La chute de la poussée de diatomées est très bien simulée sur toute la période. Ce résultat est d'autant plus satisfaisant que la sédimentation des diatomées a été plus complexe à modéliser avec une représentation verticale fine.

Par exemple, en 1987, année où les mesures sont complètes sur l'ensemble des variables, la poussée des diatomées atteint son maximum sur toute la colonne d'eau dès fin avril.
Elle se maintient jusqu'à fin mai grâce à l'effet conjugué des apports externes de nutriments et des fluctuations de la thermocline transitoire qui mélangent, aux eaux de surface, les eaux profondes plus riches en nutriments (figures 13 et 14).

Dès début juin, la masse d'eau est très pauvre en silice sur les 20 premiers mètres, déclenchant la sédimentation de la population des diatomées qui a totalement disparu à la fin du mois de juin.

Dans le modèle, les diatomées ont tendance à épuiser le stock de silice plus rapidement que ce qui est observé sur les mesures, principalement
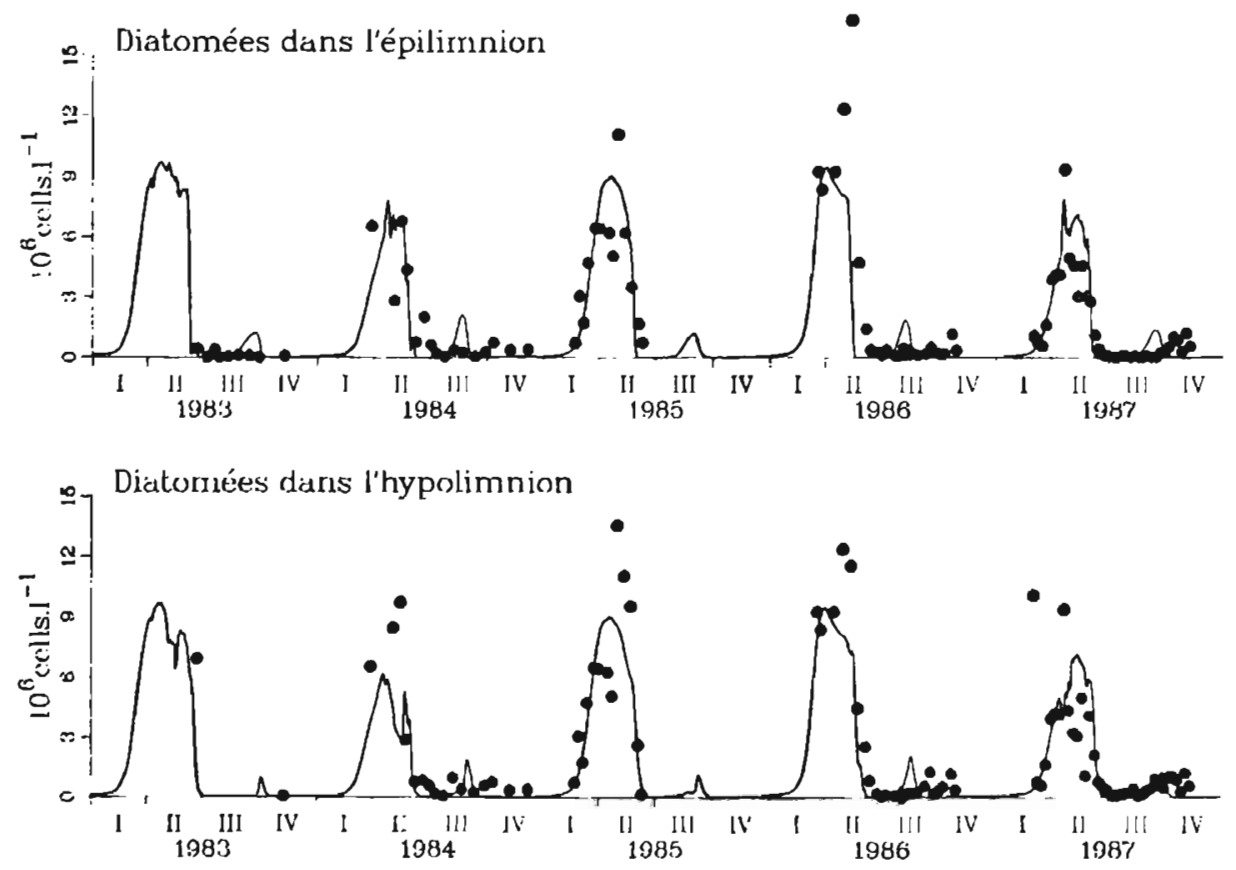

Fig. 13. - Evolution des diatomées dans l'épilimnion et l'hypolimnion durant la période 1983-1987. Modèle MELODIA.

Fig. 13. - Evolution of diatoms in the epilimnion and hypolimnion, 1983-1987 - MELODIA. 

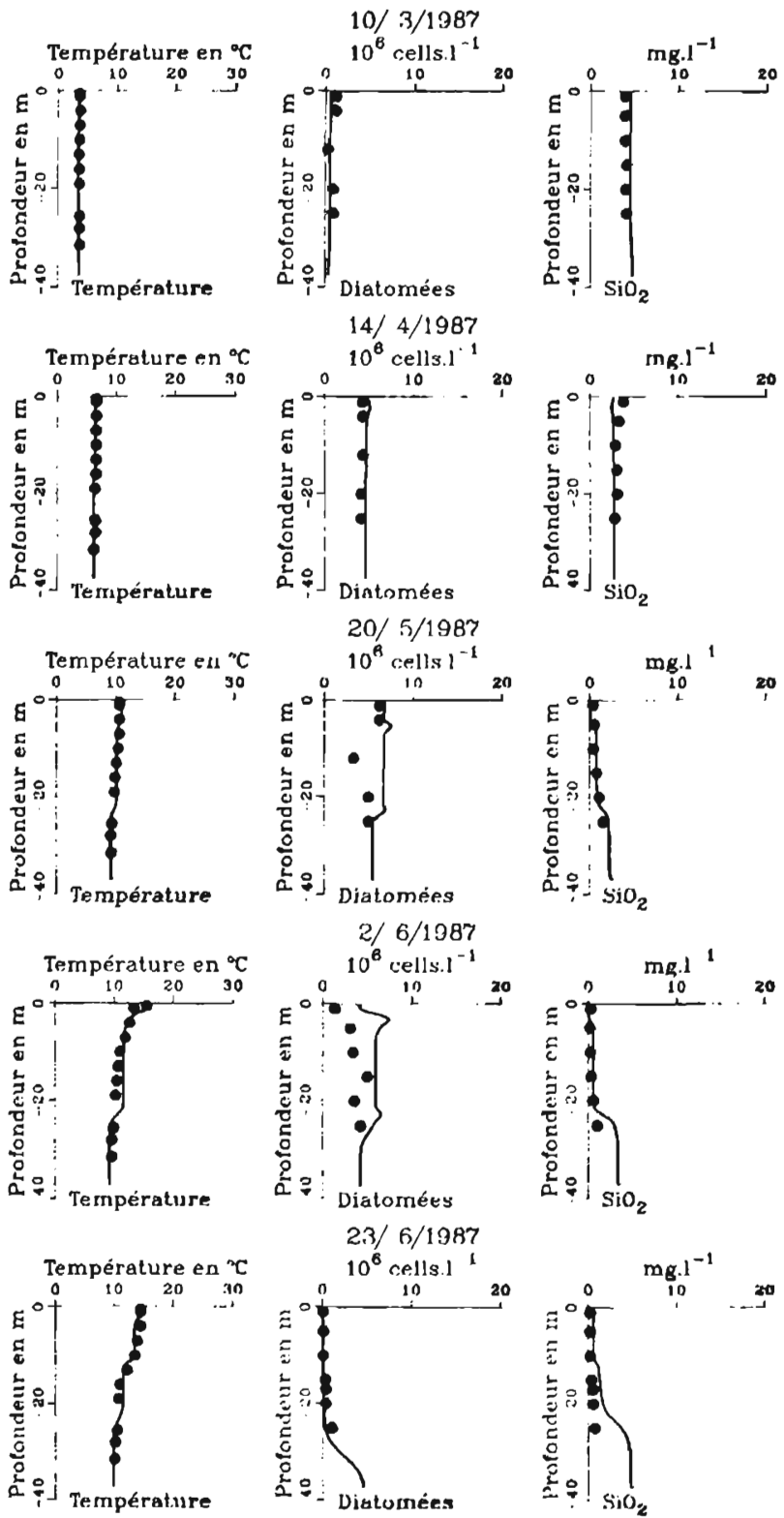

Fig. 14. - Evolution des profils calculés (trait continu) et mesurés ( $\bullet$ ) de la température, des diatomées et des silicates au printemps 1987. Modèle MELODIA.

Fig. 14. - Evolution in calculated (continuous line) and measured ( $\bullet$ ) profiles for temperature, diatoms and silicates in spring 1987 - MELODIA. 

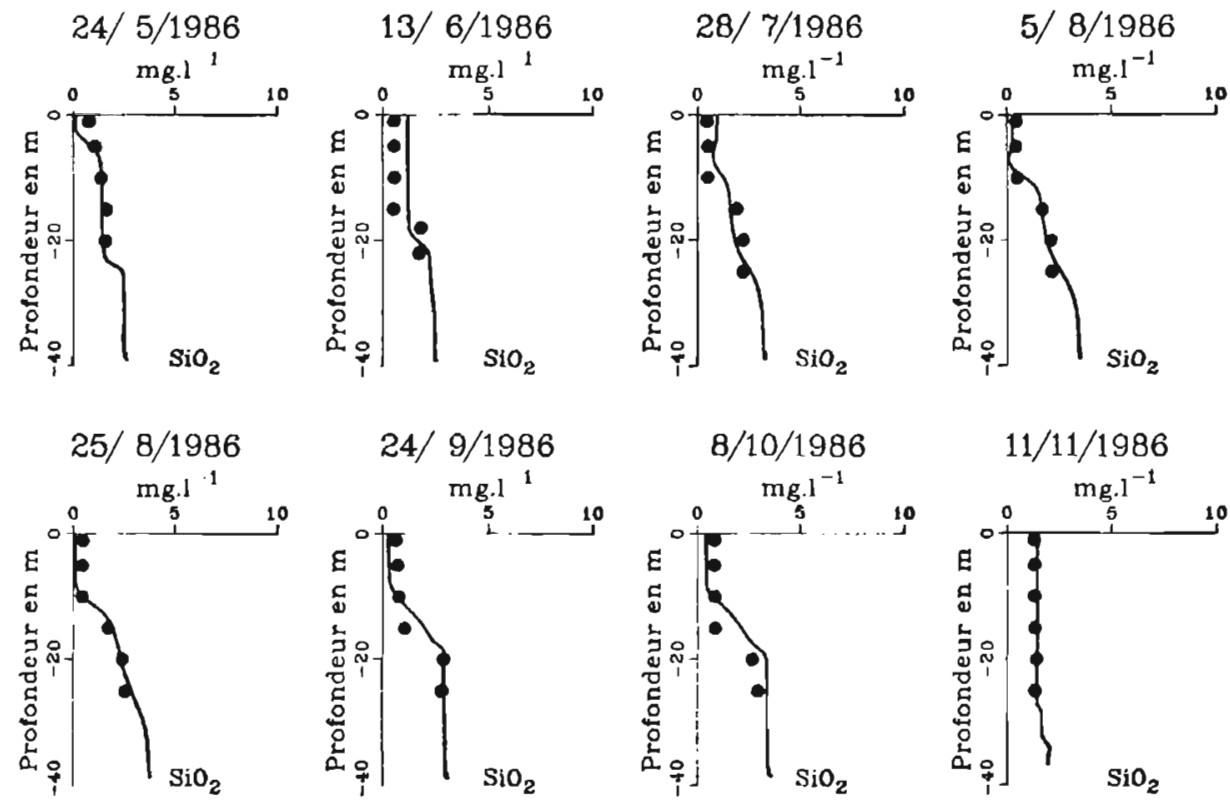

Fig. 15. - Evolution des profils calculés (trait continu) et mesurés ( $\left(^{\circ}\right)$ des silicates en 1986. Modèle MELODIA.

Fig. 15. - Evolution in calculated (continuous line) and measured $(\bullet)$ profiles for silicates in 1986 MELODIA.

pendant leur phase de croissance (jusqu'à mi-avril). Ceci est particulièrement remarquable en 1985 et 1986 où l'on observe une proportion importante d'A. ambigua. Le modèle étant basé sur l'hypothèse d'une population homogène de diatomées, la coexistence de deux populations pourrait être la cause du décalage observé ces années-là.

Lorsque la masse d'eau est stratifiée, les apports de silice par pompage restent confinés sous la thermocline, comme l'ont confirmé les traçages de masses d'eau (Salençon et al., 1988a; Salençon et Calmels, 1994). Les concentrations en $\mathrm{SiO}_{2}$ augmentent alors progressivement dans l'hypolimnion, jusqu'au mélange automnal qui a lieu vers fin septembre. La redistribution de la silice de l'hypolimnion (de faible volume) dans toute la masse d'eau diminue considérablement les concentrations dans l'hypolimnion. Cette phase de mélange a lieu très rapidement et on peut l'identifier sur les courbes (fig. 15) par une chute brutale des concentrations, aussi bien calculées que mesurées.

La silice, en contrôlant la croissance des diatomées, est un élément déterminant dans l'évolution de l'écosystème de Pareloup. Dans ce modèle, le stock de nutriments est régulé par le sédiment mais aussi par les entrées 
Algues non silice:luses dans l'épilimnion

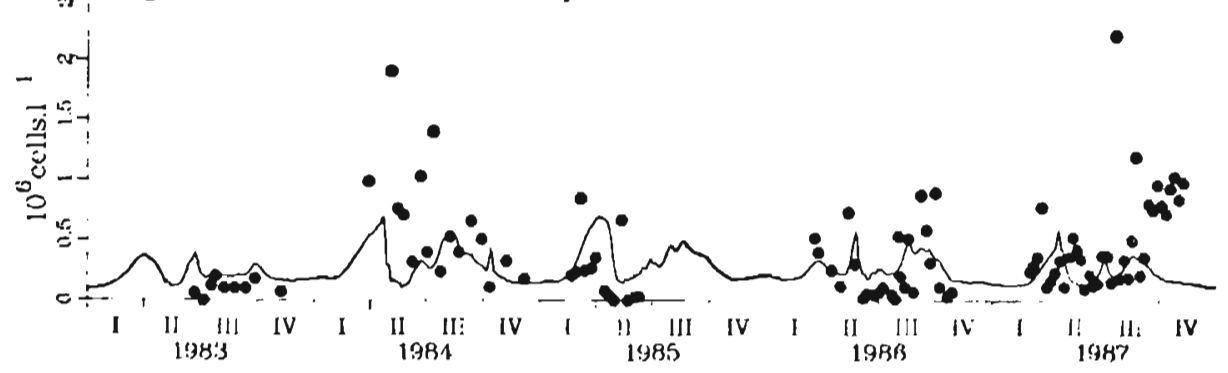

$\therefore$ Algues non siliceuses dans l'hy polimuion

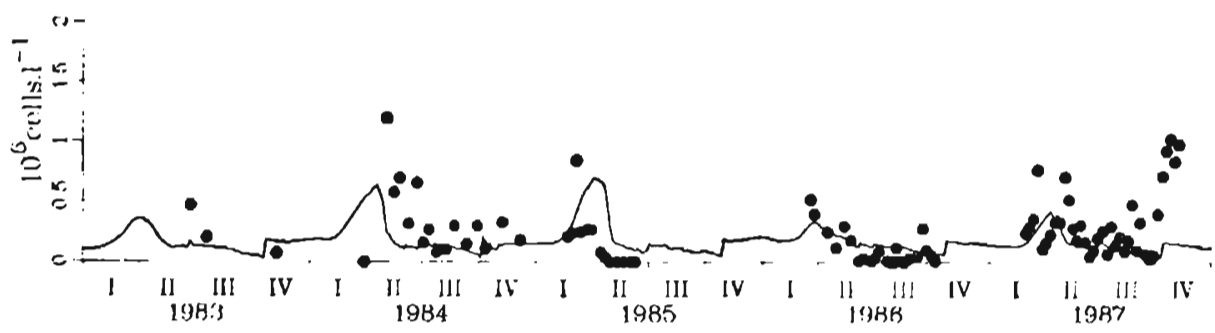

Fig. 16. - Evolution des algues non-siliceuses dans l'épilimnion et l'hypolimnion de 1983 à 1987 . Modèle MELODIA.

Fig. 16. - Evolution of non-siliceous algae in the epilimnion and hypolimnion, 1983-1987 - MELODIA.

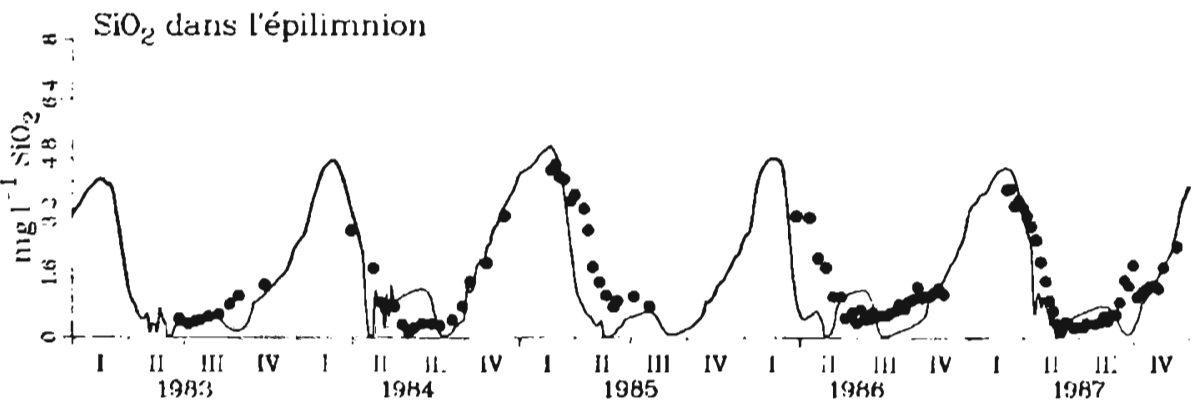

8: $\mathrm{PO}_{4}$ (lans l'épllimnion

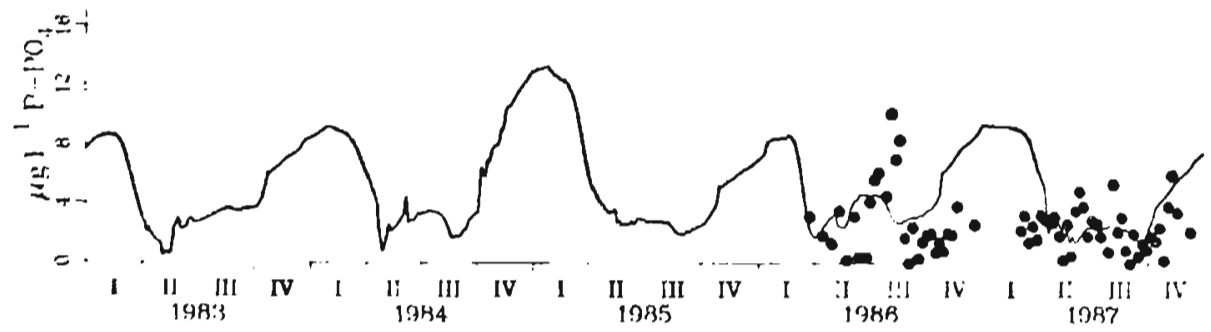

Fig. 17. - Evolution des silicates et des orthophosphates dans l'épilimnion de 1983 à 1987. Modèle MELODIA.

Fig. 17. - Evolution of silicates and orthophosphates in the epilimnion, 1983-1987 - MELODIA. 
et sorties d'eau, ce qui n'était pas le cas avec le modèle bicouche. Les figures 15 et 17 permettent de constater que la silice est globalement très bien simulée pendant le cycle annuel.

\section{IV.4.2 Les algues non-siliceuses et le phosphore}

Les deux points remarquables qui apparaissent dans les mesures des algues non-siliceuses sont leurs faibles concentrations et l'absence de cycles clairement marqués. La simulation représente globalement ce comportement. Ceci est probablement dû à une activité intense du broutage par le zooplancton herbivore lorsque la pro- duction est élevée au printemps et en été (figures 16 et 19). Cependant la variable "algues non-siliceuses" regroupant un grand nombre d'espèces, le modèle ne peut reproduire qu'un comportement moyen.

La quantité de phosphore disponible détermine la quantité de biomasse produite, (principalement sous forme de zooplancton dans ce système). A Pareloup, le phosphore $\mathrm{PO}_{4}$ bien qu'en très faibles concentrations, ne limite pas la vitesse de production des algues. Lavandier (1990) et Capblancq et al. (1994) ont montré que la production bactérienne est très forte l'été en raison des températures d'eau élevées et de la présence de substrat

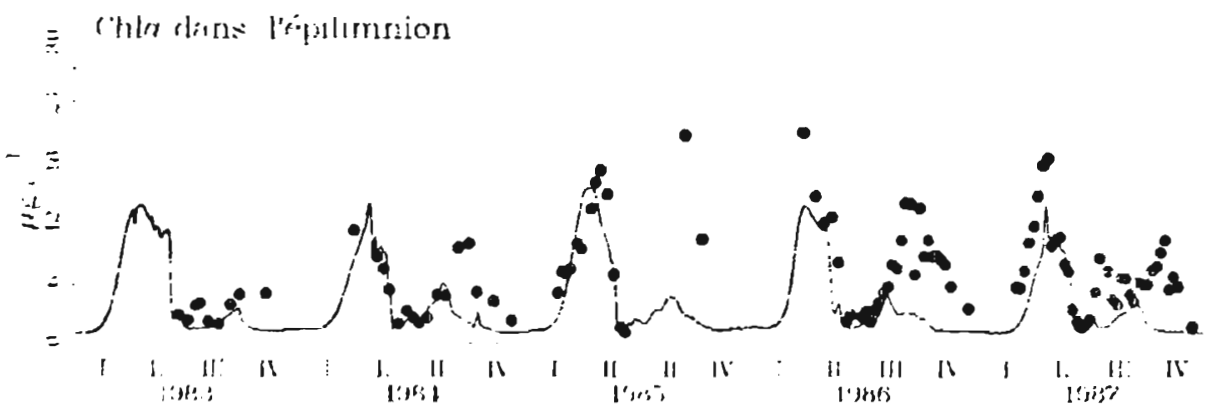

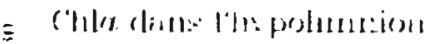

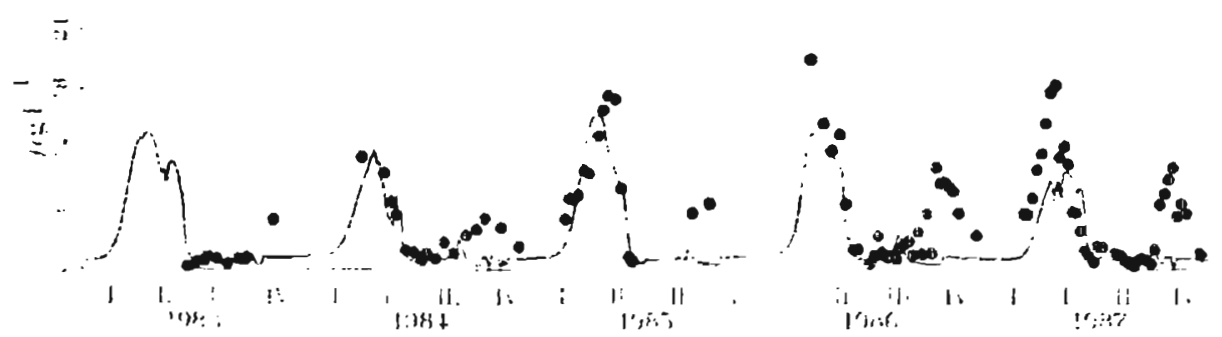

Fig. 18. - Evolution de la chlorophylle a dans l'épilimnion et l'hypolimnion de 1983 a 1987 . Modèle MELODIA.

Fig. 18. - Evolution of chlorophyll $a$ in the epilimnion and hypolimnion 1983-1987 - MELODIA. 

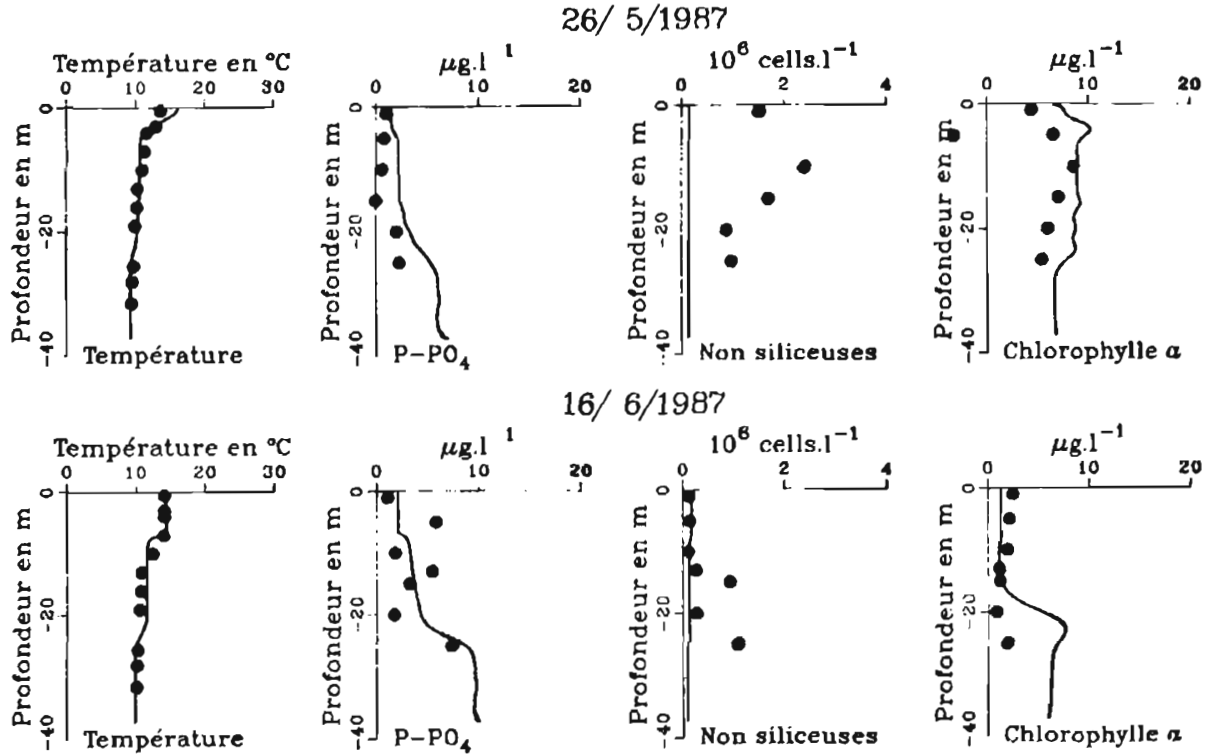

\section{$16 / 6 / 1987$}
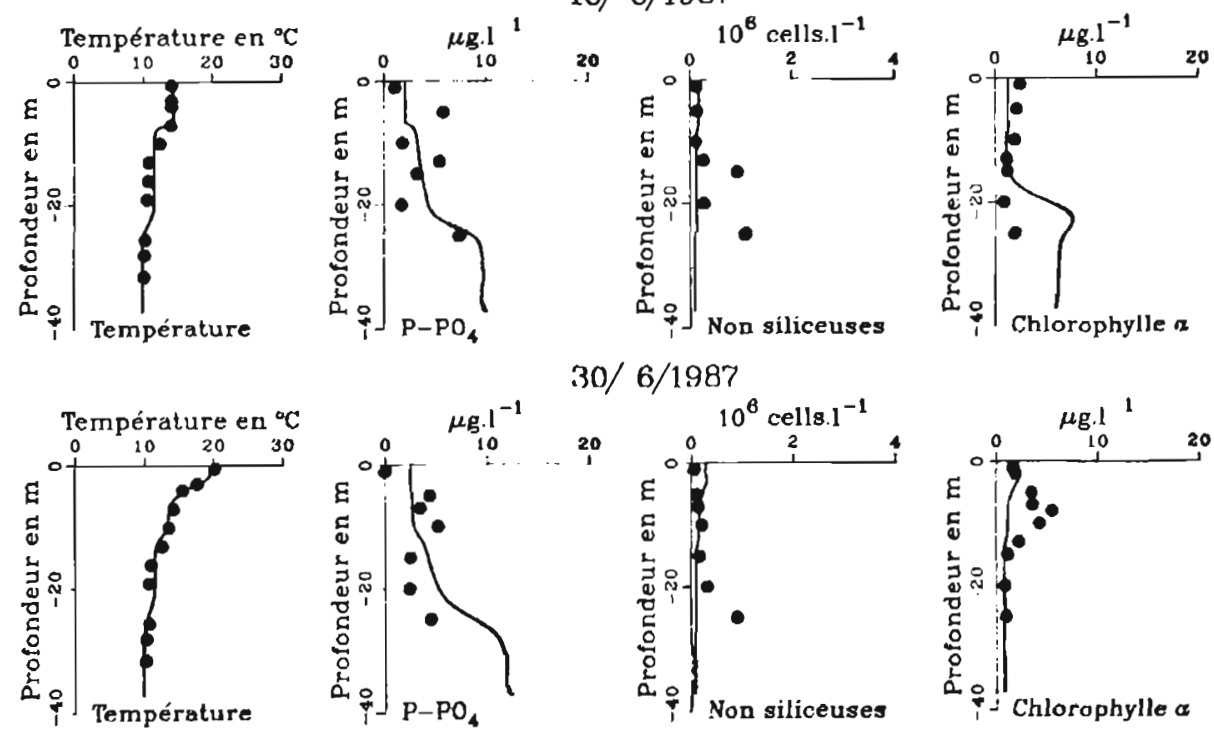

$30 / 6 / 1987$

20
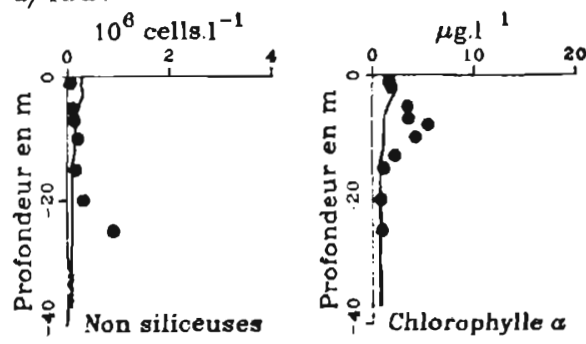

$15 / 7 / 1987$
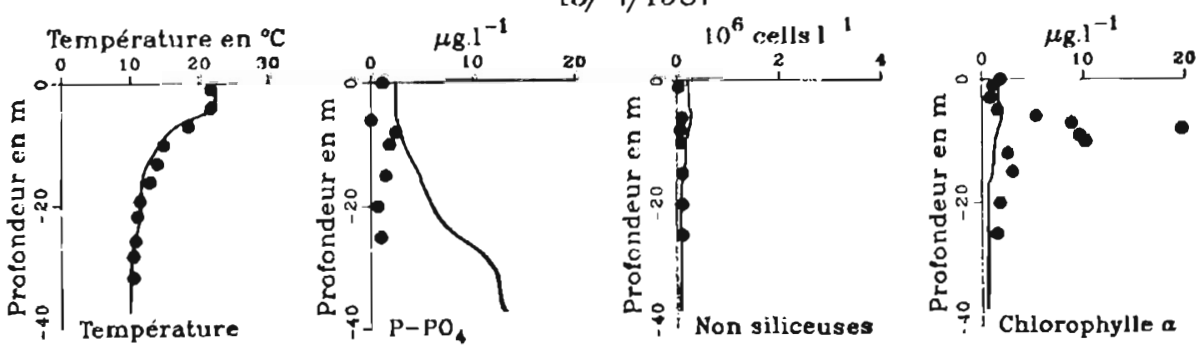

Fig. 19. - Evolution des profils calculés (trait continu) et mesurés $(\bullet$ ) des algues non-siliceuses, de la chlorophylle $a$, des orthophosphates et de la température durant l'été 1987. Modèle MELODIA. Fig. 19. - Evolution in calculated (continuous line) and measured ( $\bullet$ ) profiles for non-siliceous algae, chlorophyll $a$, orthophosphates and temperature in summer 1987 - MELODIA. 

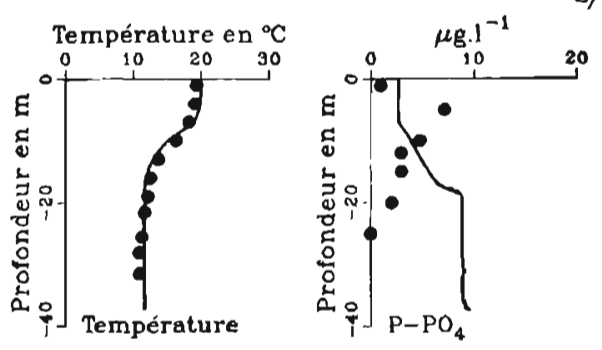

$5 / 8 / 1987$
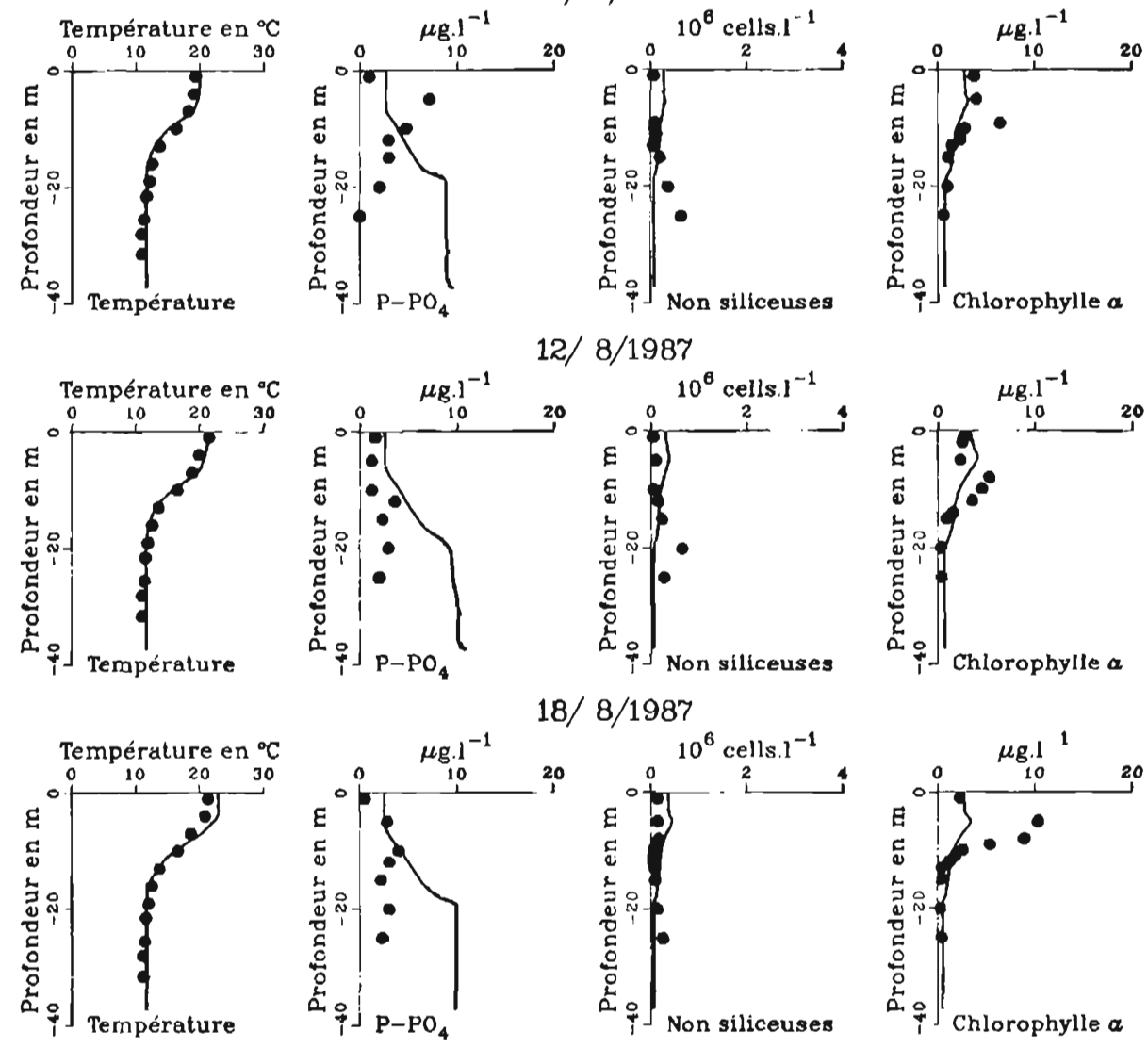

$18 / 8 / 1987$
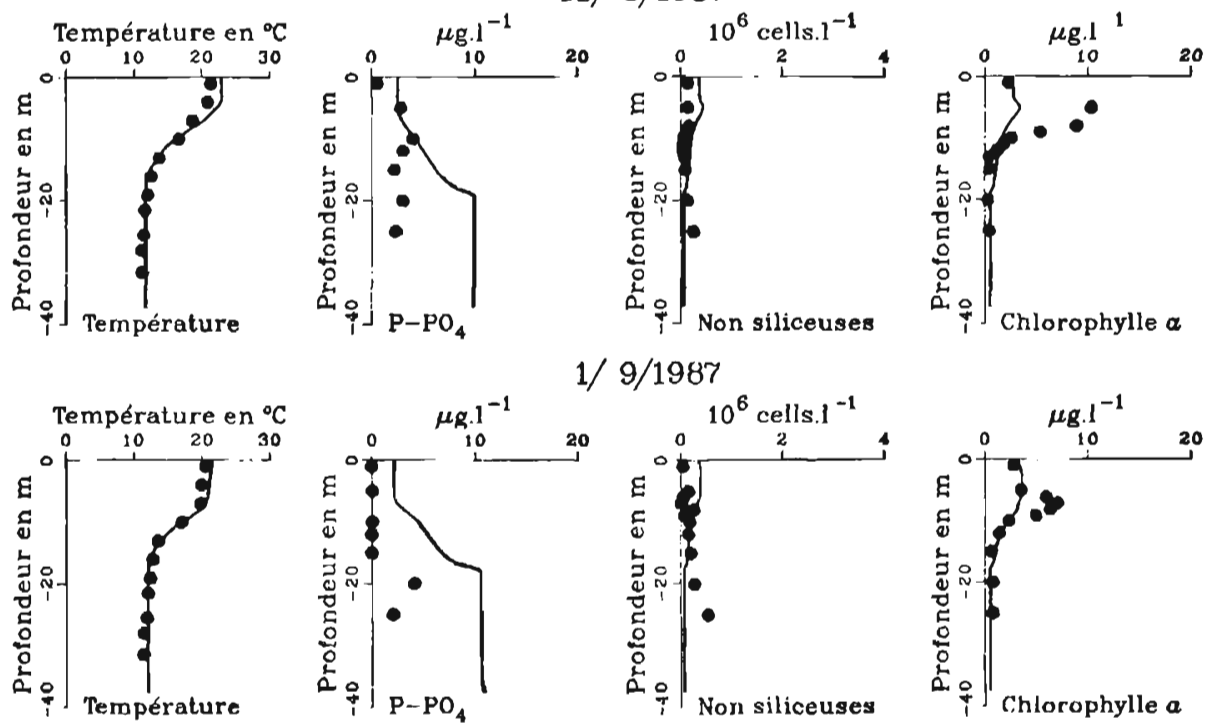

$1 / 9 / 1987$
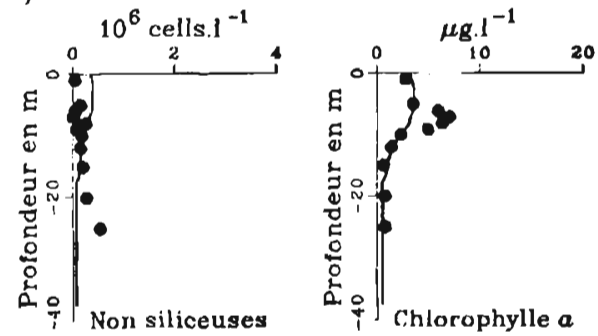

Fig. 19. - (suite)

Fig. 19. - (continued) 
organique. Cette activité bactérienne permet au phosphore d'être rapidement remis à la disposition des algues.

L'ordre de grandeur des quantités de phosphore calculé est correct. Comme nous l'avons déjà noté dans le modèle bicouche, nous ne simulons pas la dynamique complexe ni les différentes formes du phosphore. La variable " $\mathrm{PO}_{4}$ " calculée dans le modèle représente le phosphore potentiellement disponible, résultat d'un bilan entre les apports externes, les échanges avec le sédiment, la dégradation de la matière détritique, l'excrétion du plancton et l'assimilation par les algues. Cette variable n'est donc pas directement comparable au $\mathrm{PO}_{4}$ mesuré : elle subit d'importantes fluctuations, en particulier dans l'hypolimnion, qui n'apparaissent pas dans les mesures où $\mathrm{PO}_{4}$ est relativement constant (figures 17 et 19).

\section{IV.4.3 La chlorophylle a}

Les valeurs simulées de chlorophylle a ont été obtenues en sommant les deux variables phytoplanctoniques après transformation par un rapport chla: nombre de cellules spécifique à chacun des deux groupes. La comparaison avec les valeurs mesurées (figures 18 et 19) confirme la bonne représentation de la dynamique phytoplanctonique au printemps.

Par contre, en été (particulièrement mi-juillet et fin août) et en automne, les importants pics de chlorophylle a mesurés correspondent au développement d'une algue, Gonyostomum semen (Ehr.) Diesing, espece qui fuit les fortes intensités lumineuses et se concentre en été au niveau de la thermocline. Pendant la période d'isothermie automnale, sa proportion est de 40 à $60 \%$, avec une distribution verticale quasiment homogene (Le Cohu et al., 1989; 1991).

Les deux variables du modèle ne permettent pas de reproduire la stratègie adaptative de G. semen : les algues non-siliceuses, fortement consommées par le zooplancton, ne peuvent atteindre de telles concentrations. Par contre la variable diatomée, non consommée, a tendance a "prendre la place" de $G$. semen, en se développant dans la zone de la thermocline, où elle peut disposer à la fois de suffisamment de silice et de lumière. Cependant, sa croissance est très limitée par le faible stock de silice (en réalité, totalement inutile pour la croissance de $G$. semen) et elle ne peut qu'en suggérer la dynamique (fig. 20).

Pour reproduire ce comportement dans le modèle, il aurait été nécessaire d'ajouter une variable supplémentaire, ce qui n'a pas été réalisé car, lors de la construction du modèle, le rôle de $G$. semen n'avait pas encore été mis en évidence. C'est à partir de 1987 que les méthodes de fixation des algues dans les échantillons ont été modifiées. Cela a permis, grâce à une meilleure conservation des flagellés, de quantifier le développement parfois abondant de $G$. semen durant les différentes phases de la succession phytoplanctonique (Le Cohu et al., 1994). A l'avenir, nous envisageons d'intégrer cette algue comme nouvelle variable du modèle 
car elle se différencie, par son comportement, des deux groupes d'algues modélisés et que, par sa présence, elle participe activement à la compétition pour le phosphore.

La figure 21 présente les courbes isométriques des diatomées, des silicates et de la température simulés pendant l'année 1985.

\section{IV.4.4 Le zooplancton}

Pour présenter les résultats, nous avons regroupé les variables sous forme de zooplancton herbivore et carnivore.

La dynamique du zooplancton herbivore montre un retard systématique du démarrage de la population au printemps. Ce retard est expliqué par le choix des variables du modèle. En effet, dans le modèle, seules sont consommées par le zooplancton les algues non-siliceuses qui démarrent après les diatomées. Or, au début de la poussée des diatomées, la population est composée d'une proportion $d^{\prime} A$. ambigua qui peut atteindre, certaines années, des valeurs importantes (20\% en $1985,40 \%$ en 1986$)$. A. ambigua étant consommée par les copépodes tels que les cyclopides ou les diaptomides, on retrouve bien, sur les mesures, un démarrage précoce du zooplancton herbivore ces annéeslà, avec simultanément d'importantes biomasses. Ceci est particulièrement remarquable en 1985 où les mesures ont commencé dès le mois de janvier. En 1987, le pourcentage d'A. ambigua était plus faible $(10 \%)$ et les biomasses zooplanctoniques réduites. Le modèle ne peut pas reproduire ce démarrage printanier précoce, la seule diatomée modélisée étant $A$. formosa.

Globalement, la représentation des deux groupes zooplanctoniques est meilleure que dans le modèle bicouche, dans la limite de représentativité de ce type de modèle (fig. 22).

Les fluctuations annuelles des apports externes de phosphore dans l'écosystème sont transmises au travers de la chaîne trophique et se répercutent sur le maillon final simulé, le zooplancton carnivore, qui présente de fortes variations interannuelles.

\section{IV.4.5 Discussion}

L'extinction de la lumière en hiver a été prise en compte avec une fonction de forçage ajustée sur les quelques mesures disponibles. Cette fonction a bien amélioré la représentation du démarrage des diatomées, mais comme

Fig. 20. (page 404) - Tentative de développement de la variable "diatomée " en été au niveau de la thermocline à la place de l'algue $G$. semen. Les faibles concentrations en silice limitent rapidement son développement. Modèle MELODIA.

Fig. 20. - Attempted development of the "diatom" variable in summer at the thermocline, to take the place of $G$. semen. The low silica concentrations rapidly limit its development - MELODIA.

Fig. 21. (page 405) - Courbes isométriques de la température, des diatomées et des silicates simulés en 1985. Modèle MELODIA.

Fig. 21. - Isometric curves for simulated temperature, diatoms and silicates in 1985 - MELODIA. 

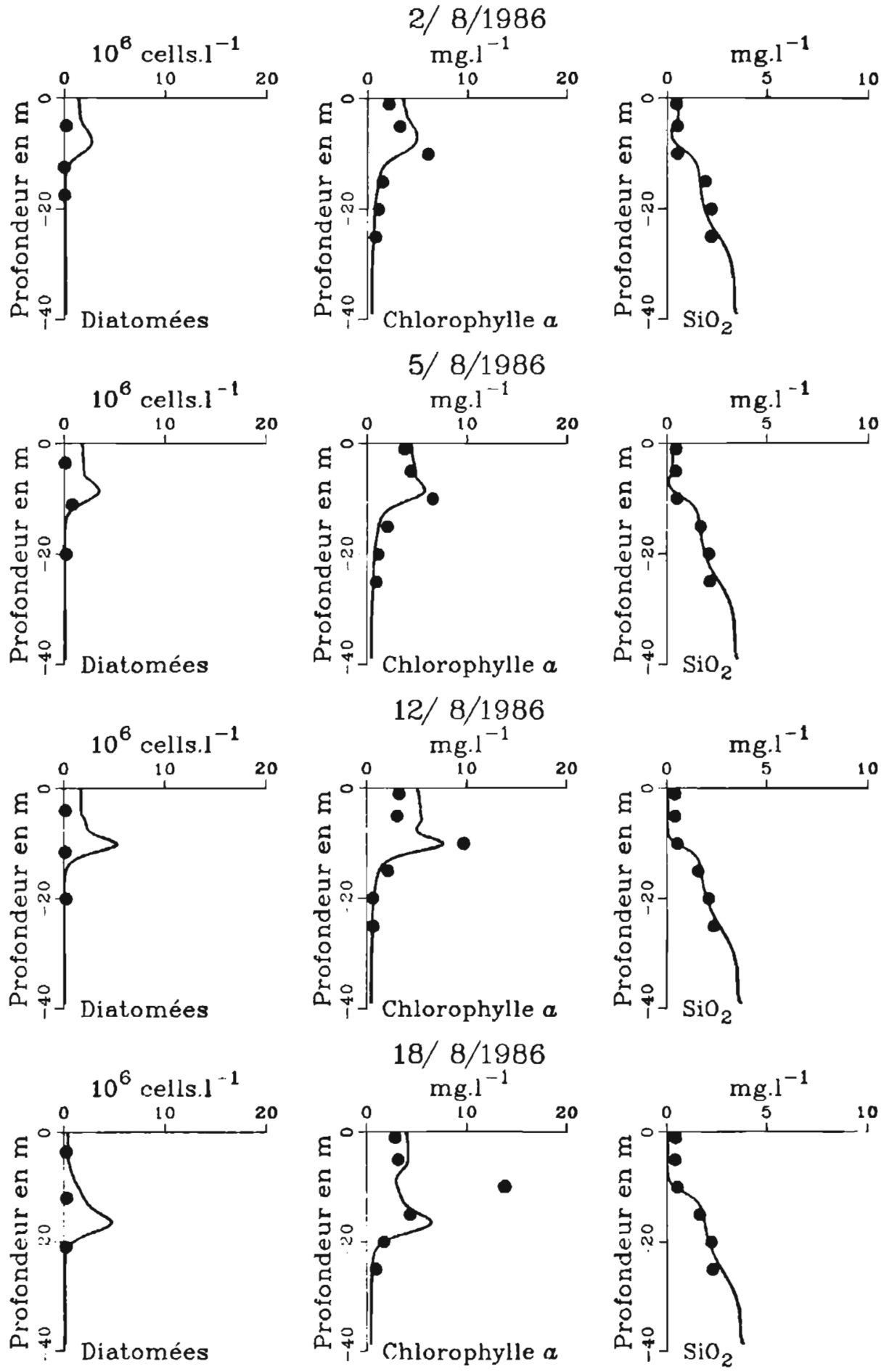


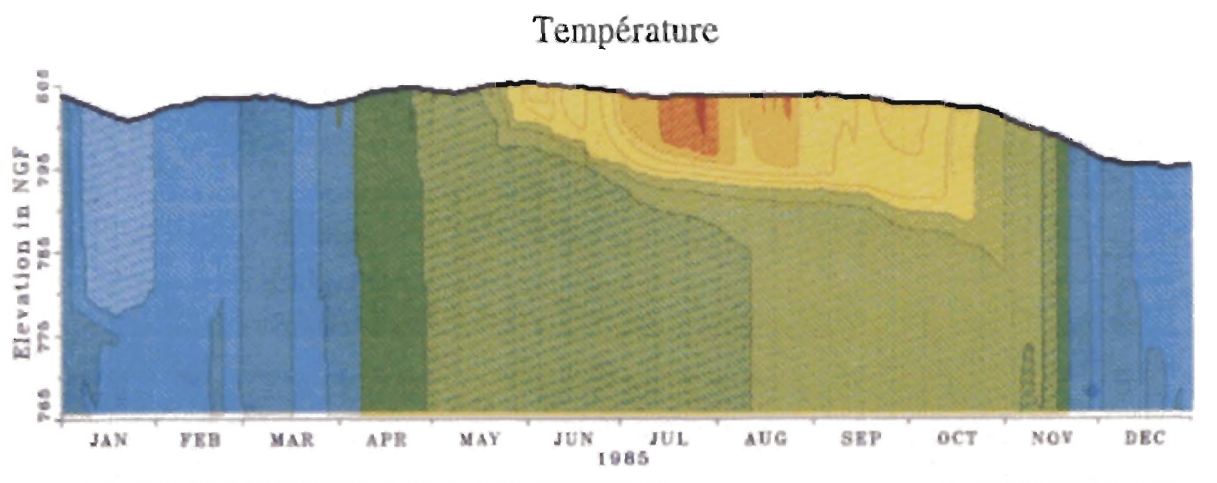

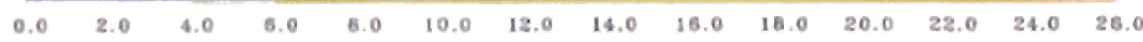
Température en ${ }^{\circ} \mathrm{C}$
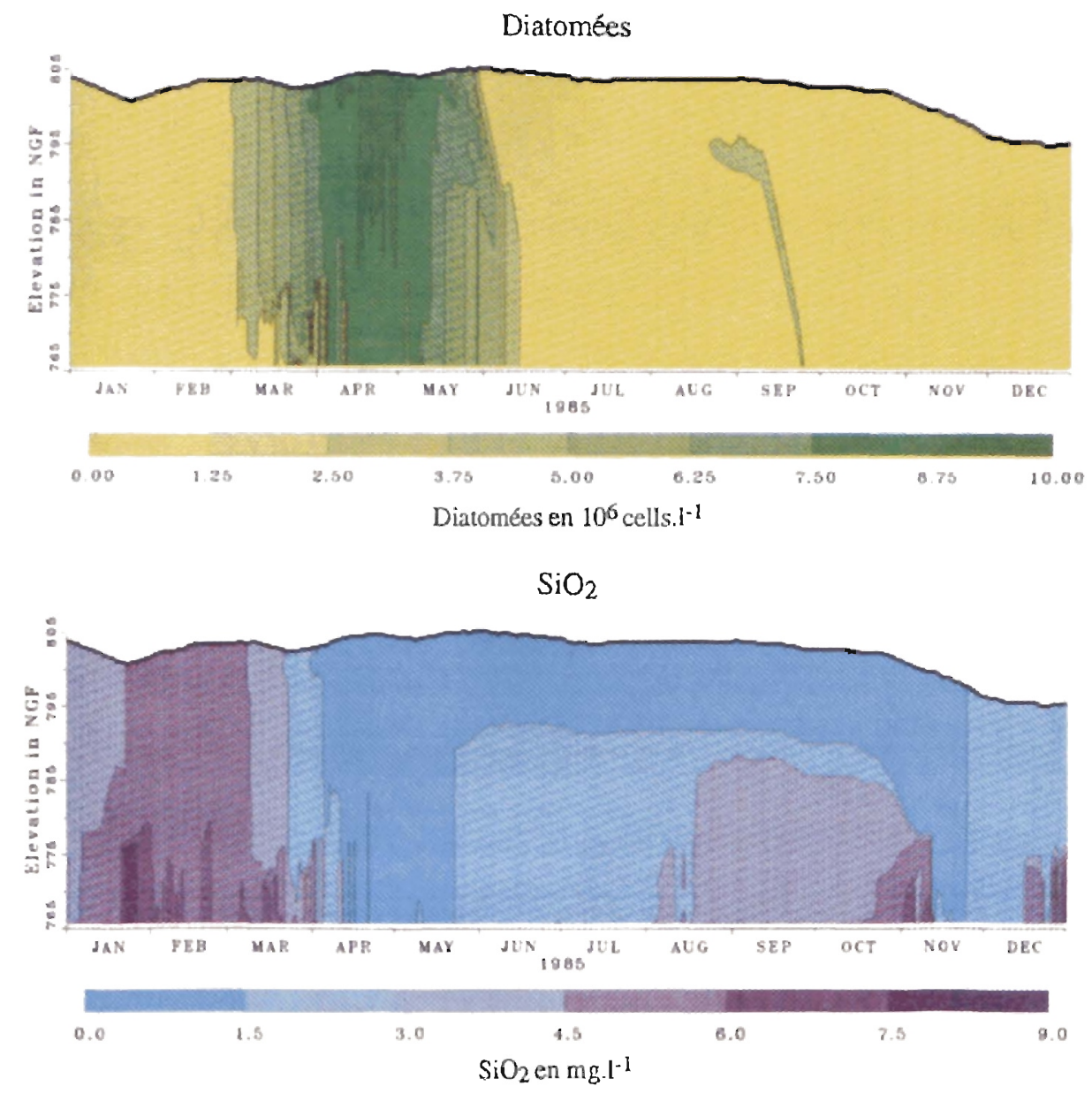


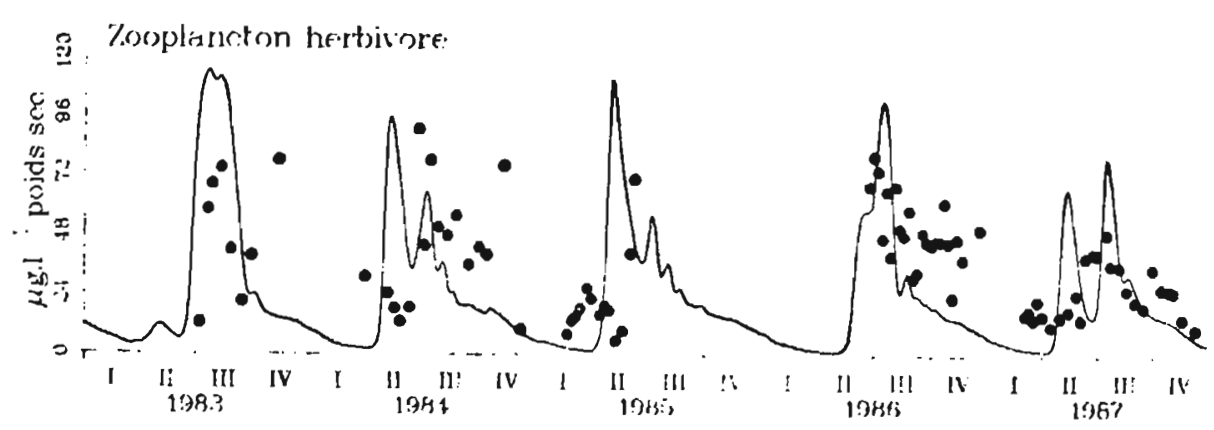

อ. Copépodes cisruivores

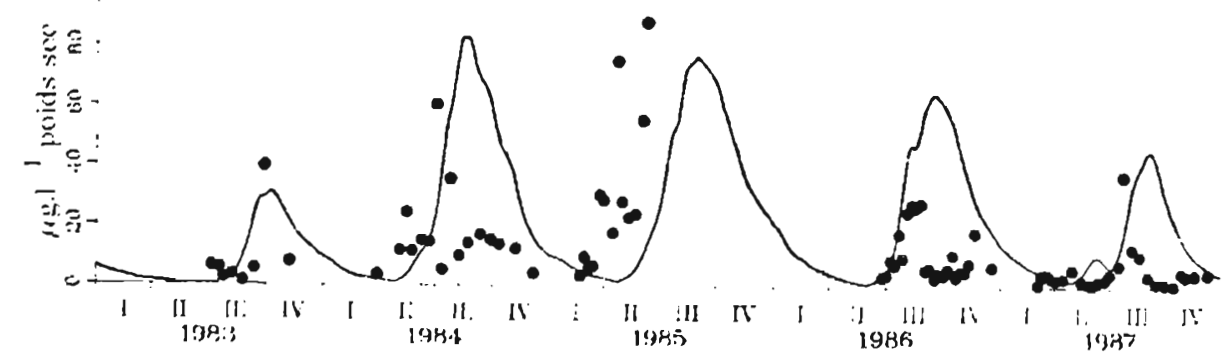

Fig. 22. - Evolution du zooplancton herbivore et carnivore de 1983 à 1987. Modele MELODIA.

Fig. 22. - Evolution of herbivorous and carnivorous zooplankton, 1983-1987 - MELODIA.

nous l'avions fait précédemment, nous insistons sur la nécessité de disposer en hiver de mesures de matériaux non-chlorophylliens et de coefficient d'extinction.

Pendant les cinq années d'étude de l'écosystème de Pareloup, on a pu observer que la dynamique printanière des diatomées était déterminée par deux points forts :

- la croissance des diatomées démarre lorsque diminue la turbidité de l'eau,

- c'est toujours la silice qui limite la croissance des diatomées avant le phosphore.
La quantité de silice disponible pour la croissance des diatomées dans les couches de surface est directement liée à la structure hydrodynamique verticale du lac pendant le printemps. Le stock total d'éléments nutritifs est reconstitué dans la masse d'eau en hiver, lors du mélange complet des eaux. Dès le début du printemps, les alternances de réchauffement de surface et de coups de vents créent des thermoclines transitoires, qui sont des micro-stratifications à l'échelle journalière. La dynamique phytoplanctonique a lieu essentiellement dans les couches de surface créées par ces stratifications journalières, avec en particulier un 
épuisement rapide des éléments nutritifs. Les fluctuations importantes (essentiellement nycthémérales) de cette thermocline transitoire permettent d'apporter en surface, par mélange, les éléments nutritifs nécessaires au phytoplancton. Si ce mélange vertical n'a pas lieu, la silice des couches de surface s'épuise rapidement, entraînant une carence nutritive des diatomées et précipitant la chute des algues par sédimentation.

De telles situations peuvent se présenter lorsque le printemps comporte des périodes chaudes et non ventées relativement longues: la thermocline transitoire se stabilise alors, diminuant considérablement les échanges verticaux. Ces effets peuvent être accrus par la gestion hydraulique: un arrêt momentané du pompage contribue fortement à la stabilisation de la thermocline transitoire, alors que l'augmentation des débits turbinés (pendant une période froide ou humide, par exemple) favorise le mélange vertical. Nous retrouvons ces deux situations caractéristiques en 1984 et 1986. En 1984, le printemps connaît, en avril, une période chaude qui coîncide avec un arrêt prolongé du pompage. La concomitance de ces deux événements favorise la permanence d'une thermocline transitoire relativement profonde (située vers $-11 \mathrm{~m}$ ) pendant une période suffisamment longue (1 mois environ) pour écourter la floraison des diatomées. Par contre, en 1986, le mois d'avril est très froid et très pluvieux; la stratification démarre seulement en mai et les diatomées sont plus abondantes.
Le printemps apparaît donc comme le moment le plus délicat du fonctionnement de l'écosystème. C'est la période transitoire d'établissement de la stratification thermique, et toute erreur commise pendant cette période induira une structure hydrodynamique irrémédiablement installée pour l'année.

Finalement, dans cet écosystème, de la dynamique des diatomées qui poussent au printemps (de février à juin) dépend le stock de nutriments qui restera disponible l'été dans l'épilimnion pour les autres algues. $\mathrm{Ce}$ phénomène est particulier à l'espèce dominante au printemps $A$. formosa, qui, n'étant pas consommée par le zooplancton, disparait par sédimentation, ce qui immobilise dans le sédiment les nutriments qu'elle a consommés. Ceux-ci seront remis à disposition ultérieurement par relargage, après décomposition de la matière organique. Cependant, ces processus sont plus lents que ceux du cycle de prédation phyto-zooplancton, et en pratique, les nutriments ne seront pas disponibles avant l'hiver. En fait, les diatomées de Pareloup se comportent comme des "épuratrices" du phosphore et de la silice dans l'épilimnion. Leur rôle dans la régulation de l'écosystème est donc capital.

Par conséquent, il est primordial que le modèle représente très précisément toute la période printanière, en particulier la structure hydrodynamique verticale de la masse d'eau, la croissance et la sédimentation des diatomées liée à la carence nutritive en silice. 


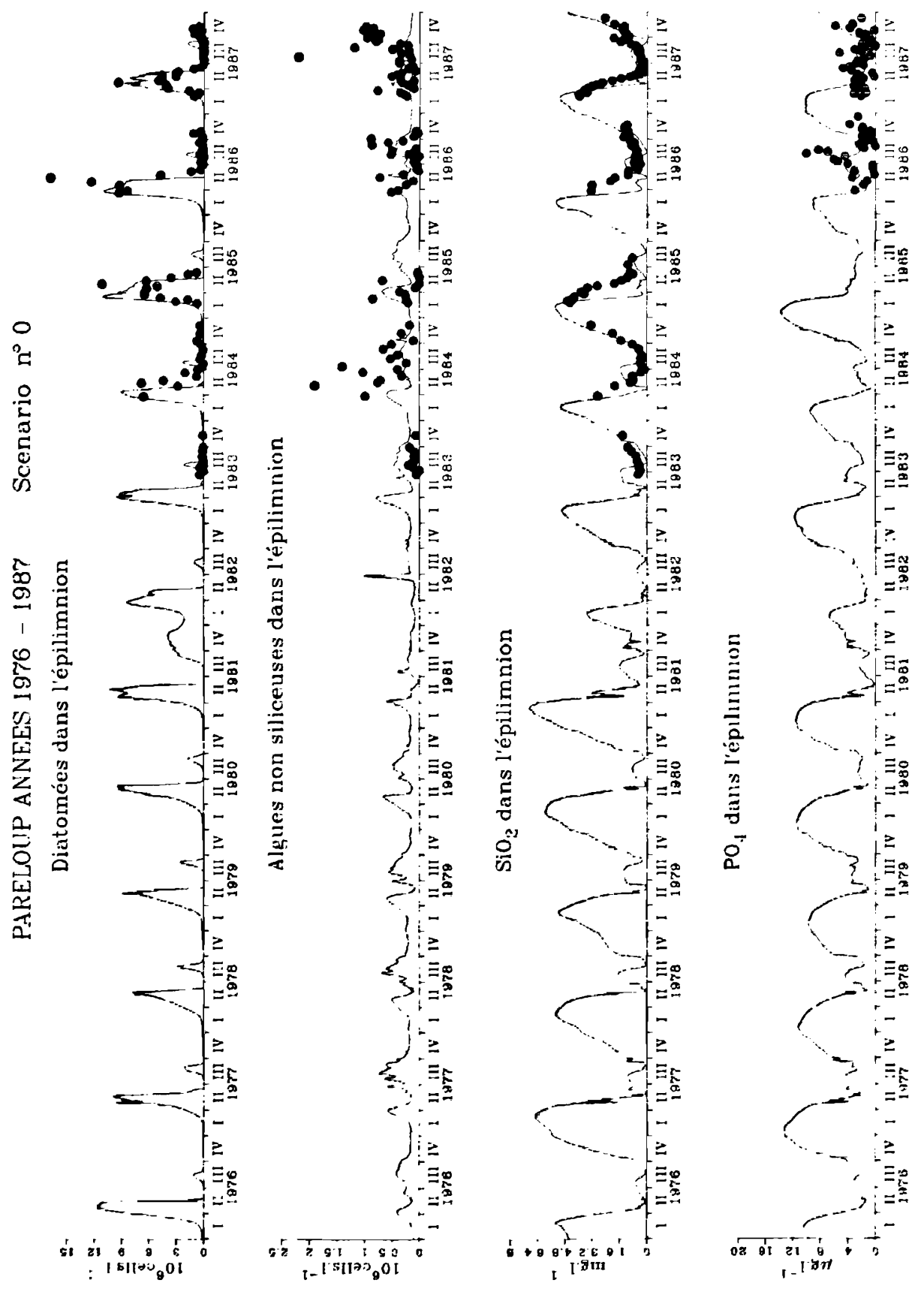



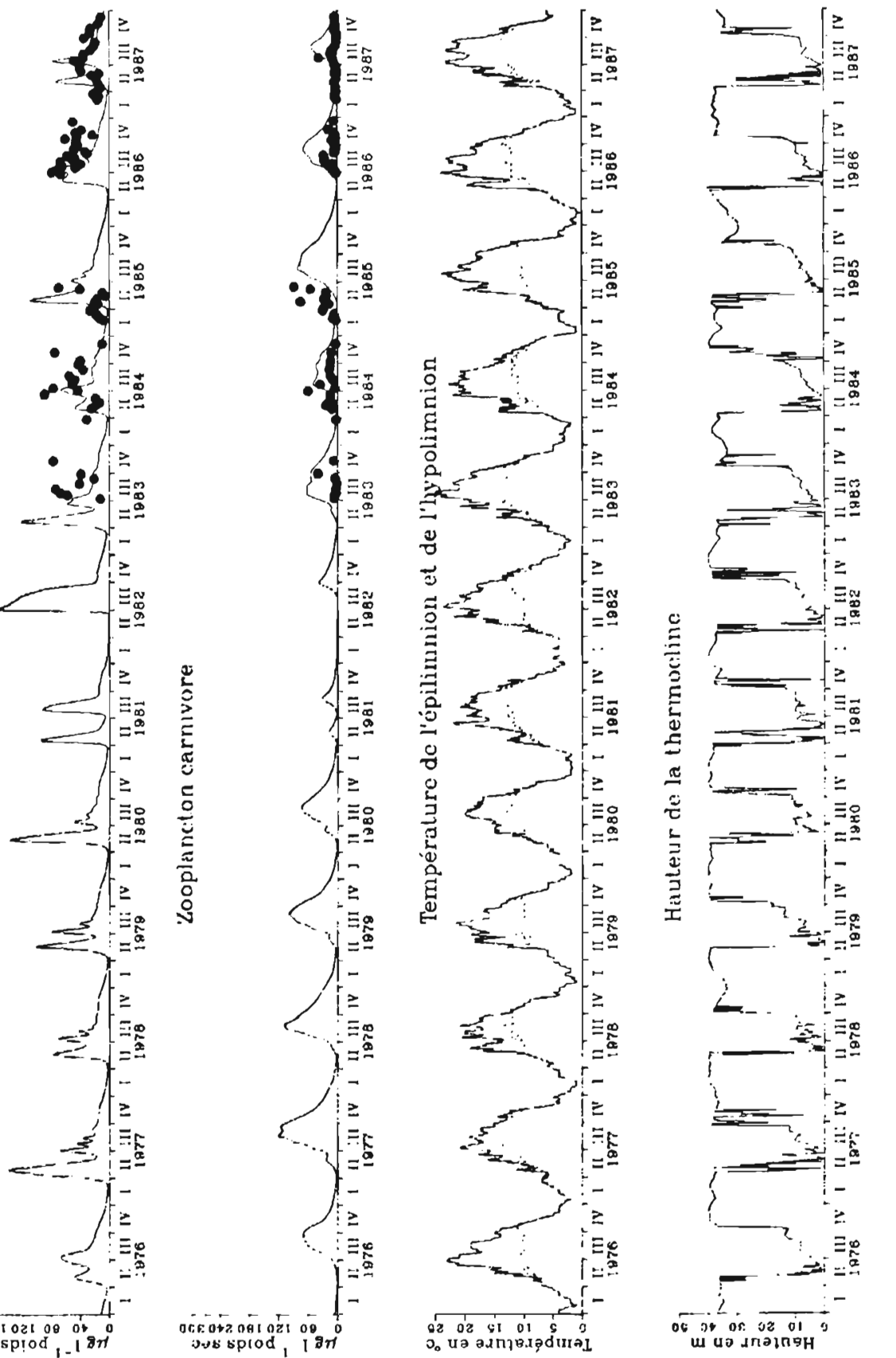

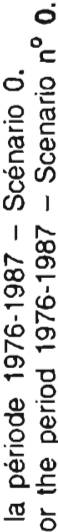
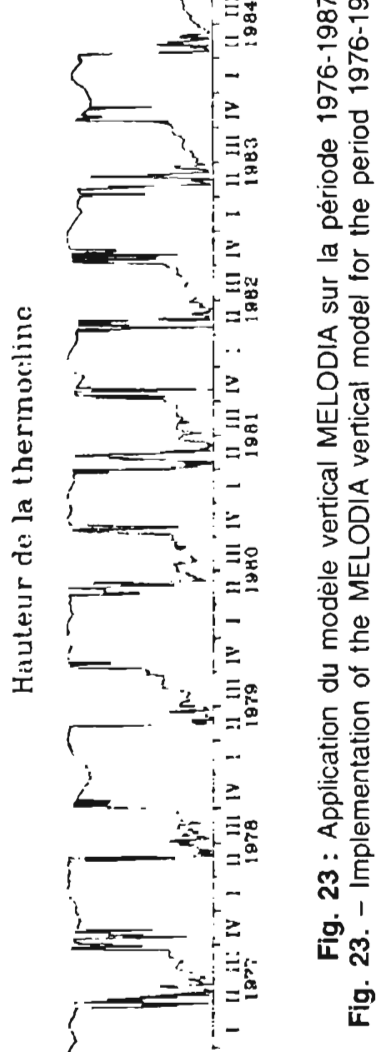

๘ $\bar{a}$

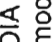

$\mathrm{O} \overline{\mathrm{T}}$

$\sum \stackrel{\square}{Q}$

尊造

Ф

送

흥

등 든

응 믐

을

로

ํํำ

문

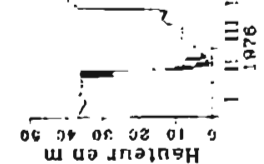


Enfin, il apparaît que les mécanismes biologiques modélisés, ainsi que le jeu des paramètres biologiques donnant le meilleur ajustement dépendent étroitement de la structure physique choisie. II est donc capital de ne jamais dissocier un jeu de paramètres de modélisation des hypothèses choisies pour réaliser le modèle.

\section{SIMULATION DE SCÉNARIOS}

L'exploitation du modèle comme outil d'aide à la gestion a été faite à partir de huit scénarios modifiant aussi bien la gestion hydraulique que les apports du bassin versant. Nous avons choisi d'en présenter quatre qui mettent bien en évidence les caractéristiques de l'écosystème de Pareloup.

Scénario 0 : Simulation de référence dans les conditions réelles de la période 1976-1987.

Scénario 1 : Arrêt complet des installations : le niveau du plan d'eau est constant, le débit réservé étant égal aux apports naturels du bassin versant.

Scénario 2 : Les concentrations en phosphates de l'eau pompée à Bage sont doublées.

Scénario 3 : La gestion hydraulique actuelle est remplacée par une gestion plus efficace qui permet de mieux utiliser le stockage saisonnier de l'eau pour la production hydroélectrique (gestion du type "pompe d'Alrance").
L'exploitation de ces différents scénarios a été réalisée pour la période 1976-1987, pour laquelle une étude climatologique et hydrologique a été présentée par Salençon (1994b). Afin de faciliter la comparaison des résultats, les courbes sont présentées avec les mêmes échelles que celles définies pour le scénario 0 de référence, malgré quelques dépassements occasionnels.

\section{V.1 Scénario 0 : Simulation de ré- férence dans les conditions réelles de la période 1976-1987}

Pour la période 1976-1987, les conditions hydrauliques et météorologiques sont connues et les résultats du modèle thermique sont très satisfaisants (Salençon, 1994b). En revanche, nous ne disposons d'aucunes données concernant les apports, aussi ceux-ci ont-ils été estimés à partir des concentrations mesurées pendant la période 1983-1987.

II est intéressant de constater que les résultats obtenus en 1983-1987 avec un démarrage en 1976 sont pratiquement similaires à ceux obtenus avec un démarrage en 1983. Le modèle n'introduit donc pas de biais de mémoire (fig. 23).

Les résultats de la simulation montrent une grande reproductibilite du cycle annuel de l'écosysteme d'une année à l'autre. Les diatomées printanières disparaissent après le début de la stratification, lorsque le stock de silice est épuisé dans les couches de surface. Les algues non-siliceuses, fortement consommées par le zoo- 
plancton herbivore, ne peuvent atteindre de fortes concentrations en été, bien que leur production soit forte. C'est le zooplancton carnivore, dernier maillon de la chaîne trophique, qui bénéficie de cette production. Par contre les diatomées, non consommées, ont tendance a "prendre la place " d'un autre groupe d'algues estivales non simulées ( $G$. semen ou cyanophycées) dans la mesure où elles disposent de suffisamment de silice. Cette situation apparaît régulièrement dans la simulation sous la forme d'une petite poussée de diatomées au mois d'août. Seule l'année 1981 connaît une perturbation signalée par un fonctionnement particulier de l'écosystème en été, dont les conséquences se répercutent jusqu'à l'année suivante.

L'année 1981 a été marquée par un hiver froid et un printemps très pluvieux entraînant un pompage régulier, ce qui a empêché une thermocline bien marquée de s'établir. Les diatomées, bien mélangées dans toute la masse d'eau, ont bien utilisé tout le stock hivernal de nutriments apporté par le pompage, et ont formé un pic printanier d'autant plus important que le court refroidissement du mois de mai a remélangé le lac, apportant silice et phosphore dans la couche euphotique en quantités suffisantes pour maintenir la forte biomasse des diatomées. Cependant, le flux de nutriments nécessaire au maintien d'une population importante est considérable. Dès le début de l'installation de la thermocline, qui a eu lieu en juin, le stock de nutriments de l'épilimnion, non régénéré par le pompage, n'a pas été suffisant pour soutenir la poussée algale. Le phosphore étant devenu limitant avant la silice, les diatomées printanières ont disparu ainsi que les algues non-siliceuses. Le zooplancton herbivore présente également une forte décroissance à cette période et le zooplancton carnivore ne parvient pas à se développer. Dans ces conditions particulières et exceptionnelles, le stock printanier de silice n'était pas complètement épuisé au moment du déclin des diatomées. II a suffi que les concentrations en phosphore augmentent pour que, dans la simulation, les algues redémarrent. Cette situation s'est présentée à la faveur du fort refroidissement de juillet qui a provoqué un approfondissement inhabituel de la thermocline. Lors de ces épisodes de mélange tardifs, les fluctuations de la couche de mélange ont régénéré dans l'épilimnion un stock de nutriments suffisant pour permettre le démarrage d'une poussée des deux groupes d'algues. Les diatomées ont poussé abondamment. La quantité de silice, inhabituellement importante à cette période dans l'épilimnion, a permis à cette deuxième poussée de ne pas être limitée avant que le mélange automnal ne régénère le stock de nutriments de la colonne d'eau. Ainsi, cette deuxième poussée a pu se maintenir jusqu'au printemps de l'année suivante. Les algues non-siliceuses ont été rapidement consommées par le zooplancton herbivore qui, cette année-là, présente deux pics consécutifs simulaires. La fin du premier pic correspond, non pas au développement du zooplancton carnivore, comme les 

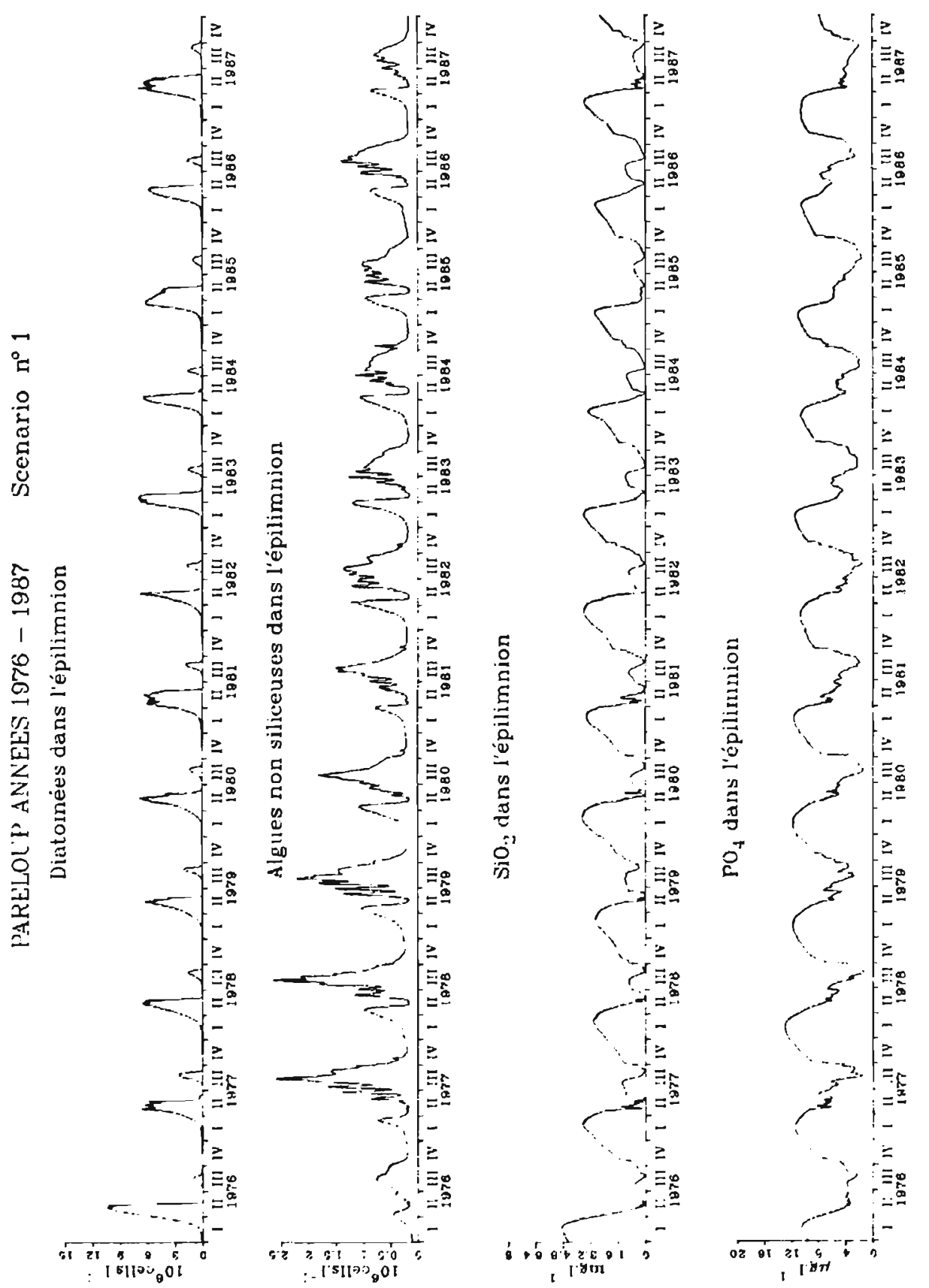
autres années, mais à une forte diminution de la production primaire consommable limitée par le phosphore. Aussi, cette année-là, le zooplancton carnivore n'a pas pu se développer, en été, en quantité suffisante.

Nous disposons, pour 1981, de quelques données planctoniques réalisées dans le cadre de l'étude d'impact de la pompe d'Alrance (Electricité de France, 1985). Ces observations ne signalent pas la présence de diatomées en été. Par contre, elles révèlent la présence abondante de cyanophycées, le lac de Pareloup ayant été jugé eutrophe cette annéelà. Cette tendance à l'eutrophisation a gardé un caractère exceptionnel car une telle situation n'a jamais été observée depuis 1981.

En 1982, les diatomées, qui se sont maintenues tout l'hiver, ont empêché les algues non-siliceuses de pousser. Celles-ci ont démarré en juin, dès le déclin des diatomées. Le zooplancton herbivore n'a donc démarré qu'à partir de juillet, retardant le développement du zooplancton carnivore et limitant son abondance.

Si le maintien des diatomées en hiver fait partie des situations envisageables (comme l'ont montré les observations de 1991 et 1992), il est vrai qu'un démarrage des diatomées en été est peu probable en raison d'une compétition algale qui favoriserait, à cette période, des espèces plus adaptées comme les cyanophycées ou $G$. semen. Dans l'état de développement actuel du modèle, il n'est pas possible de simuler cette situation : on note bien que la "variable diatomée" n'est pas appropriée pour décrire la poussée algale estivale. Si le modèle comportait une "variable cyanophycées" adaptée aux conditions estivales, son développement empêcherait peut-être la poussée des diatomées l'été.

Dans de telles situations, nous atteignons les limites d'application du modèle qui représente mal, dans ces conditions extrêmes, un écosystème en mutation. Nous recommandons alors la prudence dans l'interprétation des résultats. II est cependant possible de dire que le comportement du modèle lors de conditions hydrométéorologiques particulières permet de signaler les périodes où le système est très fortement perturbé, ce qui pourrait aboutir, dans certains cas, à un risque d'eutrophisation.

\section{V.2 Scénario 1 : arrêt complet du pompage et du turbinage}

Cette simulation (fig. 24) permet de supprimer l'effet des entrées et sorties d'eau dues à la gestion hydraulique, aussi bien sur les apports de nutriments que sur la stratification. Le niveau du plan d'eau est maintenu constant tout au long de l'année, le débit réservé étant égal aux apports naturels du bassin versant. Etant donné le très faible renouvellement de l'eau (temps de séjour de 590 jours environ), la retenue se comporte alors comme un lac naturel, essentiellement influencé par les conditions météorologiques. 
La masse d'eau se stratifie dès fin avril et une thermocline très marquée s'installe de fin mai à fin septembre. La quantité de silice disponible pour les diatomées est moindre dans ce scénario, car ce sont surtout les eaux de Bage qui contribuent à enrichir en silice le lac de Pareloup. Aussi les diatomées sont-elles moins abondantes que dans le scénario de référence.

Généralement, le déclin des diatomées provoqué par une carence en silice est accentué par l'installation de la stratification. Cependant, si un refroidissement important et prolongé survient lorsque la thermocline est déjà établie, le mélange vertical qui en résulte apporte dans les couches de surface des nutriments de l'hypolimnion qui retardent la disparition des diatomées. Cette situation est observée en 1977, 1981 et 1987.

Les diatomées étant moins abondantes, le stock de phosphore disponible pour les algues non-siliceuses est plus important. Aussi, leurs pics printaniers sont-ils plus élevés. Dès la disparition des diatomées, elles ne sont plus en compétition pour le phosphore et on assiste à une explosion de la population, qui se répercute sur le zooplancton, lui-même très abondant.

\section{V.3 Scénario 2 : les concentrations en $\mathrm{PO}_{4}$ de l'eau pompée à Bage sont doublées}

Dans ce scénario (fig. 25), les concentrations en $\mathrm{PO}_{4}$ sont doublées dans les eaux de Bage. Le réservoir de Bage, en vase communicant avec celui de Pont-de-Salars, apporte les eaux du bassin versant du Viaur, de plus en plus chargées en nutriments et matière organique (Sivadier et al., 1994). Ce scénario est destiné à apprécier l'effet d'une pollution accrue dans ce bassin versant, qui contribue à fournir $55 \%$ de l'eau de Pareloup par le pompage de Bage.

Dans ce scénario, le phosphore est toujours surabondant dans l'eau.

Pour les diatomées, les résultats sont peu modifiés car elles étaient déjà limitées par la silice dans le scénario 0 . On note cependant que leur vitesse de croissance est plus rapide au démarrage. Grâce à l'apport supplémentaire de phosphore, les conditions de croissance des diatomées dans le lac se rapprochent des conditions optimales. Le maximum de biomasse atteint est légèrement plus élevé car la quantité de phosphore disponible est plus importante alors que la silice est encore abondante. Même si le stock printanier de silice est mieux utilisé, le déclin de la population est anticipé. La perturbation qui était simulée en 1981 dans le scénario 0 n'apparaît plus car le phosphore n'est plus limitant pour les diatomées dans ce scénario.

Ce sont finalement les algues nonsiliceuses qui profitent surtout de l'apport supplémentaire de $\mathrm{PO}_{4}$, avec des pics beaucoup plus élevés. Le zooplancton carnivore, dernier maillon de la chaîne trophique, est particulièrement développé. Pour les algues nonsiliceuses et le zooplancton, cette situation est similaire à celle du scénario 1 , car elle correspond à une disponibilité de phosphore accrue. 


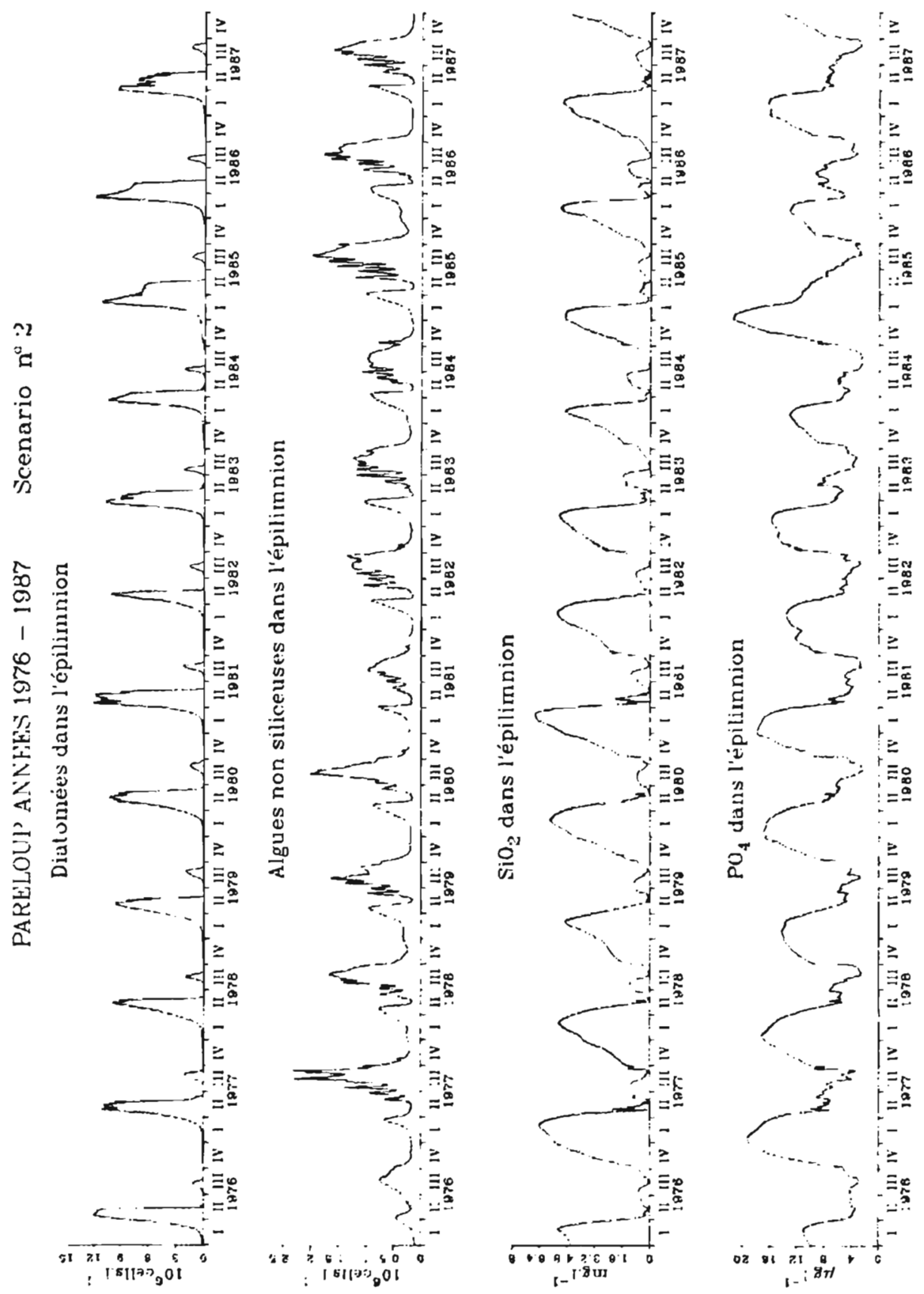



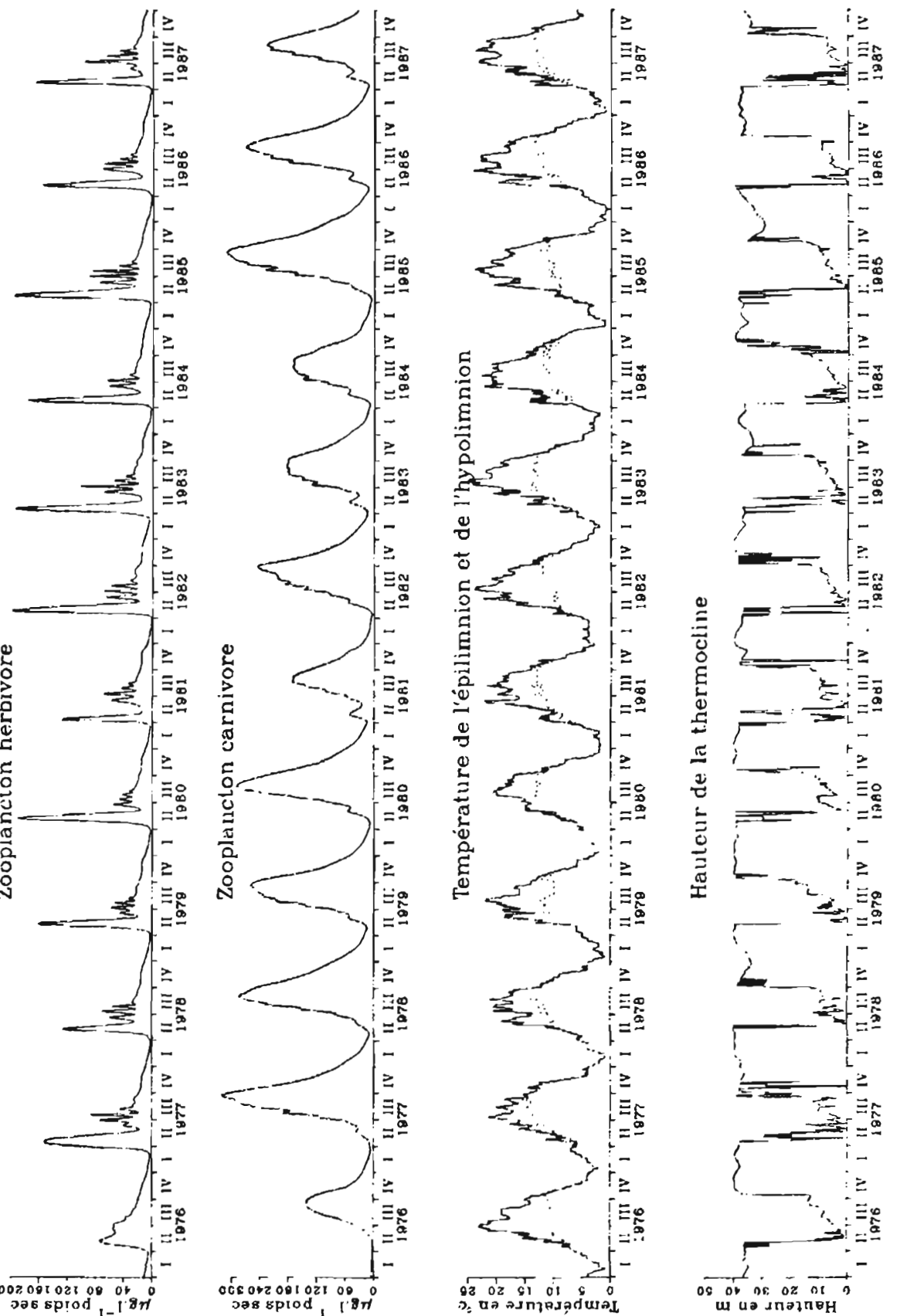

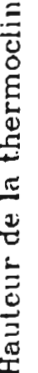

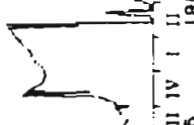

은

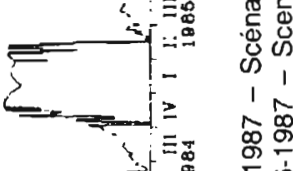

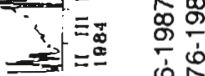
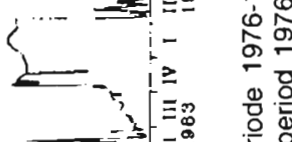

$==$

$-1 \geq \quad$ 正

$=\Longleftarrow \begin{array}{ll}2 & = \\ = & 0\end{array}$

든

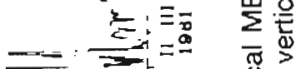

[-

- $\div \geq \geq$

$\therefore . \equiv$

$\Xi \equiv$

L - ‥ 궁

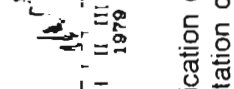
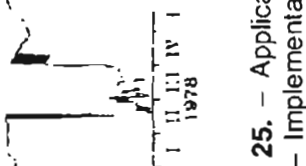

[- 유

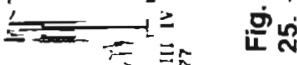

ว26 spiod $1.9 n$

sas rpiod, [II

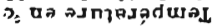

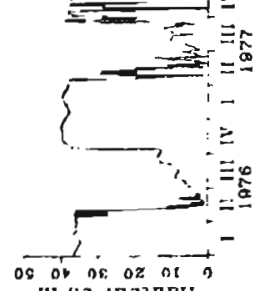

몬 
Cependant, dans le scénario 2, la production globale de biomasse est beaucoup plus forte que dans le scénario 1 , ce qui conduit à un niveau trophique plus élevé.

Si l'on devait tester des scénarios d'apports de phosphore plus importants que ceux du scénario 2, il faudrait envisager l'éventualité que cette augmentation excessive du phosphore fasse apparaître une limitation par l'azote qui favoriserait le développement des cyanophycées. Le modèle MELODIA, dont l'objectif n'est pas d'étudier l'eutrophisation, ne prend en compte ni l'azote, qui n'est pas limitant actuellement à Pareloup, ni les cyanophycées. II ne pourrait donc pas simuler correctement les conséquences de ces hypothèses d'apports.

\section{V.4 Scénario 3 : gestion hydrauli- que du type "pompe d'Alrance"}

La gestion hydraulique du scénario 3 (du type "pompe d'Alrance") a pour objectif d'utiliser de façon plus efficace le stockage saisonnier de l'eau dans le réservoir pour la production hydroélectrique. La période de turbinage d'hiver s'étend du mois d'octobre au mois de mars. A partir du mois d'avril, débute la période de remplissage qui se poursuit jusqu'en septembre. Pendant les mois d'été, la retenue est maintenue à un niveau maximum faiblement variable pour satisfaire à l'activité touristique.

C'est une gestion de ce type qui a été envisagée lors du projet d'équipement de la pompe d'Alrance (Electricité de France, 1985).

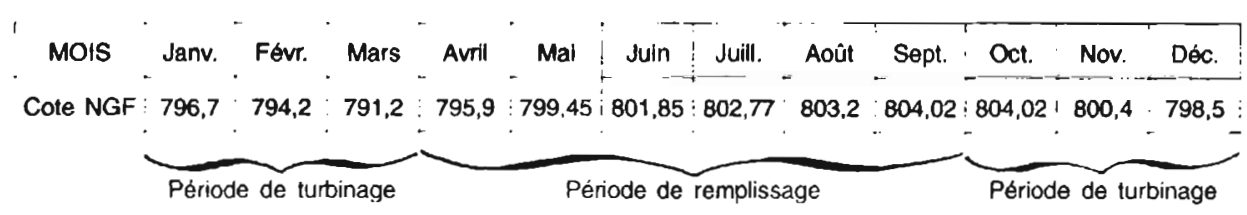

Cette gestion (fig. 26) a pour effet d'augmenter considérablement les apports par pompage au printemps, mais également de maintenir un léger pompage l'été jusqu'en septembre, ce qui n'existe pas dans la gestion actuelle du scénario 0 . Ce pompage estival est plus ou moins important, selon les apports du bassin versant et entraîne d'importantes concentrations de nutriments dans l'hypolimnion. Dès le mélange automnal, le stock de nutriments dans la masse d'eau est beaucoup plus important que dans le scénario 0 . Le développement des diatomées est alors plus précoce et plus rapide. La forte biomasse présente en hiver consomme ce stock presque intégralement, car il est peu renouvelé avant le début du pompage. La période de remplissage débute en avril avec l'eau de Bage riche en silice. Ces apports ont lieu à une période où la population de diatomées entre en situation de carence. Lorsque le régime thermique du réservoir permet leur mise à disposition dans la couche euphotique, ils contri- 
buent à retarder la disparition des diatomées. Globalement, les pics printaniers de diatomées sont plus élevés et plus larges, et la poussée estivale parfois plus importante. La perturbation simulée en 1981 dans le scénario 0 disparaît, alors qu'apparaissent des perturbations en 1984 et 1985.

En 1981, le phosphore est toujours limitant avant la silice en juin dans le scénario 3 , ce qui provoque le déclin de la floraison de diatomées. Cependant, les apports par pompage d'été sont plus importants qu'avec le scénario 0 , dans lequel la gestion hydraulique était à l'arrêt, et enrichissent l'hypolimnion. Aussi, lors de l'approfondissement de la thermocline de juillet lié au refroidissement météorologique, les nutriments apportés dans l'épilimnion sont en quantité plus importante que dans le scénario 0 . La deuxième poussée de diatomées est donc plus forte. Elle consomme toute la silice disponible dans l'épilimnion avant le mélange automnal et ne peut donc se maintenir jusqu'à l'année suivante, comme c'était le cas dans le scénario 0 .

En 1984, le réchauffement du mois d'avril a amplifié l'effet des stratifications de surface, ce qui a suffi à précipiter la chute des premières diatomées par manque de silice. Les épisodes froids du mois de mai ont remélangé le lac, régénérant le stock de nutriments de l'épilimnion pour permettre une reprise de leur poussée en juillet. L'été ayant été sec, l'apport du bassin versant a été faible et le pompage plus important pour atteindre l'objectif de remplissage. De ce fait, l'hypolimnion s'est enrichi en nutriments, au cours de l'été, ce qui a permis d'atteindre, dès le début du mélange automnal, des concentrations en nutriments suffisantes pour qu'une troisième poussée de diatomées démarre plus tôt en automne, atteignant une biomasse forte en hiver. Ainsi une situation perturbée apparaît en 1985. La silice devient limitante dès le mois de mars, bien avant le début du pompage, provoquant le déclin des diatomées hivernales. Un deuxième pic apparaît en juin, profitant des nutriments apportés par le pompage. A nouveau limité par la silice, ce pic disparaît, et on assiste, en août, au démarrage d'une troisième poussée qui se maintient jusqu'au printemps suivant.

Les algues non-siliceuses et le reste de la chaîne trophique ont été peu perturbés car leur équilibre dépend de la quantité de $\mathrm{PO}_{4}$ disponible lorsque la silice devient limitante pour les diatomées. Globalement, on note une augmentation de biomasse.

Ces résultats indiquent, certaines années, une grave perturbation de l'évolution des diatomées. Cependant, avec le modèle actuel, il n'est pas possible d'être sûr que les perturbations réelles de l'écosysème seraient de cette nature.

\section{V.5 Remarques sur l'outil de gestion}

En schématisant très grossièrement le modèle utilisé ici pour simuler l'écosystème de Pareloup, nous pouvons l'assimiler, dans un premier temps, à un bilan de matière (phosphore et si- 

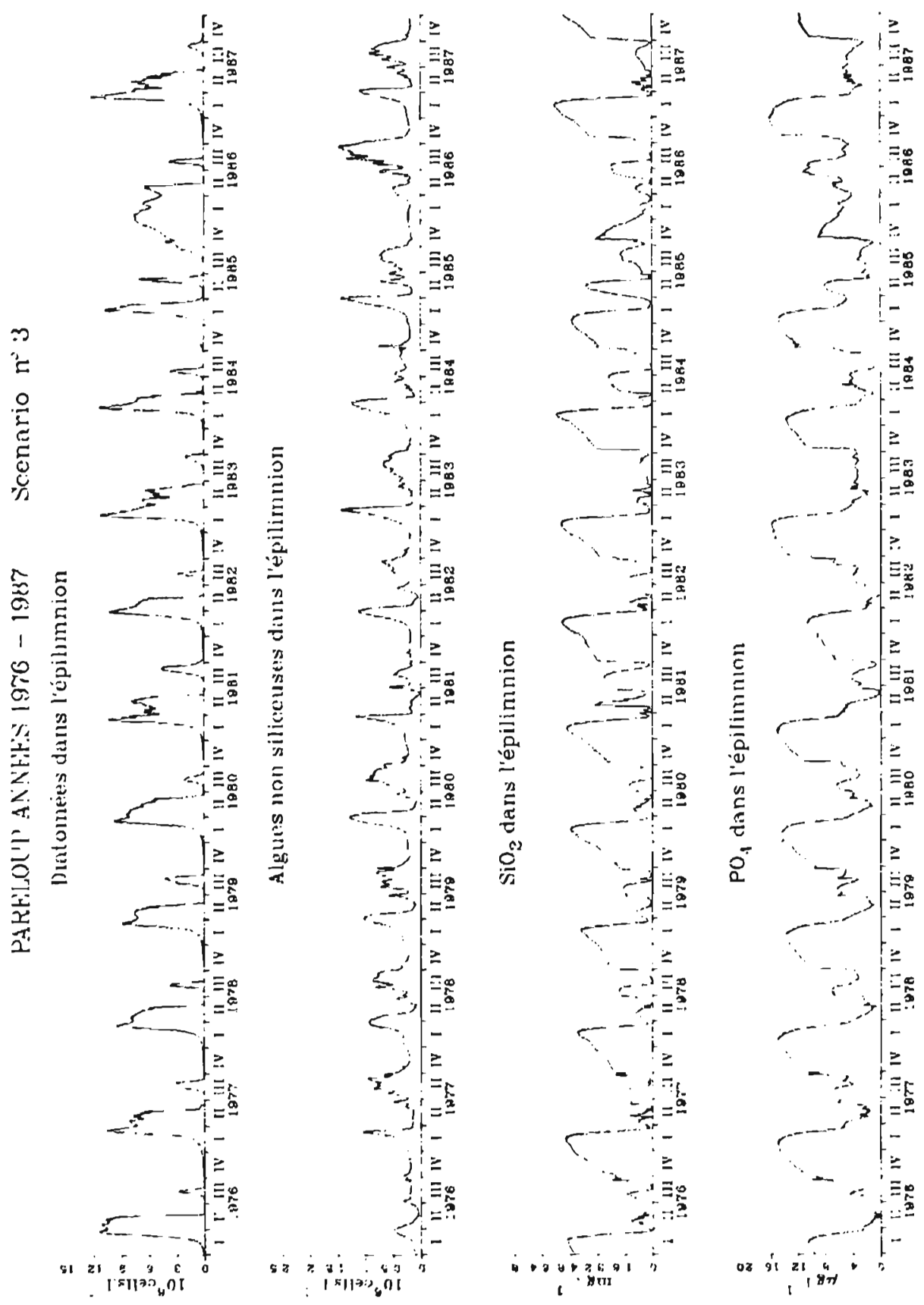
lice). Dans un bilan de matière, deux points sont fondamentaux: les entrées et les sorties. Les entrées sont en principe bien connues avec l'étude des apports du bassin versant. Les sorties (turbinage, débit réservé...), lorsque le modèle simule une répartition verticale de la matière, dépendront directement de la dynamique du modèle puisqu'elles sont prélevées à un certain niveau et sont déterminées à partir du profil vertical calculé par le modèle.

Finalement, on peut dire que les deux points fondamentaux dans un tel modèle sont les apports exogènes du bassin versant et la répartition de matière au sein de la masse d'eau.

Les différents scénarios étudiés ici montrent la grande sensibilité de l'écosystème à ces deux points (par le biais de la gestion hydraulique et des apports du bassin versant) qui se manifeste le plus souvent par le comportement des diatomées, véritable clé de voûte de la dynamique de cet écosystème.

Lorsque la gestion affecte les apports de nutriments, c'est la production totale de biomasse qui est affectée, ainsi que la compétition entre groupes d'algues.

Lorsque la gestion hydraulique est modifiée, c'est avant tout la dynamique de la stratification thermique qui est affectée. En modifiant le rôle de barrière de densité de la thermocline, la gestion règle les périodes où les nutriments sont disponibles pour la poussée phytoplanctonique. En modifiant le volume et la nature des apports (quantité et période), elle joue ainsi un rôle très important sur la compétition entre groupes d'algues.

En conclusion, on peut dire que le modèle de la retenue de Pareloup a montré à quel point la réponse de l'écosystème est sensible à la structure hydrodynamique: les phénomènes essentiels qui interagissent dans un lac sont reliés à la dimension verticale et il est important de bien la représenter, à l'échelle de temps et d'espace des processus biologiques étudiés. Le couplage étroit entre hydrodynamique et biologie nous a confirmé à quel point une approche globale comme la modélisation est indispensable pour bien représenter la dynamique d'un écosystème.

Dans ces conditions, le modèle sera un bon outil de simulation de scénarios. Cependant, le modèle ne peut pas prévoir une modification de la structure de l'écosystème. Tout changement d'équilibre se manifestera par une grave perturbation dans l'évolution de ses composantes, et il est important de tenir compte des limites d'application du modèle dans l'interprétation des résultats.

\section{CONCLUSION}

Nous venons de présenter la démarche que nous avons suivie pendant quatre ans pour l'étude de l'écosystème de la retenue de Pareloup.

C'est un travail qui a pu bénéficier d'importants moyens financiers indispensables à une entreprise de cette envergure. Fruit d'une interaction permanente entre modélisation et expé- 
rimentation, physique et biologie, ce travail pluridisciplinaire a abouti à un résultat opérationnel: MELODIA, le modèle de l'écosystème.

Cet outil est un modèle hydrodynamique, thermique et biologique permettant de simuler finement sur une verticale la stratification thermique et les composantes de l'écosystème, pendant une durée de plusieurs années.

Ce modèle a été calé avec les données acquises pendant le suivi expérimental de 1983 à 1987. II a permis de mettre en évidence et d'approfondir des phénomènes importants comme l'estimation des flux, l'étude des peuplements piscicoles, le bilan des apports du bassin versant, les traçages des circulations des masses d'eau, l'écophysiologie des algues.....

Appliqué à une plus longue période, 1976-1987, il a permis de mettre en évidence les fluctuations interannuelles liées aux conditions hydrométéorologiques en signalant les périodes où le risque de perturbation est grand. Cette étude a permis de mieux comprendre le rôle joué par la diatomée $A$. formosa, dominante au printemps. Cette diatomée se comporte comme une épuratrice en phosphore du lac. Si un phénomène vient perturber son développement, la quantité de $\mathrm{PO}_{4}$ disponible l'été est plus importante, favorisant une forte croissance algale estivale. Si les perturbations printanières sont liées aux conditions météorologiques, elles dépendent également de la gestion hydraulique. C'est ce qu'a mis en évidence l'étude de scénarios de gestion.
Finalement, cette étude a rempli les objectifs initiaux que s'étaient fixés Electricité de France et le Ministère de l'Environnement: améliorer la connaissance d'un écosystème de réservoir et proposer un outil permettant d'intégrer des critères de qualité d'eau dans la gestion des réservoirs. La démarche suivie pour l'étude de Pareloup $a$, depuis, été appliquée pour l'étude d'autres sites qui ont ainsi bénéficié de l'expérience acquise, même si chaque lac constitue un écosystème spécifique.

Une des premières applications de cette étude a été le pilotage de la vidange du lac de Pareloup, en 1993.

Enfin, sur un plan plus général, cette étude a permis de montrer la puissance d'un travail pluridisciplinaire ainsi que la nécessité d'une approche globale pour bien représenter un écosystème. Si tous les efforts ont convergé vers l'outil de modélisation, dépositaire de cette connaissance commune, cet outil n'existe que grâce à l'investissement à long terme de chacun, dans des domaines de compétence très variés. C'est, à n'en pas douter, le plus bel enseignement de ce travail.

\section{REFERENCES}

Bannister, T.T., 1974. A general theory of steady-state phytoplankton growth in a nutrient saturated mixed layer. Limnol. Oceanogr., $19: 13-20$.

Canale, R.P., De Palma, L.M. and Vogel, A.H., 1976. A plankton-based food web model for Lake Michigan. In : R.P. Canale (Editor), Modelling biochemical 
processes in aquatic ecosystems. Ann Arbor Sciences, Michigan, pp. 33-74.

Capblancq, J., Labroue, L. et Fardeau, J.C. 1986. Echanges de phosphore entre les sédiments et l'eau. Influence de la dilution sur les cinétiques de traçage isotopique. Ann. Limnol., 22 : 277-283.

Capblancq, J., Lavandier, P. et Petit, M. 1994. Production du phytoplancton et du bactérioplancton dans le lac de retenue de Pareloup. Hydroécol. Appl. 6(1/2) : 153-174.

Capblancq, J., Thébault, J.M. et Jrad, A., 1988. Relations entre la lumière et la photosynthèse du phytoplancton dans un résenoir mésotrophe (Pareloup). Ann. Limnol., 24 : 39-48.

Droop, M.R., 1974. The nutrient status of algal cells in continuous culture. J. mar. biol. Ass. U.K., $54:$ 825-855.

Droop, M.R., 1975. The nutrient status of algal cells in batch culture. J. mar. biol. Ass. U.K., 55 : 541-555.

Electricité de France, 1985. Pompe d'Alrance - Dossier d'enquête: Etude d'impact (pièce 11), Paris, $139 \mathrm{pp}$.

Francisco, P. et Rey, J., 1994. Etude du peuplement zooplanctonique de la retenue de Pareloup (Aveyron, France). Hydroécol. Appl. 6(1/2) : 175-196.

Harris, G.P., 1986. Phytoplankton ecology : structure, function and fluctuation. Chapman and Hall, London, 384 pp.

Harrison, P.J. and Turpin, D.H., 1982. The manipulation of physical, chemical and biological factors to select species from natural phytopiankton communities. In: G.D. Grice and M.R. Reeve (Editors), Marine Mesocosms. Biological and chemical research in experimental ecosystems. Springer-Verlag, New York, pp. 275-289.

Humphries, S.E. and Lyne, V.D., 1988. Cyanophyte blooms: The role of cell buoyancy. Limnol. Oceanogr., 33 : 7991.
Jorgensen, S.E., Mejer, $H$. and Friis, M., 1978. Examination of a lake model. Ecol. Modelling, 4 : 253-278.

Keller, A.A., 1989. Modeling the effects of temperature, light and nutrients on primary productivity: An empirical and a mechanistic approach compared. Limnol. Oceanogr., $34: 82-95$.

Kremer, J.N. and Nixon, S.W., 1978. A coastal marine ecosystem. Simulation and analysis. Ecological Studies 24, Springer-Verlag, Berlin, $217 \mathrm{pp}$.

Labroue, L., Capblancq, J., Salençon, M.J., Tourenq, J.N. et Mur, C., 1994. Evolution saisonnière des éléments minéraux nutritifs $(P, N, S i)$ et de l'oxygène dissous dans le lac de Pareloup, Hydroécol. Appl. 6(1/2) : 87-114

Lam, R.K. and Frost, B.W., 1976. Model of copepod filtering response to changes in size and concentration of food. Limnol. Oceanogr., 21 : 490-500.

Lavandier, P., 1990. Dynamics of bacterioplankton in a mesotrophic French reservoir (Pareloup). Hydrobiologia, 207: 79-86

Le Cohu, R., Brabet, J., Guitard, J. et Comoy, N., 1994. Evolution temporelle et spatiale du phytoplancton dans le réservoir de Pareloup. Hydroécol. Appl. 6(1/2) : 139-151.

Le Cohu, R., Comoy, N., Guitard, J. et Brabet, J., 1991. Périodicité du phytoplancton dans un réservoir de moyenne profondeur: le lac de Pareloup (Massif Central, France), un exemple de succession cyclique. Ann. Limnol., 27 : 197-214.

Le Cohu, R., Guitard, J., Comoy, N. et Brabet, J., 1989. Gonyostomum semen (Raphidophycées), nuisance potentielle des grands réservoirs trançais? L'exemple du lac de Pareloup. Arch. Hydrobiol., 117 : 225-236.

Lehman, J.T., 1976. The filter-feeder as an optimal forager, and the predicted shapes of feeding curves. Limnol. Oceanogr., 21 : 501-516. 
Lehman, J.T., Botkin, D.B. and Likens, G.E., 1975. The assumptions and rationales of a computer model of phytoplancton population dynamics. Limnol. Oceanogr., 20 : 343-364.

Le Jolivet, C., 1988. Contribution à l'étude du recrutement des poissons du réservoir de Pareloup (Aveyron). Thèse de doctorat de l'Institut National Polytechnique de Toulouse, Toulouse, 288 pp.

Lund, J.W.G., 1949. Studies on Asterionella. I. The origin and nature of the cells producing seasonal maxima. J. Ecol., 37 : 389-419.

Lund, J. W. G., 1950a. Studies on Asterionella formosa Hass. II. Nutrient depletion and the spring maxima. I. Observations on Windermere, Esthwaite Water and Blelham Tarn. J. Ecol., 38 : 1-14.

Lund, J. W. G., 1950b. Studies on Asterionella formosa Hass. II. Nutrient depletion and the spring maximum. II. Discussion. J. Ecol., 38 : 15-35.

Mullin, M.M., Stewart, E.F. and Fuglister, F.J., 1975. Ingestion by planktonic grazers as a function of concentration of food. Limnol. Oceanogr., 20 : 259-262.

Peters, R.H., 1979. Concentration and kinetics of phosphorus fractions along the trophic gradient of lake Memphremagog. J. Fish. Res. Bd. Can., 38 : 970-979.

Platt, T., Denman, K.L. and Jassby, A.D., 1977. Modeling the productivity of phytoplankton. In : E.D. Goldberg, I.N. Mc Cave, J.J. O'Brien and J.H. Steele (Editors), Marine Modeling. The Sea. J. Wiley \& Sons, New York, $2^{\text {nd }}$ ed., vol. 6 , pp. 807-856.

Pourcher, A.M. et Salençon, M.J., 1990. Modélisation du plancton dans une retenue oligotrophe: Sainte-Croix sur le Verdon. Hydroécol. Appl., 2(1/2) : 91134.

Rhee, G.Y., 1978. Effects of $N: P$ atomic ratios and nitrate limitation on algal growth, cell composition and nitrate uptake. Limnol. Oceanogr., 23 : 10-25.

Rhodes, T.E. et Le Cohu, R., 1987. Sédiments et paléolimnologie d'un réservoir: Le lac de Pareloup (Aveyron, France). Premiers résultats. Ann. Limnol., 23 : 3-7.

Riley, G.A., 1956. Oceanography of Long Island Sound 1952-54. II. Physical oceanography. Bull. Bing. Ocean. Coll., 15 : 15-46.

Salençon, M.J., 1994a. Stratification thermique d'un réservoir : le modèle à bilan d'énergie, EOLE. Rapport HE31/94-1, Electricité de France, Paris, $120 \mathrm{pp}$.

Salençon, M.J., 1994b. Etude du régime thermique du Lac de Pareloup avec le modèle EOLE. Hydroècol. Appl. $6(1 / 2): 329-368$.

Salençon, M.J. et Calmels, P., 1994. Etude de la dynamique des masses d'eau du lac de Pareloup par traçages. Hydroécol. Appl. 6(1/2): 19-58.

Salençon, M.J. et Thébault, J.M., 1994. Démarche de modélisation d'un écosystème lacustre: application au Lac de Pareloup. Hydroécol. Appl. 6(1/2) : 315-327.

Salençon, M.J. and Thébault, J.M., 1995. Simulation model of a mesotrophic reservoir (Lac de Pareloup) : MELODIA, an ecosystem management reservoir model. Ecol. Modelling, (sous presse)

Salençon, M.J., Pujo, H., Calmels, P. et Marion, D., 1988a. Traçage des masses d'eau de la retenue de Pareloup: septembre 1987. Rapport HE31/88-15, Electricité de France, Paris, $28 \mathrm{pp}$.

Salençon, M.J., Thébault, J.M. et Capblancq, J., 1988b. Etude de la retenue de Pareloup. Bilan des travaux réalisés en 1987 dans le cadre de la Convention EDF-Ministère de l'Environnement. Rapport HE-31/88.23, Electricité de France, Paris, 43 pp.

Salençon, M.J., Thébault, J.M. et Capblancq, J., 1989. Etude de la retenue 
de Pareloup. Bilan des travaux réalisés en 1988 dans le cadre de la Convention EDF-Ministère de l'Environnement. Rapport HE-31/89.13, Electricité de France, Paris, $77 \mathrm{pp}$.

Salençon, M.J., Thébault, J.M. et Capblancq, J., 1990. Etude de la retenue de Pareloup. Synthèse des travaux réalisés dans le cadre de la Convention EDF-Ministère de l'Environnement (mars 1986-mars 1990). Rapport HE31/90.23, Electricité de France, Paris, $40 \mathrm{pp}$.

Sciandra, A., 1986. Study and modelling of a simple planktonic system reconstitued in an experimental microcosm. Ecol. Modelling, 34 : 61-82.

Sivadier, F., Thébault, J.M. et Salençon, M.J., 1994. Bilan du phosphore total dans la retenue de Pareloup. Hydroécol. Appl., 6(1/2) : 115-138.

Smayda, T.J. and Boleyn, B.J., 1965. Experimental observations on the flotation of marine diatoms. I. Thalassiosira cf. nana, Thalassiosira rotula and Nitzschia seriata. Limnol. Oceanogr., 10 : 499-509.

Smayda, T.J. and Boleyn, B.J., 1966. Experimental observations on the flotation of marine diatoms. II. Skeletonema costatum and Rhizosolenia setigera. Limnol. Oceanogr., 11 : 18-34.

Sommer, U., 1989. Plankton Ecology. Succession in Plankton Communities. Springer-Verlag, Berlin, 369 pp.

Sommer, U. and Stabel, H.H., 1983. Silicon consumption and population density changes of dominant planktonic diatoms in Lake Constance. J. Ecol., $73: 119-130$.
Stabel, H.H., 1985. Mechanisms controlling the sedimentation sequence of various elements in prealpine lakes. In: W. Strumm (Editor), Chemical processes in lakes. J. Wiley \& Sons, New York, pp. 143-167.

Talbot, P., Thébault, J.M., Dauta, A. and de la Noüe, J., 1991. A comparative study and mathematical modeling of temperature and light on growth of three microalgae potentially useful for wastewater treatment. Water Res., $25: 465-472$.

Thébault, J.M., 1984. Modélisation des premiers niveaux du réseau trophique pélagique marin. Mise au point de modules et simulation de séries expérimentales. Thèse de $3^{\text {eme }}$ cycle, Université Paris 7, Paris, 94 pp.

Thébault, J.M., 1985. Etude expérimentale de la nutrition d'un copépode commun (Temora stylifera Dana). Effets de la température et de la concentration de nourriture. J. Exp. Mar. Biol. Ecol., 93 : 223-234.

Thébault, J.M. and Salençon, M.J., 1993. Simulation model of a mesotrophic reservoir (Lac de Pareloup) : biological model. Ecol. Modelling, 65 : 1-30.

Tilzer, M. M., 1984. Estimation of phytoplankton loss rates from daily photosynthetic rates and observed biomass changes in Lake Constance. J. Plankton Res., 6 : 309-324.

Yanenko, N.N., 1968. Méthode à pas fractionnaires - Résolution de problèmes polydimensionnels de physique mathématique. Armand Colin, Paris, 205 pp. 